\title{
House Prices and Job Losses
}

\author{
Gabor Pinter*
}

November 7, 2015

\begin{abstract}
What explains the strong comovement between house prices and job losses over the UK business cycle? To study this question, I build a general equilibrium model with collateral constraints, endogenous job separation and housing shocks, and confront it with macroeconomic data via Bayesian methods. The results suggest that shocks to house prices (i) explain about $10-20 \%$ of output fluctuations and about $20-30 \%$ of fluctuations in unemployment and job separation rates via the collateral channel, and (ii) were a major cause in triggering the 1990 and 2008 recessions in the UK.

Keywords: business cycle, house prices, financial frictions, labour market frictions
\end{abstract}

\footnotetext{
*Bank of England and Centre for Macroeconomics; email: gabor.pinter@bankofengland.co.uk. This paper contains the views of the author and not necessarily those of the Bank of England.

First draft: March 2015. The author would like to thank, but not implicate Saleem Bahaj, Andy Blake, Ambrogio Cesa-Bianchi, Clodo Ferreira, Angus Foulis, Peter Gal, Rogrido Guimaraes, Wouter den Haan, Bart Hobijn, Nobuhiro Kiyotaki, Peter Kondor, Istvan Konya, David Miles, Ben Nelson, Michele Piffer, Christopher Sims, Vincent Sterk, Pawel Zabczyk, Francesco Zanetti, Tao Zha and seminar participants at the Bank of England for useful comments. Thanks to Felicity Geary, Emma Lyonette and Ivan Wong for excellent research assistance, and to Andrew Presland for his continuous help with the planning regulation data.
} 


\section{Introduction}

The Great Recession has drawn increasing attention to the relationship between house prices, labour markets and the business cycle. ${ }^{1}$ Motivated by recent experience, the present paper aims to provide a structural analysis of the dynamic links between real estate prices, corporate credit and labour markets in the UK. The proposed mechanism that can explain these dynamic links is the one related to the collateral channel: adverse movements in real estate prices reduce the borrowing capacity of firms resulting in an increase in job destruction and a decrease in job creation, leading to higher levels of unemployment rates and to potential shifts in the Beveridge curve. ${ }^{2}$

The strong negative relationship between house prices and the unemployment rate is a feature not only of the recent crisis, but characterises historical UK business cycles as well. ${ }^{3}$ I document that house prices co-move at least as strongly with job separation rates as with job finding rates. Figure 1 shows that the cyclical components of real house prices and separation rates have about $-80 \%$ correlation in the sample 1985Q1-2013Q2. This may question the suitability of theoretical models, such as Blanchard and Gali (2010) and Liu, Miao, and Zha (2013) amongst others, that assume constant separation rates and focus on fluctuations in job finding rates in order to explain unemployment dynamics. ${ }^{4}$

To explain the stylised facts, this paper develops a structural model whereby shocks that increase house prices, also raise the market value of collateralisable assets that firms own, thereby increasing their borrowing capacity, leading to an expansion of corporate credit, business investment and a reduction in job separation rates. Regarding the implications for the UK business cycle, the model

\footnotetext{
${ }^{1}$ Figure 12 of the Appendix plots some of the key macroeconomic time series since 2007.

${ }^{2} \mathrm{~A}$ formal microeconometric study by Bahaj, Foulis, and Pinter (2015) shows that over 2000-2012 a $£ 100,000$ increase in real estate values enabled the representative UK firm to increase investment by about $£ 6,000$ pounds and to hire one additional worker. Studies for the US have found similar effects of property prices on investment and entrepreneurship via the collateral channel (Chaney, Sraer, and Thesmar, 2012; Corradin and Popov, 2015).

${ }^{3}$ This is illustrated by Figure 13 of the Appendix which shows that the HP-filtered real house prices and the unemployment rate have a $-72 \%$ correlation during the 1972Q1-2013Q3 period. Figure 14 shows the relationship in levels. Figure 15 shows the comovement between house prices and the vacancy-unemployment ratio, and Figure 16 shows the relationship with job finding rates.

${ }^{4}$ This is partly explained by the evidence for the US where job separation has found by Hall (2005) and Shimer (2012) to be acyclical. These findings have subsequently been challenged by Solon, Michaels, and Elsby (2009) and Fujita and Ramey (2009). The international evidence is also mixed (Hobijn and Sahin, 2009).
} 
Figure 1: HP-filtered UK House Prices and Separation Rates

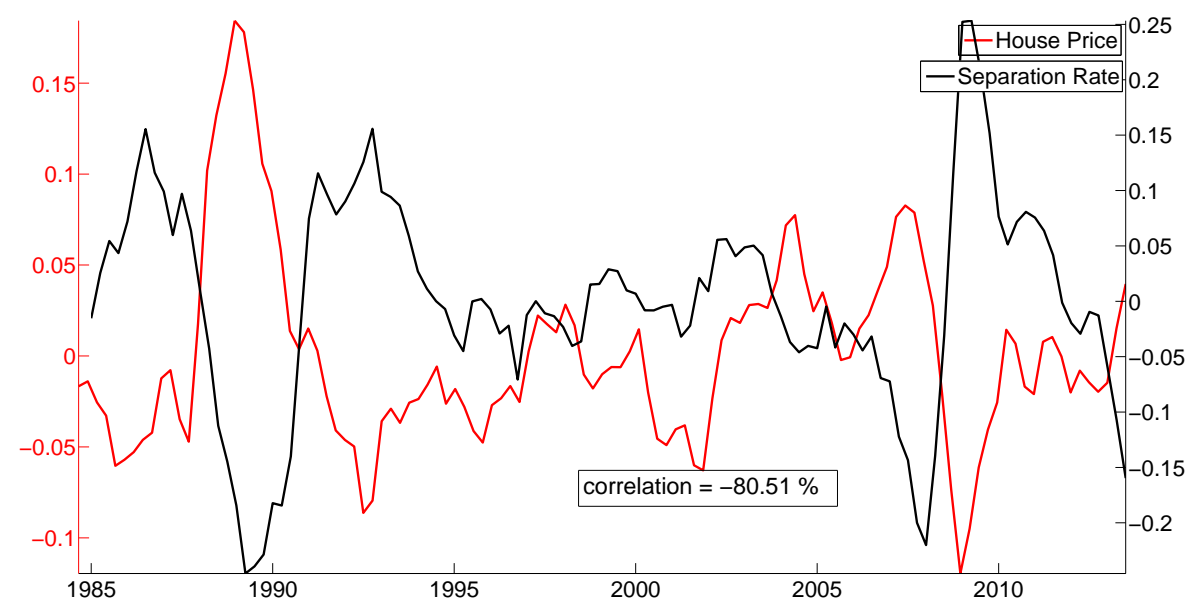

Note: House price data are from Nationwide and deflated by CPI; data on separation rates are from Petrongolo and Pissarides (2008). The updated data runs from 1985Q1 to 2013Q2. The logarithm of both series are HP-filtered with $\lambda=1600$.

implies that house price shocks (unanticipated movements in house prices, not caused by innovations in technology or labour markets) (i) explain about 10-20\% of output fluctuations and about 20-30\% of fluctuations in unemployment and job separation rates via the collateral channel over the forecast horizon, and (ii) were a major cause in triggering the 1990 and 2008 recessions in the UK.

The theoretical part of the paper builds on two strands of literature. First, it draws on the vast literature studying the interactions between financial markets and the macroeconomy such as Kiyotaki and Moore (1997), Bernanke, Gertler, and Gilchrist (1999), Iacoviello and Neri (2010), Jermann and Quadrini (2012) and Liu, Wang, and Zha (2013) amongst many others including the studies focusing on the UK such as Aoki, Proudman, and Vlieghe (2004) and Campbell and Cocco (2007). Second, it builds on the literature of search and matching models in the spirit of Mortensen and Pissarides (1994) with an explicit focus on the link between labour markets and financial frictions including Monacelli, Quadrini, and Trigari (2011), Veracierto, Fisher, and Davis (2012), Christiano, Eichenbaum, and Trabandt (2013), Liu, Miao, and Zha (2013), Ravn and Sterk (2014), Petrosky-Nadeau (2014) and Mumtaz and Zanetti (2015).

The present paper is closest to Liu, Miao, and Zha (2013) that estimates a model with exogenous job separation and shows that shocks to real estate prices can generate substantial volatility in labour market variables in the US 
via the collateral channel (Kiyotaki and Moore, 1997). ${ }^{5}$ However, the theoretical assumption of constant separation rates is in stark contrast with the large empirical contribution of the unemployment inflow rate to the dynamics of the UK unemployment rate. Table 1 shows the decomposition, used by Fujita and Ramey (2009), Petrongolo and Pissarides (2008) and Smith (2011) amongst others, confirming the increased role of separation rates during UK recessions. Relative to Petrongolo and Pissarides (2008), the additional result is that more than half of unemployment volatility is explained by the inflow rate during and after the Great Recession.

Table 1: Contributions from the Inflow Rate to Unemployment Volatility, UK Claimant Count

\begin{tabular}{ccc}
\hline Period & Feature & $\beta_{s}$ \\
\hline 1985Q1-2006Q4 & Pre- Great Recession & 0.385 \\
1993Q1-2006Q4 & Falling $u$ & 0.265 \\
1985Q1-2014Q2 & Whole sample & 0.422 \\
2007Q1-2014Q2 & Great Recession & 0.584 \\
\hline
\end{tabular}

Notes: $\beta_{s}$ is calculated as the ratio of the covariance between the contribution of the inflow rate and the change in steady-state unemployment to the variance of the change in steady-state unemployment. The calculation follows Petrongolo and Pissarides (2008) and Fujita and Ramey (2009).

Motivated by the strong cyclical comovement between house prices and job separation in the UK (Figure 1) and the decomposition of Table 1, I extend the baseline financing frictions model by introducing endogenous job separation along the lines of Ramey, den Haan, and Watson (2000), Krause and Lubik (2007), Trigari (2009) and Christiano, Trabandt, and Walentin (2011). This theoretical extension is important for understanding not only the UK business cycle, but may help better quantify the causes of the Great Recession in the US as well. This is because the results of Liu, Miao, and Zha (2013) suggest that a shock that reduces real estate prices by $10 \%$ increases the unemployment rate by $0.34 \%$ points in the US. Given that the US unemployment rate increased by

\footnotetext{
${ }^{5}$ In a similar framework, but without financial frictions, Liu and Leduc (2013) studies the macroeconomic effects of uncertainty shocks on labour markets. They too assume exogenous job separation, and therefore focus on responses of equilibrium vacancy and unemployment caused by a movement along the downward-sloping Beveridge curve. In their conclusion, they specifically call for an extension with endogenous separation: "A more realistic model should incorporate endogenous job separation along the lines of Ramey, den Haan, and Watson (2000) and Walsh (2005), which is likely to further strengthen the aggregate demand effects of uncertainty shocks that we have studied in this paper. This should prove a fruitful avenue that we intend to pursue in future research."
} 
about $5 \%$ points in 2008-2009, and that US separation rates spiked rapidly, the model of Liu, Miao, and Zha (2013) may substantially underestimate the impact of house prices shocks because of not accounting for endogenous job separation.

The structure of the paper is as follows. Section 2 describes the data and provides some preliminary empirical evidence on the impact of house price shocks on labour market variables. Section 3 describes the theoretical model. Section 4 presents the results of the Bayesian estimation of the theoretical model. Section 5 discusses the policy implications and concludes.

\section{Data and Some Empirical Evidence}

This section provides some preliminary empirical evidence on the impact of house price shocks on macroeconomic and labour market variables. The main text will present the empirical results from an aggregate Bayesian VAR model. The implied structural housing shocks series and forecast error decompositions will subsequently be compared to those implied by the estimated DSGE model in Section 4. In addition, section $\mathrm{C}$ of the Appendix present empirical results from a regional static panel model.

To construct job finding and job separation rates, I use administrative data on workers joining or leaving the unemployment register during a period. The data, often referred to as the claimant count, cover workers who claim unemployment compensation or who are registered at government agencies. Quarterly averages of monthly, seasonally adjusted series for unemployment and new claims are used. Aggregate UK data covering the period 1983Q3-2007Q2 are taken directly from Petrongolo and Pissarides (2008), and are extended for the period 2007Q3-2014Q2. Claimant count data for the English regions are taken from ONS covering the period 1983Q3-2014Q2. Aggregate and regional house price data at quarterly frequency are taken from Nationwide for the period 1974Q12014Q4. The rest of the data on aggregate variables including consumption, output, house price index, consumer price index, population, credit and unemployment rate are from the ONS and Bank of England database. Details can be found in Section A of the Appendix.

A detailed description of the regional data are provided in sections C. Moreover, Figures 18-20 in Section B of the Appendix provide some descriptive analysis in the form of scatter plots on the comovements between regional house price 
growth rates and growth rates of various economic and labour market variables. Specifically, Figure 18 confirms the positive statistical relationship between house prices and economic activity, proxied by the growth rate of output in the construction sector, new mortgage lending, number of new VAT registrations, number of new immigrants, investment (gross fixed capital formation) and average weekly income. Figure 19 confirms the positive (negative) relationship between house price growth and the growth rate of the unemployment rate, number of new claimants and job separation rates (job finding rates). Figure 20 shows that strong positive relationship between house price growth and changes in regulatory constraints on housing supply captured by the rejection rates of planning applications for all new developments.

To provide empirical evidence on the aggregate effects of house prices shocks, Figure 2 plots the impulse responses of house prices, consumption, output, labour hours, the unemployment rate, the level of corporate debt, household debt, job finding rates and separation rates. These impulse responses are estimated from an nine-variable Bayesian vectorautoregression (BVAR) model with two lags covering the sample period 1985Q1-2012Q4. ${ }^{6}$ Following the recent literature (Liu, Wang, and Zha, 2013; Sterk, 2015), Choleski orthogonalisation is used to identify housing shocks.

A positive shock that instantaneously increases house prices by $1 \%$ leads to an economic expansion over the forecast horizon, with the impact on real output, investment and hours peaking after about one year. The peak effect on the unemployment rate is $0.08 \%$ points, whereas the impact on separation rates is as strong as on job finding rates. Regarding the credit variables, the median peak impact occurring after about 10 quarters is about twice as high for corporate debt $(1 \%)$ than for household debt $(0.5 \%){ }^{7}$

To provide further empirical evidence, Section C of the Appendix presents microeconomic estimates obtained from a regional-panel model, whereby rejection rates of planning applications are used to find exogenous variation in house prices. $^{8}$ The empirical estimates are in line with the macroeconometric evidence

\footnotetext{
${ }^{6}$ See Banbura, Giannone, and Reichlin (2010) for further details on the estimation methodology. I use relatively loose priors, captured by the hyperparameter $\lambda=1$ in their notation.

${ }^{7}$ The results are qualitatively robust to changes in lag length. However, reducing (increasing) the number of lags reduces (increases) the persistence and hump-shaped effects of house price shocks. These results are available upon request.

${ }^{8} \mathrm{~A}$ more rigorous microeconomic identification based on difference-in-differences is provided by the firm-level study of a companion paper by Bahaj, Foulis, and Pinter (2015).
} 
Figure 2: The Effects of a House Price Shock in the UK
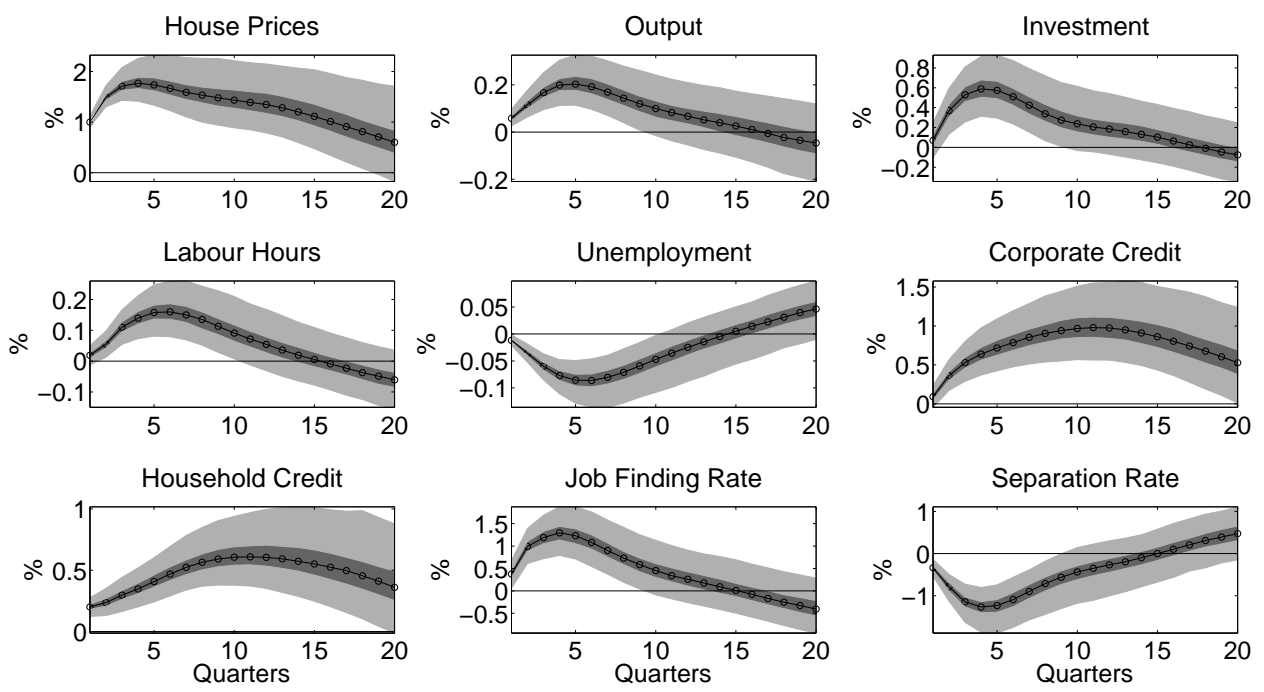

Note: The identification is with Choleski ordering. The sample period is 1985Q1 - 2012Q4. Each plot shows the pointwise median, 32nd-68th and 5th-95th percentiles of the posterior.

presented in this section.

Overall, the empirical evidence suggests that a shock to house prices leads to a strong comovement between house prices, labour markets and other macroeconomic variables in the UK. These findings are quantitatively similar to those found by Liu, Wang, and Zha (2013) and Liu, Miao, and Zha (2013) for the US. However, an additional feature of my empirical model is the impact on job separation that has been ignored by previous papers, partly because of the increased focus of US studies on job finding rates. The purpose of the theoretical model presented in the next Section is to provide a structural interpretation of these results.

\section{The Theoretical Model}

The model is infinite horizon and is in discrete time. The economy features three agents: households, entrepreneurs and firms. Households work, consume, purchase residential land and save through a one-period riskless discount bond. Entrepreneurs consume, purchase capital and commercial land which they partly finance with debt issuance that is collateralised by their capital stock and commercial land holdings. Each firm, owned by the entrepreneurial sector, rents 
capital and land from the entrepreneur, and hires one worker from the household sector to form an employment match.

Each employment match is subject to an idiosyncratic preference shock that hits the worker. Intuitively, this shock can be thought of as a degree of 'shirking', which is different across individuals. If the realisation of the shock is above a certain threshold level, the employment relationship is discontinued. This threshold level is lower and job separation is increased when aggregate credit constraints tighten and economic conditions deteriorate. Another words, shirking is not what will drive job separation in the model, but it is firms' tolerance to shirking that shrinks when aggregate credit constraints tighten, resulting in increased firing activity.

The model builds on the work of Liu, Wang, and Zha (2013); Liu, Miao, and Zha (2013), and the modelling of the labour market together with endogenous job separation follows Ramey, den Haan, and Watson (2000), Krause and Lubik (2007) and Trigari (2009).

\subsection{Households}

Each household can be thought of as a large extended family with a continuum of employed and unemployed members. The utility function is written as:

$$
U=\mathbb{E}_{0} \sum_{s=0}^{\infty} \beta_{h}^{s}\left\{\log \left(C_{h, t+s}-h_{h} C_{h, t+s-1}\right)+\varphi_{t+s} \log L_{h, t+s}-G_{t}\right\},
$$

where $C_{h, t}$ denotes consumption and $h_{h}$ is the degree of internal habit formation. The parameter $\beta_{h}$ is the subjective discount factor, land holdings of the household are denoted by $L_{h, t}$ with the corresponding taste shifter $\varphi_{t}$ referred to as a housing demand shock, whereas $G_{t}$ denotes the sum of disutilities from labour supply of the employed household members. The housing demand shock, which will be the key driver of the comovement between housing and labour markets, follows the stationary process:

$$
\ln \varphi_{t}=\left(1-\rho_{\varphi}\right) \ln \bar{\varphi}+\rho_{\varphi} \ln \varphi_{t-1}+\sigma_{\varphi} \varepsilon_{\varphi, t}
$$

where $\bar{\varphi}>0$ is a constant, $\rho_{\varphi} \in(-1,1)$ measures the persistence of the land demand shock, $\sigma_{\varphi}$ is the standard deviation of the i.i.d innovation $\varepsilon_{\varphi, t}$. Following Trigari (2009), each household member has the following disutility from 
supplying labour:

$$
g\left(h_{t}, a_{t}\right)=\chi \frac{h_{t}^{1+\nu}}{1+\nu}+\mathbb{1} a_{t},
$$

where $h_{t}$ denotes labour hours with a scale parameter $\chi$ and an inverse Frisch elasticity $\nu$. Moreover, $a_{t}$ is an idiosyncratic shock to the disutility of working which is assumed to be i.i.d. across individuals and across time with cumulative distribution function of the lognormal family $F(a)$ with parameters $\mu_{a}$ and $\sigma_{a}$, and density $f$. The indicator function $\mathbb{1}$ takes the value one (zero) if the individual is employed (unemployed). The sum of the disutilities of employed members is equal to the family's disutility from supplying labour hours, which is denoted by $G_{t}$ in equation 3.1. The flow-of-funds constraint is:

$$
C_{h, t}+q_{l, t}\left(L_{h, t}-L_{h, t-1}\right)+\frac{S_{t}}{R_{t}}=W_{t} h_{t} N_{t}+S_{t-1}+b Z_{t}^{p}\left(1-N_{t}\right)-T_{t},
$$

where $W_{t}$ is the real wage, $R_{t}$ is the gross riskfree return, $S_{t}$ is the purchase in period $t$ of the loanable bond that pays off one unit of consumption good in all states of the world in period $t+1$, which is known in advance. In period 0 , the household starts with $S_{-1}>0$ units of the loanable bonds. $T_{t}$ refers to lump-sum taxes, and unemployment benefit is denoted by $b$ which is scaled by $Z_{t}^{p}$ so that it remains stationary relative to labour income. The household does not choose $h_{t}$ or $N_{t}$, as these variables will be determined in the labour market equilibrium with search and matching frictions. The household's problem is to choose a sequence $\left\{C_{h, t}, S_{t}, L_{h, t}\right\}_{t=0}^{\infty}$ to maximise its utility. Using the flow-of-funds constraint 3.4, this yields the familiar Euler-equation:

$$
\mathbb{E}_{t} \Lambda_{t, t+1}^{h} R_{t}=1
$$

where $\lambda_{h, t} \equiv \frac{1}{C_{h, t}-h_{h} C_{h, t-1}}-\mathbb{E}_{t} \frac{h_{h} \beta_{h}}{C_{h, t+1}-h_{h} C_{h, t}}$ is the marginal utility of consumption, and $\Lambda_{t, t+1}^{h} \equiv \mathbb{E}_{t} \beta_{h} \lambda_{h, t+1} / \lambda_{h, t}$ is the household's stochastic discount factor. The household's first-order condition with respect to residential land is:

$$
q_{l, t}=\mathbb{E}_{t} \Lambda_{t, t+1}^{h} q_{l, t+1}+\varphi_{t} \frac{u_{l, t}^{h}}{\lambda_{h, t}},
$$

where $u_{l, t}^{h}$ is the marginal utility of residential land owned by the household. Equation 3.6 implies that the land price is equal to the sum of the marginal rate of substitution (MRS) of the household between land and consumption and the expected discounted future land price. Note that the housing shock $\varphi_{t}$ will take 
a centre stage in the analysis of the DSGE model.

\section{$3.2 \quad$ Entrepreneurs}

The entrepreneur's utility function is written as:

$$
U=\mathbb{E}_{0} \sum_{s=0}^{\infty} \beta^{s}\left\{\log \left(C_{e, t+s}-h_{e} C_{e, t+s-1}\right)\right\},
$$

where $C_{e, t}$ denotes the entrepreneur's consumption and $h_{e}$ is the habit persistence. The entrepreneur is endowed with $K_{-1}$ units of initial capital stock and $L_{-1, e}$ units of land. Capital accumulation follows the law of motion:

$$
K_{t}=(1-\delta) K_{t-1}+\left[1-\frac{\Omega}{2}\left(\frac{I_{t}}{I_{t-1}}-\bar{\lambda}_{I}\right)^{2}\right] I_{t},
$$

where $I_{t}$ is investment, $\bar{\lambda}_{I}$ denotes the steady-state growth rate of investment, and $\Omega>0$ is the adjustment cost parameter. The entrepreneur faces the following flow-of-funds constraint:

$$
C_{e, t}+q_{l, t}\left(L_{e, t}-L_{e, t-1}\right)+\frac{I_{t}}{Q_{t}}+B_{t-1}=\frac{B_{t}}{R_{t}}+R_{k, t} K_{t-1}+R_{l, t} L_{e, t-1}+\Pi_{t}
$$

where $B_{t-1}$ is the amount of matured entrepreneurial debt and $B_{t} / R_{t}$ is the value of new debt. $R_{l, t}$ and $R_{k, t}$ are the rental rates of land and capital, respectively. $\Pi_{t}$ denotes profits, $Q_{t}$ is the investment-specific technological change, defined as $Q_{t}=Q_{t}^{p} \nu_{q, t}$, where the permanent component $Q_{t}^{p}$ follows the stochastic process:

$$
Q_{t}^{p}=Q_{t-1}^{p} \lambda_{q, t}, \quad \ln \lambda_{q, t}=\left(1-\rho_{q}\right) \ln \bar{\lambda}_{q}+\rho_{q} \ln \lambda_{q, t-1}+\sigma_{q} \varepsilon_{q, t},
$$

and the transitory component follows the stochastic process:

$$
\ln \nu_{q, t}=\rho_{\nu_{q}} \ln \nu_{q, t-1}+\sigma_{\nu_{q}} \varepsilon_{\nu_{q}, t} .
$$

The parameter $\bar{\lambda}_{q}$ is the steady-state growth rate of $Q_{t}^{p}$, the parameters $\rho_{q}$ and $\rho_{\nu_{q}}$ measure the degree of persistence. The innovations $\varepsilon_{q, t}$ and $\varepsilon_{\nu_{q}, t}$ are iid with variances $\sigma_{q}^{2}$ and $\sigma_{\nu_{q}}^{2}$.

The entrepreneur's ability to obtain credit is subject to the following collateral 
constraint:

$$
B_{t} \leq \theta_{t} \mathbb{E}_{t}\left[q_{l, t+1} L_{e, t}+q_{k, t+1} K_{t}\right]
$$

where $q_{k, t+1}$ is the shadow value of capital in consumption units, also referred to as Tobin's $q$. The credit constraint 3.12 limits the amount of borrowing by a fraction of the gross value of the collateralisible assets: land and capital. As in Kiyotaki and Moore (1997), the credit constraint reflects problems of limited contract enforceability. Similar to Liu, Wang, and Zha (2013) and Liu, Miao, and Zha (2013), the credit constraint will be instrumental in propagating a shock $\varphi_{t}$ to the household's land demand condition (3.6) into increased business investment. This is because increased land prices $q_{l, t+1}$ raise the market value of collateralisable assets, thereby increasing the borrowing capacity of entrepreneurs.

As in Jermann and Quadrini (2012), the collateral constraint 3.12 is subject to exogenous disturbances:

$$
\ln \theta_{t}=\left(1-\rho_{\theta}\right) \ln \theta+\rho_{\theta} \ln \theta_{t-1}+\sigma_{\theta} \varepsilon_{\theta, t}
$$

where $\theta$ is the steady-state value of $\theta_{t}$, and $\rho_{\theta} \in(0.1)$ is the persistence parameter, and $\varepsilon_{\theta, t}$ is iid with variance $\sigma_{\theta}^{2}$. The entrepreneur's problem is to choose a sequence $\left\{C_{e, t}, B_{t}, K_{t}, I_{t}, L_{e, t}\right\}_{t=0}^{\infty}$ to maximise utility.

\subsection{The Labour Market}

At the beginning of time $t$, there are $u_{t}$ unemployed workers looking for jobs, and there are $v_{t}$ vacancies posted by producers. The technology of matching workers with vacancies is:

$$
m_{t}=\psi_{t} u_{t}^{\omega} v_{t}^{1-\omega}
$$

where $\omega \in(0,1)$ is the technology scaling parameter. The variable $\psi_{t}$ is an exogenous matching efficiency shock which follows the stationary process:

$$
\ln \psi_{t}=\left(1-\rho_{\psi}\right) \ln \bar{\psi}+\rho_{\psi} \ln \psi_{t-1}+\sigma_{\psi} \varepsilon_{\psi, t},
$$

where $\bar{\psi}>0$ is a constant, $\rho_{\psi} \in(-1,1)$ measures the persistence and $\sigma_{\psi}$ is the standard deviation of the i.i.d innovation $\varepsilon_{\psi, t}$. 
The probability of an open vacancy being matched with a searching worker is $q_{t}^{v}=m_{t} / v_{t}$ (job filling rate), whereas the probability of an unemployed worker being matched with an open vacancy is $q_{t}^{u}=m_{t} / u_{t}$ (job finding rate). Labour market tightness is defined as $\Theta_{t}=v_{t} / u_{t}$. The number of workers employed at the beginning of time $t$ is denoted by $N_{t-1}$. Before matching takes place, workers lose their jobs with probability $\rho_{t}$ before matching starts at time $t$. Job separation has an exogenous, constant component, $\rho^{x}$, and an endogenous component, $\rho_{t}^{n}$ :

$$
\rho_{t}=\rho^{x}+\left(1-\rho^{x}\right) \rho_{t}^{n}
$$

The endogenous component of job separation $\rho_{t}^{n}$ depends on whether the realisation of the idiosyncratic preference shock $a_{t}$ (equation 3.3) is above a certain threshold $\bar{a}_{t}$, at which the employment relationship is discontinued:

$$
\rho_{t}^{n}=\operatorname{Pr}\left(a_{t}>\bar{a}_{t}\right)=1-F\left(\bar{a}_{t}\right) .
$$

The number of unemployed workers searching for jobs at time $t$ is written as:

$$
u_{t}=1-\left(1-\rho_{t}\right) N_{t-1} \text {. }
$$

The evolution of employment follows the law of motion:

$$
N_{t}=\left(1-\rho_{t}\right) N_{t-1}+m_{t}
$$

which implies that employment at the current period is the sum of the workers that survived from the last period and the number of matches formed at the beginning of the current period. ${ }^{9}$ Given the dynamics of employment, the unemployment rate is determined by the identity $U_{t}=1-N_{t}$.

\subsection{Producers}

Firms rent capital $k_{t}$ as well as entrepreneurial labour $l_{e, t}$, and produce only if they match with a worker, using the following technology:

$$
y_{t}=Z_{t}\left(l_{e, t}^{\phi} k_{t}^{1-\phi}\right)^{\alpha} h_{t}^{1-\alpha}
$$

\footnotetext{
${ }^{9}$ The assumption regarding the timing of the probability of separation follows Krause and Lubik (2007), and the timing of newly formed matches is the same as in Blanchard and Gali (2010) and Liu, Miao, and Zha (2013). Changing these assumption has little quantitative impact on the estimation. These results are available upon request.
} 
where $\alpha \in(0,1)$ and $\phi \in(0,1)$ are the output elasticities of the production factors. The total factor productivity $Z_{t}$ is composed of a permanent component $Z_{t}^{p}$ and a transitory component $\nu_{z, t}$ such that $Z_{t}=Z_{t}^{p} \nu_{z, t}$, where the permanent component $Z_{t}^{p}$ follows the stochastic process:

$$
Z_{t}^{p}=Z_{t-1}^{p} \lambda_{z, t}, \quad \ln \lambda_{z, t}=\left(1-\rho_{z}\right) \ln \bar{\lambda}_{z}+\rho_{z} \ln \lambda_{z, t-1}+\sigma_{z} \varepsilon_{z, t},
$$

and the transitory component follows the stochastic process:

$$
\ln \nu_{z, t}=\rho_{\nu_{z}} \ln \nu_{z, t-1}+\sigma_{\nu_{z}} \varepsilon_{\nu_{z}, t} .
$$

The parameter $\bar{\lambda}_{z}$ is the steady-state growth rate of $Z_{t}^{p}$, the parameters $\rho_{z}$ and $\rho_{\nu_{z}}$ measure the degree of persistence. The innovations $\varepsilon_{z, t}$ and $\varepsilon_{\nu_{z}, t}$ are iid with variances $\sigma_{z}^{2}$ and $\sigma_{\nu_{z}}^{2}$.

A firm matched with a worker makes profits from the current-period production, and continues to receive the value of the employment match $\left(J_{t}^{F}\right)$, if the match survives (with probability $1-\rho_{t}$ ) in the next period:

$$
J_{t}^{F}=\pi_{t}-w_{t}\left(a_{t}\right) h_{t}+\mathbb{E}_{t} \Lambda_{t, t+1}^{e}\left[\left(1-\rho_{t+1}\right) \int_{0}^{\bar{a}_{t}} J_{t+1}^{F}\left(a_{t+1}\right) \frac{d F\left(a_{t+1}\right)}{F\left(\bar{a}_{t+1}\right)}\right],
$$

implying that the value of the job depends on profits $\pi_{t}$ net the real wage, plus the discounted continuation value. With probability $1-\rho_{t+1}$, the employment relationship survives and earns the expected value, whereas with probability $\rho_{t+1}$, job separation occurs leading to zero match value. Profits prior to wage payments are determined as follows:

$$
\pi_{t}=\max _{k_{t}, l_{e, t}} Z_{t}\left(l_{e, t}^{\phi} k_{t}^{1-\phi}\right) h_{t}^{1-\alpha}-R_{k, t} k_{t}-R_{l, t} l_{e, t},
$$

where factor prices $R_{k, t}$ and $R_{l, t}$ are taken as given. The aggregate wage $W_{t}$ not only depends on aggregate factors but also on workers' idiosyncratic preference shocks:

$$
W_{t}=\int_{0}^{\bar{a}_{t}} w_{t}\left(a_{t}\right) \frac{d F\left(a_{t+1}\right)}{F\left(\bar{a}_{t+1}\right)} .
$$

When the firm posts a job vacancy, it pays a vacancy cost $\kappa$, and the firm receives 
the value $J_{t}^{F}$ when the vacancy is filled (with probability $q_{t}^{v}$ ). If the vacancy is not filled, the firm continues to have it open next period:

$$
V_{t}=-\kappa \Gamma_{t}+\mathbb{E}_{t} \Lambda_{t, t+1}^{e}\left[q_{t}^{v}\left(1-\rho_{t+1}\right) \int_{0}^{\bar{a}_{t}} J_{t+1}^{F}\left(a_{t+1}\right) \frac{d F\left(a_{t+1}\right)}{F\left(\bar{a}_{t+1}\right)}+\left(1-q_{t}^{v}\right) V_{t+1}\right],
$$

where the term $\Gamma_{t}$ is the growth factor (defined in Section D of the Appendix) to ensure that the ratio of vacancy cost to output is stationary. Given that free entry reduces the value of an open vacancy to zero $\left(V_{t}=0\right)$, equation 3.25 implies the following optimality condition for vacancy posting:

$$
\frac{\kappa \Gamma_{t}}{q_{t}^{v}}=\mathbb{E}_{t} \Lambda_{t, t+1}^{e}\left(1-\rho_{t+1}\right) \int_{0}^{\bar{a}_{t}} J_{t+1}^{F}\left(a_{t+1}\right) \frac{d F\left(a_{t+1}\right)}{F\left(\bar{a}_{t+1}\right)},
$$

which implies that the optimal vacancy posting is at the point where the benefit of having a new employment match is equal to the cost of posting and maintaining a vacancy.

\subsection{The Labour Market and Nash Bargaining}

After a worker is matched with a vacancy, the firm and the worker bargain over the wage and working hours, defined as the following Nash bargaining problem:

$$
\max _{W_{t}, h_{t}}\left(J_{t}^{W}-J_{t}^{U}\right)^{\xi_{t}}\left(J_{t}^{F}\right)^{1-\xi_{t}}
$$

The term $J_{t}^{W}$ in problem 3.27 denotes the current value of employment which depends on the current wage, the disutility of working and the next period probability weighted value of job loss and of continued employment, written formally as:

$$
J_{t}^{W}=w_{t}\left(a_{t}\right) h_{t}-\frac{g\left(h_{t}, a_{t}\right)}{\lambda_{i, t}}+\mathbb{E}_{t} \Lambda_{t, t+1}^{h}\left[\left(1-\rho_{t+1}\right) \int_{0}^{\bar{a}_{t}}\left(J_{t+1}^{W}\left(a_{t+1}\right)-J_{t+1}^{U}\right) \frac{d F\left(a_{t+1}\right)}{F\left(\bar{a}_{t+1}\right)}+J_{t+1}^{U}\right] .
$$

The term $J_{t}^{U}$ in problem 3.27 denotes the current value of unemployment which depends on the unemployment benefit, the next period probability weighted value of finding a job and of continued unemployment, written formally as: 


$$
J_{t}^{U}=b \Gamma_{t}+\mathbb{E}_{t} \Lambda_{t, t+1}^{h}\left[q_{t}^{u}\left(1-\rho_{t+1}\right) \int_{0}^{\bar{a}_{t}}\left(J_{t+1}^{W}\left(a_{t+1}\right)-J_{t+1}^{U}\right) \frac{d F\left(a_{t+1}\right)}{F\left(\bar{a}_{t+1}\right)}+J_{t+1}^{U}\right]
$$

The term $\xi_{t}$ in problem 3.27 denotes the worker's relative bargaining power, which is subject to exogenous disturbances:

$$
\ln \xi_{t}=\left(1-\rho_{\xi}\right) \ln \bar{\xi}_{t}+\rho_{\psi} \ln \xi_{t-1}+\sigma_{\xi} \varepsilon_{\xi, t},
$$

where $\bar{\xi}>0$ is the steady-state value of the worker's relative bargaining power, which will be estimated. The parameter $\rho_{\xi} \in(-1,1)$ measures the persistence and $\sigma_{\xi}$ is the standard deviation of the i.i.d innovation $\varepsilon_{\xi, t}$. The bargaining solution is written as:

$$
\xi_{t} J_{t}^{F}=\left(1-\xi_{t}\right)\left(J_{t}^{W}-J_{t}^{U}\right)
$$

Substituting the value of the match to the firm 3.22, the vacancy posting condition 3.26, the value of employment 3.28 and the value of unemployment 3.29 into the bargaining solution 3.31 yields the optimal individual wage rate:

$$
w_{t}\left(a_{t}\right) h_{t}=\xi_{t}\left(\pi_{t}+\kappa \Gamma_{t} \Theta_{t}\right)+\left(1-\xi_{t}\right)\left(\frac{g\left(h_{t}, a_{t}\right)}{\lambda_{h, t}}+b \Gamma_{t}\right),
$$

where the marginal rate of substation (MRS) between leisure and consumption is equal to the marginal product of labour, $g^{\prime}\left(h_{t}, a_{t}\right) / \lambda_{h, t}=(1-\alpha) y_{t} / h_{t}$. Note that the optimal wage rate is different from the MRS because of the costs related to vacancy posting and unemployment benefit in the current search and matching framework. The bargained wage increases in labour market tightness $\Theta_{t}$, the outside option of work $b$ and the realised value of the idiosyncratic preference shock $a_{t}$. Given 3.24, the aggregate wage is written as:

$$
W_{t} h_{t}=\xi_{t}\left(\pi_{t}+\kappa \Gamma_{t} \Theta_{t}\right)+\left(1-\xi_{t}\right)\left(\frac{\chi \frac{h_{t}^{1+\nu}}{1+\nu}+\int_{0}^{\bar{a}_{t}} a_{t} \frac{d F\left(a_{t+1}\right)}{F\left(\bar{a}_{t+1}\right)}}{\lambda_{h, t}}+b \Gamma_{t}\right)
$$

Similar to Krause and Lubik (2007) and Trigari (2009), condition 3.32 splits the wage into the costs and benefits of an employment match according to the bargaining power $\xi_{t}$. Specifically, the wage compensates the worker up to $\xi_{t}$ 
fraction of the firm's profits and the saving of hiring costs, and up to $\left(1-\xi_{t}\right)$ fraction of the disutility of labour and the foregone unemployment benefit.

Endogenous separation depends on the endogenous preference shock threshold $\bar{a}_{t}$ which in turn is determined by the zero joint surplus condition. The joint surplus is written as:

$$
\begin{aligned}
S_{t}\left(a_{t}\right) & =J_{t}^{F}+J_{t}^{W}-J_{t}^{U} \\
& =\pi_{t}-\frac{g\left(h_{t}, a_{t}\right)}{\lambda_{h, t}}-b \Gamma_{t}+\mathbb{E}_{t} \Lambda_{t, t+1}^{e}\left[\left(1-\xi_{t+1} q_{t}^{u}\right)\left(1-\rho_{t+1}\right) \int_{0}^{\bar{a}_{t}} S_{t+1}\left(a_{t+1}\right) \frac{d F\left(a_{t+1}\right)}{F\left(\bar{a}_{t+1}\right)}\right] .
\end{aligned}
$$

The total surplus equals current revenues net of the labour disutility and the foregone unemployment benefit plus the continuation value of the employment relationship. Job separation occurs whenever the realisation of the preference shock reduces the value of the joint surplus to zero. The condition that determines the threshold value $\bar{a}_{t}$ is $S_{t}\left(\bar{a}_{t}\right)=0$, which allows condition 3.34 to be written as:

$$
\pi_{t}-\frac{g\left(h_{t}, \bar{a}_{t}\right)}{\lambda_{h, t}}-b \Gamma_{t}+\frac{1-\xi_{t+1} q_{t}^{u}}{1-\xi_{t+1}} \frac{\kappa \Gamma_{t}}{q_{t}^{v}}=0,
$$

which pins down the threshold value of the preference shock $\bar{a}_{t}$, above which job separation occurs. Finally, using the forward value of 3.22 , the vacancy posting condition 3.26 can be rewritten as:

$$
\frac{\kappa \Gamma_{t}}{q_{t}^{v}}=\mathbb{E}_{t} \Lambda_{t, t+1}^{e}\left(1-\rho_{t+1}\right)\left[(1-\alpha) \frac{Y_{t+1}}{N_{t+1}}-W_{t+1} h_{t+1}+\frac{\kappa \Gamma_{t+1}}{q_{t+1}^{v}}\right]
$$

\subsection{Market Clearing}

In a competitive equilibrium, the markets for goods, labour, land and bonds all clear. The goods market clearing condition is:

$$
C_{e, t}+C_{h, t}+\frac{I_{t}}{Q_{t}}+\kappa \Gamma_{t} v_{t}=Y_{t}
$$

The land market clearing condition implies:

$$
L_{h, t}+L_{e, t}=\bar{L}
$$

where $\bar{L}$ is the fixed aggregate land endowment. The bond market clearing condition implies: 


$$
S_{t}=B_{t}
$$

The capital market clearing condition is given by:

$$
K_{t-1}=N_{t} k_{t}
$$

I abstract from modelling government spending to simplify the analysis, and assume that all unemployment benefits are financed by lump-sum taxes:

$$
b \Gamma_{t}\left(1-N_{t}\right)=T_{t} .
$$

Aggregate output is given by:

$$
Y_{t}=Z_{t}\left[\left(K_{t-1}\right)^{1-\phi}\left(L_{e, t-1}\right)^{\phi}\right]^{\alpha}\left(h_{t} N_{t}\right)^{1-\alpha} .
$$

A competitive search equilibrium consists of sequences of prices $\left\{W_{t}, q_{l, t}, q_{k, t}, R_{t}, R_{k, t}, R_{l, t}\right\}_{t=0}^{\infty}$ and allocations $\left\{C_{h, t}, L_{h, t}, B_{t}\right\}_{t=0}^{\infty}$ for households, allocations $\left\{C_{e, t}, I_{t}, L_{e, t}, S_{t}, K_{t}\right\}_{t=0}^{\infty}$ for entrepreneurs, and allocations $\left\{y_{t}, k_{t}, l_{e, t}, h_{t}\right\}_{t=0}^{\infty}$ for each firm, and labour market variables

$\left\{m_{t}, u_{t}, v_{t}, N_{t}, q_{t}^{u}, q_{t}^{v}, \bar{a}_{t}, \rho_{t}\right\}_{t=0}^{\infty}$ such that (i) taking prices as given, the allocations solve the optimising problems for the household, the entrepreneur and each firm, (ii) new matches are formed based on the matching technology, with wages and labour hours determined via the bilateral Nash-bargaining process, (iii) endogenous separation satisfies the zero joint surplus condition, and (iv) all markets clear.

\section{Empirical Results}

\subsection{Estimation}

The model is log-linearised around the deterministic steady-state in which the credit constraint is binding. The model is used to fit six quarterly UK time series: real house prices, real per capita investment, real per capita output, real per capita corporate (PNFC) debt, the unemployment rate and the job separation rate. The data sample covers the period from 1985Q1 to 2012Q4. ${ }^{10}$ The choice

\footnotetext{
${ }^{10}$ Per capital measures are calculated based on the population series of people aged 16 or above, obtained from the Labour Force Survey.
} 
of the starting date of the estimation period coincides with the liberalisation of UK financial markets and the increasing reliance of the UK corporate sector on external financing. ${ }^{11}$ In addition, the period before 1985 was characterised by big structural changes in the UK labour markets (Pissarides, 2003).

The model is estimated using Bayesian methods as done in Smets and Wouters (2007), Liu, Wang, and Zha (2013) and Christiano, Motto, and Rostagno (2014) amongst others. The model parameters are partitioned into three subsets. The first subset of deep parameters is estimated. The second subset is calibrated using steady-state relations or previous studies. The third subset contains the estimated parameters of shock processes.

The estimated parameters collected in the vector $\Psi_{1}=\left\{h_{h}, h_{e}, \nu, \Omega, g_{y}, \bar{\lambda}_{q}, \bar{\xi}\right\}$, consist of the habit parameters $h_{h}$ and $h_{e}$, the inverse Frisch-elasticity $\nu$, the investment adjustment cost parameter $\Omega$, the growth rate of per capita output $g_{y}$ and that of investment $\bar{\lambda}_{q}$, and the relative bargaining power of workers $\bar{\xi}$. The calibrated parameters, collected in the vector $\Psi_{2}=\left\{\beta, \chi, \alpha, \phi, \delta, \theta, m, a, \mu_{a}, \sigma_{a}, \kappa, b\right\}$, consist of the subjective discount factor $\beta$, the leisure preference parameter $\chi$, the production parameters $\alpha$ and $\phi$, the depreciation rate $\delta$, the average loanto-asset ratio $\theta$, the scale and elasticity parameters of the matching function $m$ and $\bar{\xi}$, the mean and the standard deviation of the lognormal distribution for the idiosyncratic preference shock, $\mu_{a}$ and $\sigma_{a}$, the vacancy cost parameter $\kappa$ and the unemployment benefit parameter $b$.

The habit parameters follow a beta distribution with shape parameters $\underline{a}=$ 1.5 and $\underline{b}=1.5$, implying a symmetric prior distribution with $70 \%$ probability the parameters lying between 0.2 and $0.8 .^{12}$ The same prior is used for the bargaining power parameter $\bar{\xi}$, similar to Faccini, Millard, and Zanetti (2013). The prior for the investment adjustment cost parameter $\Omega$ follows a gamma distribution with shape parameter $\underline{a}=4$ and rate parameter $\underline{b}=2$, implying that with $99 \%$ prior probability $\Omega$ is smaller than 5 , covering most calibrated and estimated values in

\footnotetext{
${ }^{11}$ The process of financial liberalisation started with the abolition of exchange controls in 1979 and of controls on bank lending ('the Corset') in 1980, after which banks were free to compete with building societies in the market of real estate finance. During this period, the reliance of the corporate sector on externally raised finance increased rapidly, compared to the 1970s when internally generated funds were the dominant form of corporate finance. See Chapter 2 of Buckle and Thompson (1992) for further details.

${ }^{12}$ Note that the corresponding mean $\mu$ and standard deviation $\sigma$ of the Beta distribution is calculated as $\mu=\underline{a} /(\underline{a}+\underline{b})$ and $\sigma=\sqrt{\underline{a b} /\left((\underline{a}+\underline{b})^{2}(\underline{a}+\underline{b}+1)\right)}$.
} 
the literature. ${ }^{13}$ The prior for the inverse of the Frisch-elasticity $\nu$ also follows a gamma distribution with shape parameters $\underline{a}=4$ and $\underline{b}=4$, implying that with $99 \%$ prior probability $\nu$ is less than 2.5 .

As for the second subset of parameters $\Psi_{2}$, the subjective discount factor is chosen $\beta$ such that the annualised real interest rate is $4 \%$, the patience parameter is pinned down by the estimated growth rate $g_{y}$. The depreciation rate $\delta$ is pinned down by the steady-state investment-capital ratio which is set to be 0.18 at annual level. The steady-state capital-output ratio is set to be 1, implying a steady-state investment-output ratio 0.18 at annual level, which is consistent with UK data and somewhat lower than in the US (0.20). The parameter $\chi$ is chosen such that the steady-state hours is set to $h=0.25$ in steady-state. The average labour income share is $70 \%, \alpha=0.3$. The share of land in production $\phi$ is pinned down by the steady-state ratio of entrepreneurial land to output $\left(q_{l} L_{e} / Y\right)$, which is set to 1.8 based on the estimated total value of commercial real estate in the UK, which fluctuated between $£ 580$-870billion over the 20032013 period $^{14}$ (PDR, 2014). To construct a measure for the average loan-to-value ratio $\theta$, I use the binding credit constraint 3.12 in steady-state:

$$
\theta=\frac{B}{q_{l} L_{e}+q_{k} K}
$$

where the value is calibrated to $\theta=0.72$, based on the following calculation: over the period 2003-2012 I compute the average ratio of net financial liabilities of non-financial corporations $(B)$ over the sum of (i) machinery, equipment and other buildings and structures that are not related to dwellings $\left(q_{k} K\right)$ and (ii) the estimated value of commercial real estate $\left(q_{l} L_{e}\right) .{ }^{15}$

The elasticity of the matching function is set to $a=0.7$ following the estimate of Petrongolo and Pissarides (2001) for the UK. Following Faccini, Millard, and Zanetti (2013), I set the steady-state separation rate to be $\rho=0.03$, and following Zanetti (2011) the exogenous fraction is set to be $\rho^{x}=0.02$, which implies the

\footnotetext{
${ }^{13}$ Note that the corresponding mean $\mu$ and standard deviation $\sigma$ of the Gamma distribution is calculated as $\mu=\underline{a} / \underline{b}$ and $\sigma=\sqrt{\underline{a} / \underline{b}^{2}}$.

${ }^{14}$ Commercial property is defined as including retail, offices and industrial premises as well as other commercial types typically used for business purposes such as leisure (cinemas, fitness clubs and gyms, leisure parks, etc.), hotels, petrol stations and other miscellaneous types (PDR, 2014).

${ }^{15}$ Over the 2003-2012 period, average net financial liabilities of non-financial corporations amounted to $£ 1800$ billion, whereas buildings and structures were about $£ 1200$ billion and machinery and equipment were $£ 590$ billion. The average value of commercial real estate was estimated to be $£ 690$ billion over the same period.
} 
Table 2: Prior and Posterior Distributions of Structural Parameters

\begin{tabular}{|c|c|c|c|c|c|}
\hline \multirow[t]{2}{*}{ Parameter } & \multicolumn{3}{|c|}{ Prior } & \multicolumn{2}{|c|}{ Posterior } \\
\hline & Distribution & $\underline{a}$ & $\underline{b}$ & Mode & Std \\
\hline$h_{h}$ & $\operatorname{Beta}(a, b)$ & 1.50 & 1.50 & 0.0077 & 0.0112 \\
\hline$h_{e}$ & $\operatorname{Beta}(a, b)$ & 1.50 & 1.50 & 0.0457 & 0.0683 \\
\hline$\Omega$ & $\operatorname{Gamma}(a, b)$ & 4.00 & 2.00 & 0.0738 & 0.0303 \\
\hline$\nu$ & $\operatorname{Gamma}(a, b)$ & 4.00 & 4.00 & 2.8017 & 0.6335 \\
\hline $\bar{\xi}$ & $\operatorname{Beta}(a, b)$ & 1.50 & 1.50 & 0.4258 & 0.0381 \\
\hline $100\left(g_{\gamma}-1\right)$ & $\operatorname{Gamma}(a, b)$ & 1.86 & 3.01 & 0.6149 & 0.1553 \\
\hline $100\left(\bar{\lambda}_{q}-1\right)$ & $\operatorname{Gamma}(a, b)$ & 1.86 & 3.01 & 0.2253 & 0.2428 \\
\hline$\rho_{z}$ & $\operatorname{Beta}(a, b)$ & 1.50 & 1.50 & 0.4743 & 0.0631 \\
\hline$\rho_{\nu_{z}}$ & $\operatorname{Beta}(a, b)$ & 1.50 & 1.50 & 0.4742 & 0.0654 \\
\hline$\rho_{q}$ & $\operatorname{Beta}(a, b)$ & 1.50 & 1.50 & 0.1614 & 0.0846 \\
\hline$\rho_{\nu_{q}}$ & $\operatorname{Beta}(a, b)$ & 1.50 & 1.50 & 0.0843 & 0.1187 \\
\hline$\rho_{\varphi}$ & $\operatorname{Beta}(a, b)$ & 1.50 & 1.50 & 0.9996 & 0.0000 \\
\hline$\rho_{\xi}$ & $\operatorname{Beta}(a, b)$ & 1.50 & 1.50 & 0.9528 & 0.0180 \\
\hline$\rho_{\theta}$ & $\operatorname{Beta}(a, b)$ & 1.50 & 1.50 & 0.9828 & 0.0102 \\
\hline$\rho_{m}$ & $\operatorname{Beta}(a, b)$ & 1.50 & 1.50 & 0.9642 & 0.0124 \\
\hline$\sigma_{z}$ & $\operatorname{Inv}-\operatorname{Gam}(a, b)$ & 0.3261 & $1.45 \mathrm{e}-04$ & 0.0056 & 0.0004 \\
\hline$\sigma_{\nu_{z}}$ & $\operatorname{Inv}-\operatorname{Gam}(\mathrm{a}, \mathrm{b})$ & 0.3261 & $1.45 \mathrm{e}-04$ & 0.0001 & 0.0000 \\
\hline$\sigma_{q}$ & $\operatorname{Inv}-\operatorname{Gam}(a, b)$ & 0.3261 & $1.45 \mathrm{e}-04$ & 0.0128 & 0.0015 \\
\hline$\sigma_{\nu_{q}}$ & $\operatorname{Inv}-\operatorname{Gam}(\mathrm{a}, \mathrm{b})$ & 0.3261 & $1.45 \mathrm{e}-04$ & 0.0065 & 0.0018 \\
\hline$\sigma_{\varphi}$ & $\operatorname{Inv}-\operatorname{Gam}(a, b)$ & 0.3261 & $1.45 \mathrm{e}-04$ & 0.0472 & 0.0036 \\
\hline$\sigma_{\xi}$ & $\operatorname{Inv}-\operatorname{Gam}(\mathrm{a}, \mathrm{b})$ & 0.3261 & $1.45 \mathrm{e}-04$ & 0.0942 & 0.0097 \\
\hline$\sigma_{\theta}$ & $\operatorname{Inv}-\operatorname{Gam}(\mathrm{a}, \mathrm{b})$ & 0.3261 & $1.45 \mathrm{e}-04$ & 0.0110 & 0.0010 \\
\hline$\sigma_{m}$ & $\operatorname{Inv}-\operatorname{Gam}(\mathrm{a}, \mathrm{b})$ & 0.3261 & $1.45 \mathrm{e}-04$ & 0.0345 & 0.0024 \\
\hline
\end{tabular}

Note: The parameters $\underline{a}$ and $\underline{b}$ denote the shape and scale parameters of the corresponding prior distributions. To construct the posterior distribution, two chains of 250,000 draws were sampled from the Random Walk Metropolis Hastings algorithm. The estimation is monitored to deliver an acceptance rate of around $30 \%$. The estimation is computed using version 4.2.2. of the Dynare toolbox.

steady-state threshold value of the lognormally distributed idiosyncratic preference shock to be $\bar{a}=2.25$, given the parameters $\mu_{a}=0$ and $\sigma_{a}=0.35$ similar to that used in Trigari (2009). ${ }^{16}$

The steady-state unemployment rate is set to $U=8 \%$, which is lower than the value used by Faccini, Millard, and Zanetti (2013) (10\%) and closer to the average UK unemployment rate over the 1985Q1-2012Q4 period (7.5\%). The

\footnotetext{
${ }^{16}$ The parameter choice for $\sigma_{a}$ delivers standard deviation of the job finding rates $(24 \%)$ that is similar to that (25\%) observed in the extended data of Petrongolo and Pissarides (2008). As a robustness check, I have re-estimated the model using the values $\sigma_{a}=[0.2,0.25,0.3,0.4,0.45]$, but the estimated decompositions presented in the rest of the paper do not materially change. These results are available upon request.
} 
implied steady-state job finding rate is $q^{u}=0.26$, which is between the value used by Faccini, Millard, and Zanetti (2013) based on the Labour Force Survey (0.35) and the average value over the estimation period based on the claimant count data used by Petrongolo and Pissarides (2008) (0.19). The values for $\kappa$ and $b$ are pinned down by the vacancy posting and separation conditions, respectively.

For the third subset of parameters characterising the structural shock processes, I follow Liu, Wang, and Zha (2013) in adopting agnostic priors and setting a beta distribution for the persistence parameters that lie with $90 \%$ prior probability in the interval [0.0256,0.7761], and setting an inverse gamma distribution for the standard deviations that lie with $90 \%$ prior probability in the interval $[0.0001,2]$.

Table 2 summarises the prior distributions and presents the estimates at the posterior modes together with the standard deviations. ${ }^{17}$ The posterior distributions are constructed using 250,000 draws from the MCMC chain. The estimated habit parameters, $h_{h}$ and $h_{e}$, suggest that both types of agents have low degrees of habit persistence, which is in line with the recent UK estimates of Faccini, Millard, and Zanetti (2013); Burgess, Fernandez-Corugedo, Groth, Harrison, Monti, Theodoridis, and Waldron (2013). Similar to Liu, Wang, and Zha (2013), the investment adjustment cost parameter $\Omega$ is estimated to be very small compared to the estimates of standard DSGE models without financial frictions. The steady-state growth rate of the permanent component of TFP is estimated to be larger (0.61) than that of the investment-specific technological change (0.22). The posterior mean of the inverse of the Frisch elasticity of labour supply $\nu$ is larger (2.8) than one as in Faccini, Millard, and Zanetti (2013), suggesting larger labour supply adjustment at the extensive margin as opposed to adjustments at the intensive margin as recently shown for the US by Liu, Wang, and Zha (2013), and Liu, Miao, and Zha (2013). The estimated relative bargaining power of workers $\bar{\xi}$ is around 0.43 that is somewhat lower than the recent estimate of Kamber and Millard (2012). As for the estimated structural shock series, the housing and collateral shocks are highly persistent and have large standard deviations relative to the other structural shocks, as found by Liu, Wang, and Zha (2013) for the US recently.

\footnotetext{
${ }^{17}$ To check for the recurring problem of parameter identification in DSGE models, I measure the identification strength as proposed by Iskrev (2010), and find that all parameters evaluated at their prior means have a non-negligible contribution to the first and second moment of the data, and therefore regarded as locally identified. These results are available upon request.
} 


\subsection{The Impact and Importance of Housing Shocks}

Given the estimated modes of the parameter values, the impulse responses are calculated to assess the effects of an exogenous shocks to housing demand $\varphi_{t}$, as shown in Figure 3. The IRFs are normalised to deliver 1\% increase in real house prices.

Figure 3: The Impact of Housing Shocks in the DSGE model
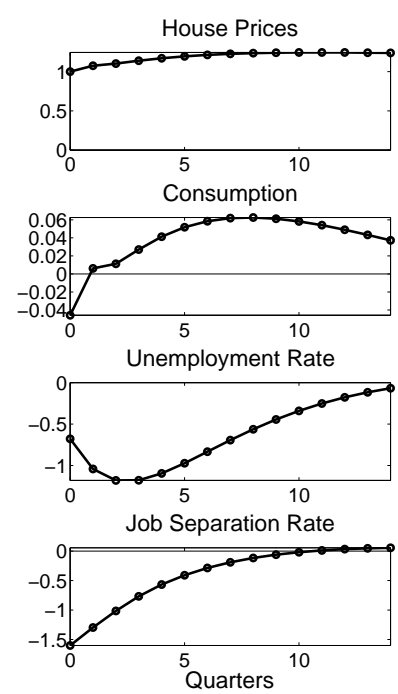
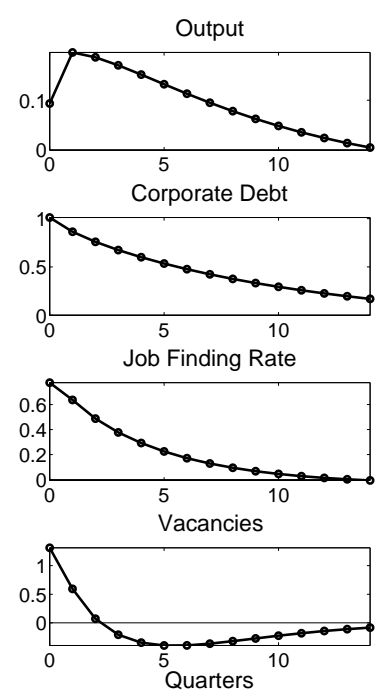
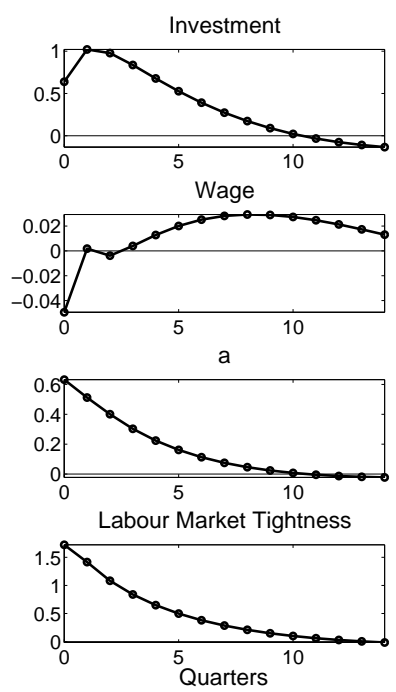

Note: The black lines represent the IRFs to a housing shock in the DSGE model using the estimated posterior modes of the parameters. The IRFs are normalised to give a $1 \%$ increase in house prices.

The results shows that shocks to house prices generate an economic expansion with a $0.2 \%$ peak impact on output. The unemployment rate falls $-1 \%$ below its steady-state value $(8 \%)$ that is consistent with the results from the BVAR model 2. As in Liu, Wang, and Zha (2013), the main mechanism of the present DSGE model is the one related to the collateral channel (Kiyotaki and Moore, 1997): a positive shock to house prices increases the borrowing capacity of the entrepreneur leading to increasing demand for capital and commercial real estate resulting in an economic expansion. As a result, profits $\pi_{t}$, the value of an employment match $J_{t}^{F}$ and the current value of vacancies $\frac{\kappa \Gamma_{t}}{q_{t}^{v}}$ all increase, resulting in increased job creation and labour market tightness, thereby movements along the downward-sloping Beveridge curve.

Moreover, the present model also features endogenous wage rigidity that the housing shock induces. This is because the direct effect of the housing preference shock is to generate a substitution away from non-durable to durable 
consumption. In turn, the collateral channel propagates the shock to generate an overall economic expansion, and the resulting wealth effect has a positive effect on non-durable consumption. The net effect of a positive housing shock in the current estimation is to generate small and positive movements in the marginal utility of non-durable consumption of the household $\lambda_{h, t}$. Therefore, workers' power during the bilateral wage bargaining process increases by little in spite of the economic expansion. To inspect this issue further, it is useful to compare the housing shock to other traditional business cycle shocks such as a permanent shock to investment-specific technological change. Figure 21 of the Appendix confirms that the effect of the technology shock on consumption and therefore on $\lambda_{h, t}$ is an order of magnitude higher than that of the housing shock. The technology shock therefore substantially increases workers' power during the bilateral bargaining process leading to large increases in wages, which reduces firms' incentives for vacancy creation (Shimer, 2005). In contrast, the housing shock generates relatively little variation in non-durable consumption and wages, therefore it can induce substantial volatility in labour market quantities.

This "labour channel" of the housing shock (Liu, Miao, and Zha, 2013) has additional consequences in the present model via the equilibrium condition 3.35 determining endogenous job separation. It is instructive to rewrite this condition in $\log$-linearised form ${ }^{18}$ :

$$
\hat{\bar{a}}_{t}=\omega_{1}\left(\hat{Y}_{t}-\hat{N}_{t}\right)+\omega_{2} \hat{\Theta}_{t}+\hat{\lambda}_{h, t} .
$$

The zero joint surplus condition implies that increases in labour productivity $\hat{Y}_{t}-\hat{N}_{t}$ and in labour market tightness $\hat{\Theta}_{t}$ are positively related to the threshold value of the preference shock $\hat{\bar{a}}_{t}{ }^{19}$ The labour productivity term in equation 4.2 captures the current joint payoff from continuing the employment relationship, whereas the labour tightness term represents the expected future joint payoffs. A key question is related to the dynamics of the marginal utility of consumption $\hat{\lambda}_{h, t}$ in response to shocks. To the extent that housing shocks generate little variation in $\hat{\lambda}_{h, t}$, a positive housing shock can thereby generate substantial increases in the threshold value $\hat{\bar{a}}_{t}$. Note that this is not necessarily the case in the presence of highly procyclical consumption induced by the investment-specific technology

\footnotetext{
${ }^{18}$ Here we assume no shocks to the bargaining power $\xi_{t}$ for expositional purposes.

${ }^{19}$ The parameters $\omega_{1}$ and $\omega_{2}$ are functions of the model's deep parameters and steady-state values: $\omega_{1} \equiv \frac{\tilde{\lambda}_{h}}{\bar{a}} \frac{\nu(1-\alpha)}{1+\nu} \frac{\tilde{Y}}{N}$ and $\omega_{2} \equiv \frac{\tilde{\lambda}_{h}}{\bar{a}} \frac{\kappa \Theta\left(\omega \Theta^{\omega-1} / \bar{\psi}-\xi\right)}{(1-\xi)}$. Under realistic parameterisations, it is true that $\omega \Theta^{\omega-1} / \bar{\psi}>\xi$.
} 
shock for example. In this case, as shown by Figure 21, the fall in $\hat{\lambda}_{h, t}$ is so large that workers' threshold value of the work preference shock $\bar{a}_{t}$ actually falls, leading to increased job separation and unemployment.

The positive housing shock increases the threshold value $\bar{a}_{t}$, which in turn lowers endogenous as well as total separation through equations 3.16-3.17. It thereby triggers an immediate fall in the number of unemployed workers searching for jobs, hence pushing down on the unemployment rate. While Liu, Miao, and Zha (2013) studied the role of the collateral channel in driving job creation via changing the value of a new employment match 3.22, the present model emphasises the additional channel via changing the destruction rate of existing employment matches. Note that the DSGE estimation results suggest that the impact of house price shocks is larger on job separation rates than on job findings rates.

The presence of endogenous job destruction is not only motivated by the conditional and unconditional time-series properties of job separation rates, but it also allows the model to capture potentially sizeable shifts in the Beveridge curve that have recently been documented by Hobijn and Sahin (2013) and Diamond and Sahin (2015) amongst others. Models with exogenous separation rates such as Liu and Leduc (2013) and Liu, Miao, and Zha (2013) focus on responses of equilibrium vacancy and unemployment caused by a movement along the downward-sloping Beveridge curve. My model allows for quantitatively important shifts in the Beveridge curve. To demonstrate this, I follow the steady-state analysis of section 2.3 of Pissarides (2000) and provide a pictorial representation of the Beveridge curve. Using the steady-states of the matching function 3.14 and the definitions of the endogenous separation 3.16-3.17 and employment 3.18-3.19, vacancies can be written as:

$$
v=\left(\frac{1-F(\bar{a})\left(1-\rho^{x}\right)}{\psi F(\bar{a})\left(1-\rho^{x}\right)} \frac{1-u}{u^{\omega}}\right)^{\frac{1}{1-\omega}}
$$

The papers by Liu and Leduc (2013) and Liu, Miao, and Zha (2013) provide a similar steady-state analysis (with exogenous separation rates) and use a 2dimensional (stylised) graph to represent the inverse relation between vacancies and unemployment. In that framework aggregate shocks such as housing shocks affect labour market dynamics by changing the value new employment matches, thereby rotating the job creation curve and causing movements along 
the downward-sloping Beveridge curve.

Figure 4: The Beveridge Curve in the DSGE Model

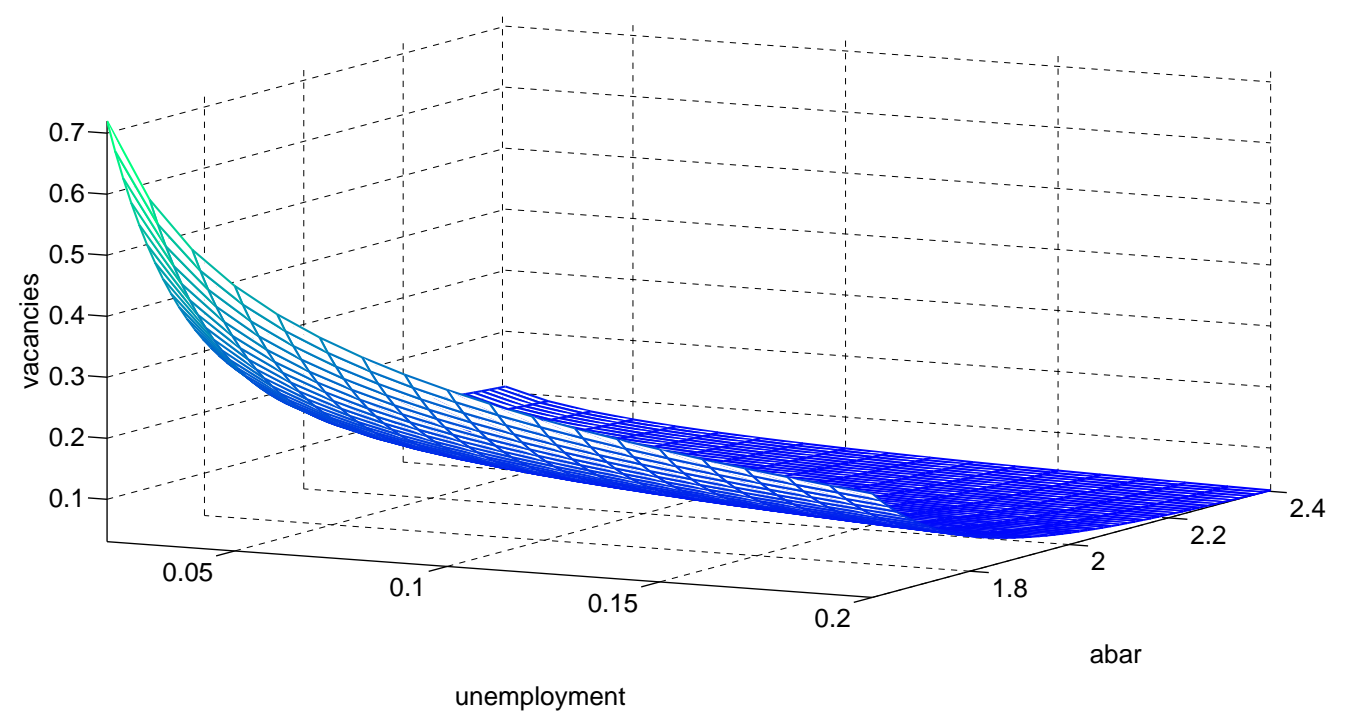

Note: The graph is constructed by using the grids $\bar{a}=\left[0.8 \times \bar{a}_{s s}: 0.016: 1.2 \times \bar{a}_{s s}\right], u=[0.02: 0.01: 0.2]$ to compute vacancies $v$ via the formula 4.3 .

In contrast, Figure 4 uses the calibrated parameter values to construct a 3dimensional graph that represents the inverse relation between vacancies and unemployment, as a function of the threshold value of the preference shock $\bar{a}$. The figure shows that higher levels of $\bar{a}$ correspond to inwardly shifted Beveridge curves. This matters for the following reason. In addition to movements along the Beveridge curve caused by rotation in the job creation curve, my model can generate quantitatively important inward (outward) shifts in the Beveridge curve when labour market tightness increases (decreases) and the threshold value of the preference shock $\bar{a}$ rises (falls), as illustrated by Figure $4 .{ }^{20}$ Allowing for endogenous job separation therefore enables the model to explain important historical episodes such as, for example, the UK recession in the early 1990s characterised by a large outward shift in the Beveridge curve and coincidentally by one of the largest real estate market collapses in the country's post-war history. Figures 15 and 17 of the Appendix provide a visual illustration of this point.

\footnotetext{
${ }^{20}$ The net effect on vacancies is therefore theoretically ambiguous. However, in the log-linear dynamics of my model, the former effect dominates the latter (as also discussed in section 2.3 of Pissarides (2000)): house price shocks have an immediate procyclical effect on vacancies, though they subsequently fall slightly below their steady-states about a year after the shock and stay there before returning to steady-state. This is shown by the lower middle panel of Figure 2 .
} 
Table 3: Posterior Variance Decomposition

\begin{tabular}{|c|c|c|c|c|c|c|c|c|}
\hline & Housing & $\begin{array}{r}\text { Collateral } \\
\text { Out }\end{array}$ & $\begin{array}{l}\text { Labour } \\
\text { it }\end{array}$ & Techn & Housing & $\begin{array}{r}\text { Collateral } \\
\text { House }\end{array}$ & $\begin{array}{l}\text { Labour } \\
\text { cice }\end{array}$ & Techn \\
\hline $4 \mathrm{Q}$ & 20.44 & 20.21 & 7.60 & 51.75 & 93.89 & 0.21 & 0.23 & 5.67 \\
\hline $8 Q$ & 18.26 & 22.75 & 14.11 & 44.87 & 94.11 & 0.42 & 0.15 & 5.32 \\
\hline $16 \mathrm{Q}$ & 14.13 & 23.95 & 24.42 & 37.50 & 95.32 & 0.96 & 0.13 & 3.59 \\
\hline $24 \mathrm{Q}$ & 12.87 & 23.86 & 29.71 & 33.57 & 96.16 & 1.12 & 0.16 & 2.56 \\
\hline & \multicolumn{4}{|c|}{ Investment } & \multicolumn{4}{|c|}{ Corporate Debt } \\
\hline $4 Q$ & 34.21 & 56.17 & 1.72 & 7.91 & 21.28 & 44.20 & 0.07 & 34.45 \\
\hline $8 \mathrm{Q}$ & 27.64 & 53.90 & 5.58 & 12.89 & 18.79 & 48.60 & 0.42 & 32.19 \\
\hline 16Q & 22.73 & 49.36 & 9.64 & 18.28 & 15.50 & 55.35 & 1.61 & 27.54 \\
\hline $24 \mathrm{Q}$ & 22.64 & 47.34 & 10.37 & 19.65 & 13.58 & 59.34 & 2.59 & 24.49 \\
\hline & \multicolumn{4}{|c|}{ Unemployment Rate } & \multicolumn{4}{|c|}{ Job Separation Rate } \\
\hline $4 \mathrm{Q}$ & 25.28 & 10.41 & 59.92 & 4.39 & 34.74 & 13.54 & 45.17 & 6.55 \\
\hline $8 \mathrm{Q}$ & 18.31 & 6.98 & 70.33 & 4.38 & 26.15 & 9.69 & 55.14 & 9.02 \\
\hline $16 \mathrm{Q}$ & 11.69 & 4.30 & 79.54 & 4.47 & 18.96 & 8.04 & 63.13 & 9.87 \\
\hline $24 \mathrm{Q}$ & 9.86 & 4.31 & 81.44 & 4.39 & 16.44 & 8.44 & 65.80 & 9.33 \\
\hline
\end{tabular}

Note: For each variable, variance decompositions over different horizons are generated by the DSGE model evaluated at the mode of the posterior distribution. The housing and collateral shocks are treated separately. The labour shock combines the effects of the matching efficiency and bargaining shocks. The column 'Techn' combines the effects of permanent and transitory shocks to TFP and investment-specific technological change.

To further explore the model's quantitative implications, I use the estimated modes of the parameters to calculate forecast error variance decompositions (FEVD) for some of the key observed macroeconomic variables. Table 3 shows that the housing shock alone explains about $10-20 \%$ of output fluctuations, and $20-35 \%$ of investment, credit, unemployment and separation rate fluctuations over the two-year horizon.

Overall, the two financial shocks (i.e. the housing shock and the collateral shock) explain more than half of investment fluctuations and about third of output fluctuations in the UK. These results confirm recent findings of Jermann and Quadrini (2012), Liu, Wang, and Zha (2013) and Christiano, Motto, and Rostagno (2014) regarding the importance of financial shocks in the US. Technologytype shocks continue to be an important source of business cycle fluctuations in the UK mainly because of their contribution to consumption volatility. They do however explain little of labour market fluctuations (Shimer (2005)). These results are quantitatively similar to recent UK findings presented by Faccini, Millard, and Zanetti (2013). Labour market shocks, not surprisingly, have large effects on unemployment and separation rates, but they propagate little into 
house prices and investment. However, their importance for output fluctuations increases with the horizon, which is consistent with the recent literature since Smets and Wouters (2007). ${ }^{21}$

Figure 5: Comparing the DSGE and BVAR Identified Housing Shocks

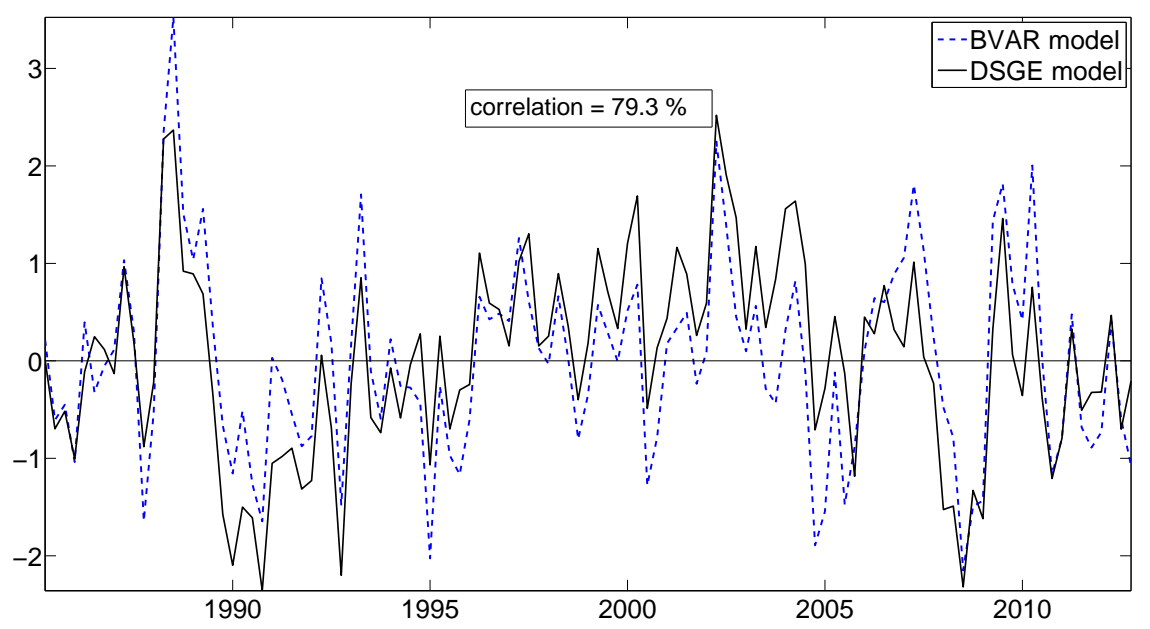

Note: The black solid (blue dashed) line is the housing shock series from the DSGE (BVAR(1)) models. The shocks are normalised by the estimated standard deviations that are 0.023 and 0.047 for the BVAR and the DSGE, respectively.

To take a closer look at the properties of the housing shock, Figure 5 plots the estimated time-path of the identified shock series in BVAR and DSGE models. In terms of the statistical implications, the two series have a high, $79 \%$, correlation. This suggests that while providing a structural interpretation of how house prices can affect labour markets via the collateral channel, the DSGE model comes close to recovering the structural shock series implied by a reduced-form BVAR model. In terms of the historical implications, Figure 5 suggests that the early 1990s were characterised by larger shocks to house prices than the recent Great Recession. To quantify the relevance of house price shocks and the collateral channel, the next subsection will compute the counter-factual paths of the UK economy that would have been realised if housing shocks had been absent.

\footnotetext{
${ }^{21}$ To further explore the model's quantitative implications relative to the BVAR model, Figure 22 of the Appendix shows the results for the DSGE model (blue line) as well as for the BVAR model (black line with orange shaded area). The results suggest that the estimated theoretical model, while providing a structural interpretation of the observed comovements in question, can not only recover the time path of the first moments of these key observables, conditional on house price shocks, but can also come close to recovering the time path of the conditional second moments implied by the BVAR model.
} 
Note that, as a robutness check, the model is re-estimated after using per capital consumption instead of per capital investment as an observable. Section G.2 of the Appendix shows that the dynamics of the housing shocks are preserved.

\subsection{Causes of the 1990-91 and 2008-09 UK Recessions}

The early 1990s were characterised one of the largest collapse of real estate prices in UK post-war economic history. Real house prices started falling rapidly in 1989Q2 and by 1995Q4 the accumulated loss in real value amounted to almost 40\%. A large fraction of the initial collapse is interpreted by both the DSGE and the BVAR models as being unrelated to other structural shocks in the economy, and the collapse was mainly driven by housing shocks as shown by Figure 5 . About a year after the initial shock, in 1990Q2, unemployment started rising from $6.9 \%$, and continued to increase for eleven consecutive quarters, reaching $10.6 \%$ by $1993 \mathrm{Q} 1$.

Figure 6 shows the counter factual paths (blue dash lines) along the actual macroeconomic outcome (black solid lines). In the counter-factual economy, house price growth would have been stable, and the fall in output would have been muted mainly because corporate credit growth would have remained positive all the way till 1991Q1, supporting business investment and to a smaller degree consumption. The implications for labour markets are vast: the unemployment rate would have remained below $7.5 \%$ throughout the recession. Note that the decomposition also suggests that house price booms preceding the crisis contributed significantly to low unemployment rates and economic activity in the late 1980s.

During the recent Great Recession, real UK house prices and real GDP contracted by about $20 \%$ and $7 \%$, respectively, over the period from 2007Q3 to 2009Q2. During the same period, the unemployment rate rose from $5.3 \%$ to $7.7 \%$. To explore the contribution of negative house price shocks via the collateral channel to the UK macroeconomy, I compute what would have been the counter-factual time-path of the business cycle, if housing shocks had been absent.

Figure 7 shows the counter factual paths (blue dash lines) along the actual macroeconomic outcome (black solid lines). Without shocks to house prices, we would not have observed the series of consecutive negative house price growth rates starting from 2007Q3 and reaching a trough of $-6.2 \%$ in 2008Q4. Adverse 
Figure 6: The 1990-91 UK recession - the Contribution of House Price Shocks
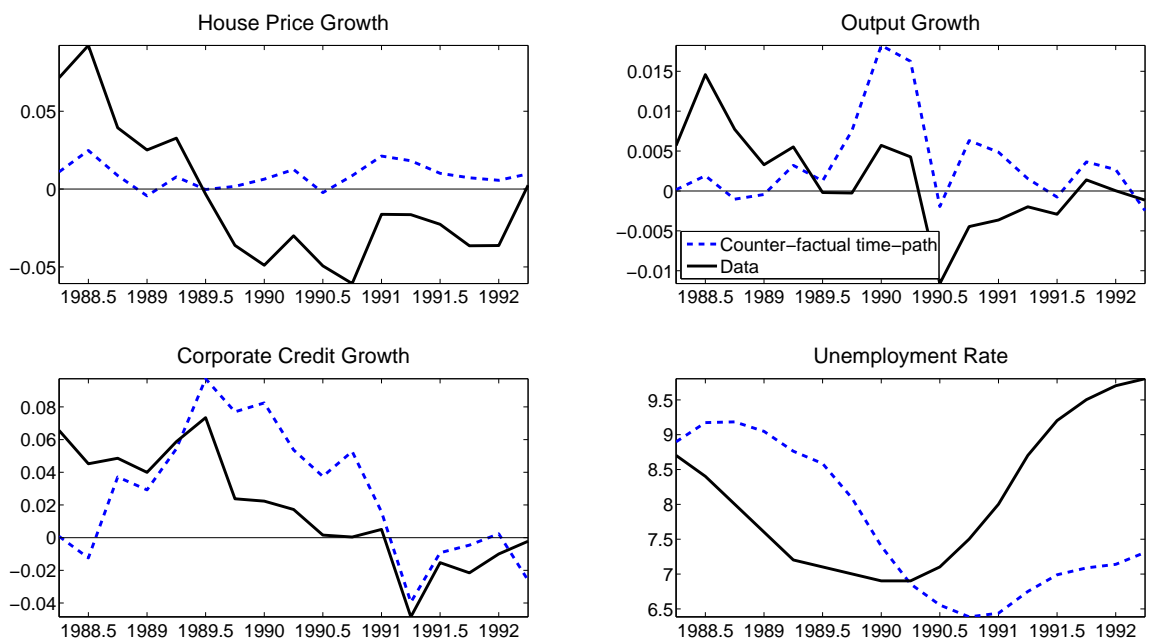

Note: To construct the counter-factual time paths of the variables, the contribution of the estimated housing demand shocks is subtracted from the observables, using the median values from the estimation.

housing shocks started feeding in the macroeconomy by the beginning of 2008 : (i) they caused the quarterly output growth rate to be more than $1 \%$ points lower on average throughout 2008, and (ii) contributed to the rapid increase in the unemployment rate. In fact, the estimation results suggest that the unemployment rate that reached $7.8 \%$ by 2009 , would have remained below $6 \%$ till the end of 2009, had house prices not collapsed.

The reason why negative house price shocks had such large effects on the macroeconomy and on labour markets is because their impact on corporate borrowing via the collateral channel. In fact, as shown in Figure 7, quarterly corporate credit growth would have remained positive throughout 2008, had house prices not collapsed.

Though the estimation provides strong evidence on the causal link between housing shocks and the macroeconomy during the recent crisis, this channel does not explain the full story, and other mechanisms were also likely to play an important role. For example, shocks to house prices explain a large part of corporate credit contraction in 2008, but they explain little of the ensuing tightening of corporate credit. The period 2009-2010 is interpreted by the estimation as being largely driven by adverse shocks to the collateral constraint (Jermann and Quadrini, 2012), suggesting that disruptions in financial intermediation (unrelated to the housing market) were responsible to the continuing corporate credit 
Figure 7: The 2008 UK recession - the Contribution of House Price Shocks
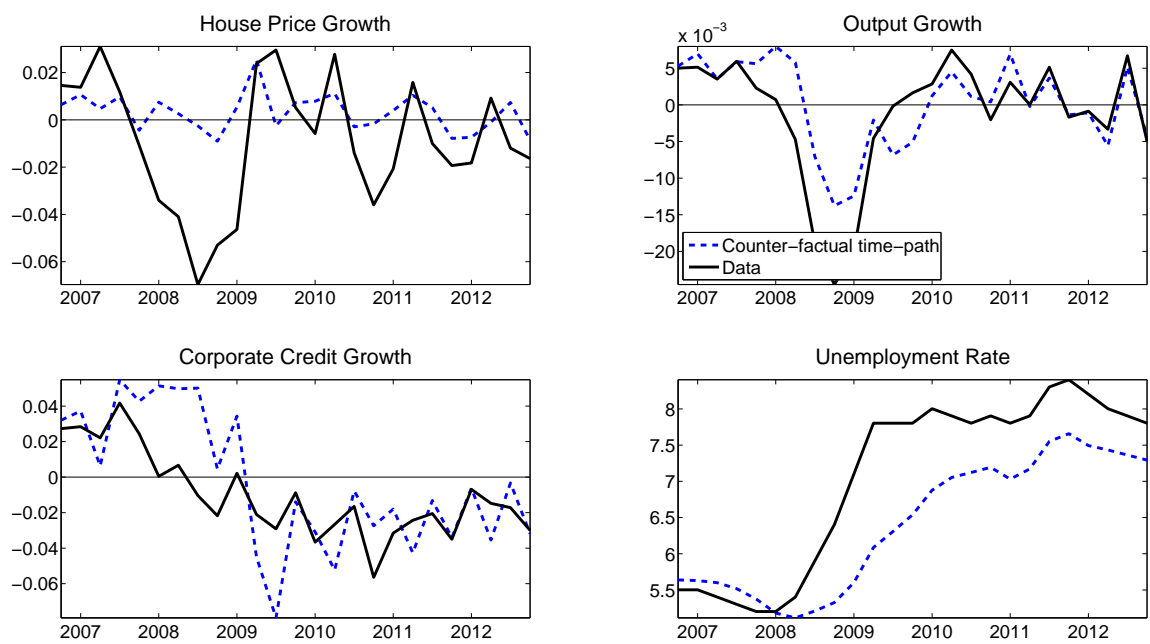

Note: To construct the counter-factual time paths of the variables, the contribution of the estimated housing demand shocks is subtracted from the observables, using the median values from the estimation..

squeeze. Future work could extend the present model by modelling financial intermediaries explicitly.

\subsection{Explaining the Vacancy-Unemployment Ratio}

To provide external validation on the DSGE model, I compare the estimated vacancy-unemployment ratio implied by the model to that implied by an offmodel empirical estimation. The off-model estimation uses vacancy data from the ONS's Vacancy Survey of businesses and from Job Centres ${ }^{22}$ to calculate quarterly averages of the monthly ratio of the vacancy rate to the unemployment rate. This is then detrended with a linear trend to obtain a series comparable with the DSGE counterpart.

Figure 8 confirms that the DSGE model (magenta line) tracks closely the offmodel estimate of the vacancy-unemployment ratio (black line). The model does well in matching the substantial drop in labour market tightness during the 1990s recession, the subsequent gradual increase till the mid 2000s and (to a smaller extent) the drop during the recent Great Recession. Note that the DSGE model

\footnotetext{
${ }^{22}$ Seasonally adjusted data from ONS's Vacancy Survey of businesses, starting in 2001, include the stock of vacancies in all industries excluding those in agriculture, forestry and fishing. For the period 1985-2001, I use spliced and seasonally adjusted data from Job Centre records, which offers a less complete coverage because employers are under no obligation to notify vacancies to Job Centres.
} 
Figure 8: The Vacancy-Unemployment Ratio: DSGE and Off-model Estimates

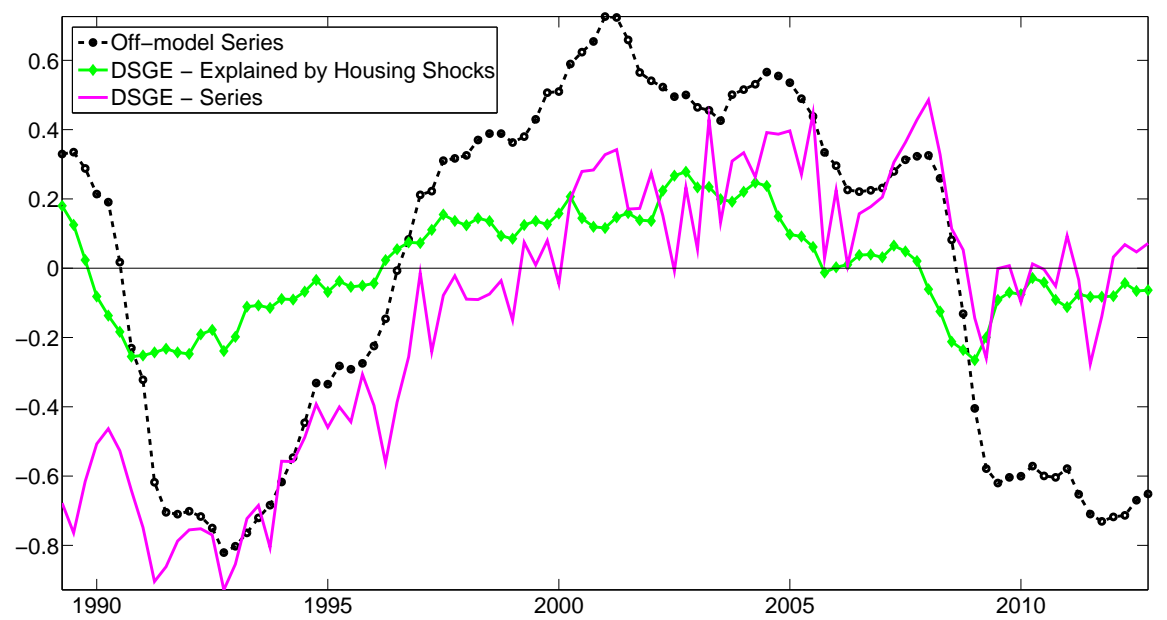

Note: The modes of the estimated parameters are used to compute the \% deviation of the ratio of the vacancy rate and the unemployment rate (magenta solid line) and the contribution of the housing shock to this series (green diamond line) in the DSGE model. The off-model estimate (black dashed line) is constructed by demeaning and linearly detrending the logarithm of the ratio of the vacancy rate and the unemployment rate, where vacancy data are from the ONS's Vacancy Survey and Job Centres records.

attributes a considerable amount of power to the housing shock (green line) in explaining the dynamics of the vacancy-unemployment ratio, especially during the outbreak of the two recessions.

These results challenge some of the previous findings that interpreted the early 1990s recessions and the corresponding movements in the Beveridge curve as entirely policy-induced. ${ }^{23}$ While the policy-based narrative may well explain some fraction of the observed dynamics, my results corroborate the presence of additional factors related to the collateral channel. ${ }^{24}$

In addition, Figure 8 confirms that my model with housing shocks and the collateral channel can explain the relatively large volatility of the vacancy-unemployment ratio that is not only a feature of the US (Shimer, 2005) but also of the UK labour market (Amaral and Tasci, 2014). Figure 23 of the Appendix shows a similar

\footnotetext{
${ }^{23}$ For example, Pissarides (2003) argues that entering the ERM together with unsustainably high inflation rates (as a result of expansionary policy related to the 1987 elections) forced the UK central bank to rapidly tighten monetary policy in 1990 leading to sharply increasing unemployment rates via the short-run Phillips curve.

${ }^{24}$ These findings are in line with previous work on the balance sheet channel in the UK. For example, Hall (2001) links the depth and persistence of the UK recession of the early 1990s to the tightening of corporate borrowing constraints and the resulting prolonged weakness of corporate investment growth.
} 
decomposition of the vacancy-unemployment ratio for the transitory and permanent components of the technology shocks. The results suggest that both types of technology shocks explain very little of the variation in labour market volatility, which is in line with the findings of Shimer (2005).

\subsection{The Role of Endogenous Job Separation}

To explore the role of endogenous job separation in determining the propagation of the housing shock on labour markets, I set the steady-state value of the endogenous share of total separation to zero $\left(\rho=\rho^{x}\right)$. Figure 9 shows the IRFs from the benchmark model along the IRFs from the model without endogenous separation.

The results are in line with Ramey, den Haan, and Watson (2000) who show that aggregate shocks can be largely amplified by endogenous job separation. Indeed my findings suggest the impact of a housing shock, that increases house prices by $1 \%$, would have an $0.03 \%$ points higher peak impact on output in the model with endogenous separation than in the model with exogenous separation.

To put the results into perspective, a housing shock that would lead to a $20 \%$ collapse in house prices (as in 2008), would lead to a peak increase of about $1.9 \%$ points in the unemployment rate after about three quarters, if one allows for endogenous job separation. In contrast, the same shock would generate 'only' a peak increase of $0.8 \%$ points in the unemployment rate over the same horizon, if endogenous separation were absent. This would also imply that output would fall by $4 \%$ when separation is endogenous as opposed to the fall of $3.4 \%$ in case of exogenous separation. ${ }^{25}$

These results may have important implications for other studies that focused on the US recession. For example, Liu, Miao, and Zha (2013) estimated the impact of housing shocks on the US unemployment rate but without accounting for the possibility of endogenously fluctuating separation rates. They find that a shock that leads to a $20 \%$ collapse in land prices in the US would generate an increase of the unemployment rate by $0.68 \%$ points, which is close to my estimate ( $0.8 \%$ points) for the UK with exogenous separation, shown by the black solid lines in Figure 9 above. ${ }^{26}$ Given that separation rates increased sharply not just

\footnotetext{
${ }^{25}$ To obtain these number, I used the peak impact on Figure 9, and calculated $0.0118 \times U \times$ $20=1.9$ and $0.005 \times U \times 20=0.8$, where $U=8 \%$ is the steady-state value of the unemployment rate. For output, I calculate the peak effect as $0.17 \times 20=3.4$ and $0.2 \times 20=4$.

${ }^{26}$ Note that the difference between these multipliers with and without endogenous separa-
} 
Figure 9: The Role of Endogenous Job Separation
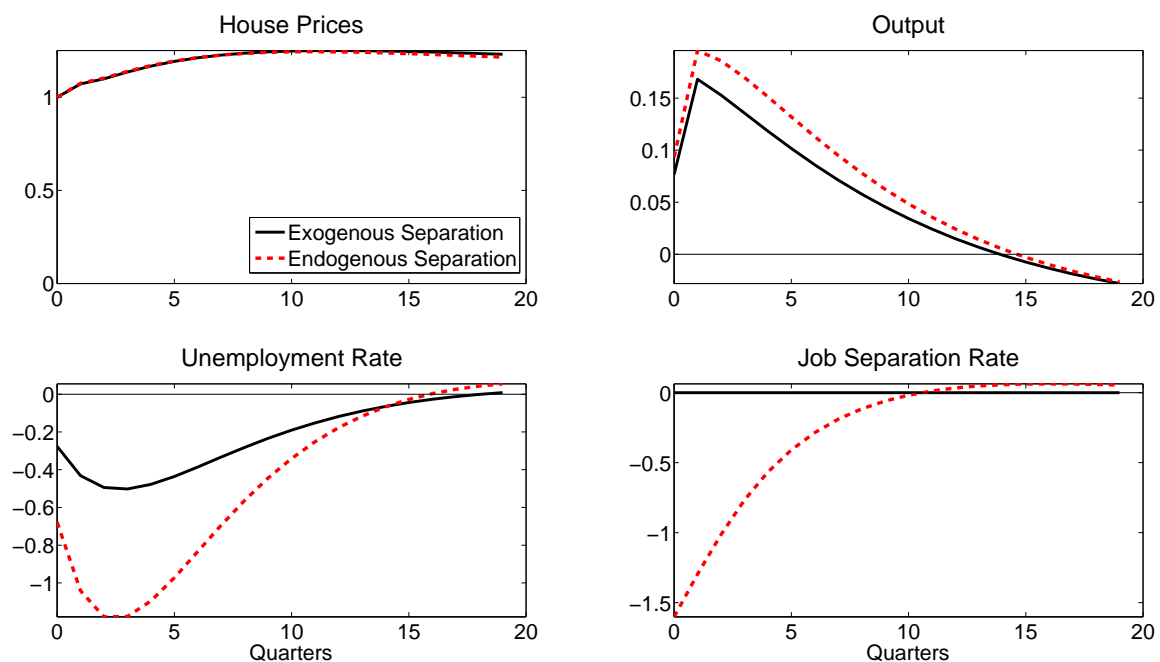

Note: The modes of the estimated parameters are used to calculate the IRFs for the two models. The IRFs are normalised such that the housing shocks increases house prices by $1 \%$.

in the UK but also in the US during the Great Recession, the results of Liu, Miao, and Zha (2013) may underestimate the true impact of housing shocks on US labour markets by not modelling endogenous separation explicitly.

\subsection{US versus UK Housing Shocks}

This section revisits the role of housing shocks as in Liu, Wang, and Zha (2013); Liu, Miao, and Zha (2013) by re-estimating the BVAR model, analysed in Section 2, on US data covering the period 1977Q3-2010Q4. Figure 10 shows the impulse response functions from the nine-variable BVAR $(2)$ model. The results show that housing shocks do have a non-trivial effect on job separation rates in the US as well. This suggests that ignoring endogenous separation in the theoretical model may indeed lead to an underestimation of the comovement between housing and labour markets. Note that the effect is smaller on job separation rates $(0.6 \%)$ than on job finding rates $(2 \%)$, which is in line with previous literature regarding the relatively more acyclical nature of US job separation rates (Shimer, 2005, 2012).

However, the time-profile of the effect is different: the peak effect on separation rates comes much earlier (after about three quarters) than the peak effect on

tion may increase substantially, if the steady-state share of endogenous separation in total separation is increased from $\rho^{n}=0.01$. These results are available upon request. 
Figure 10: The Effects of a House Price Shock in the US
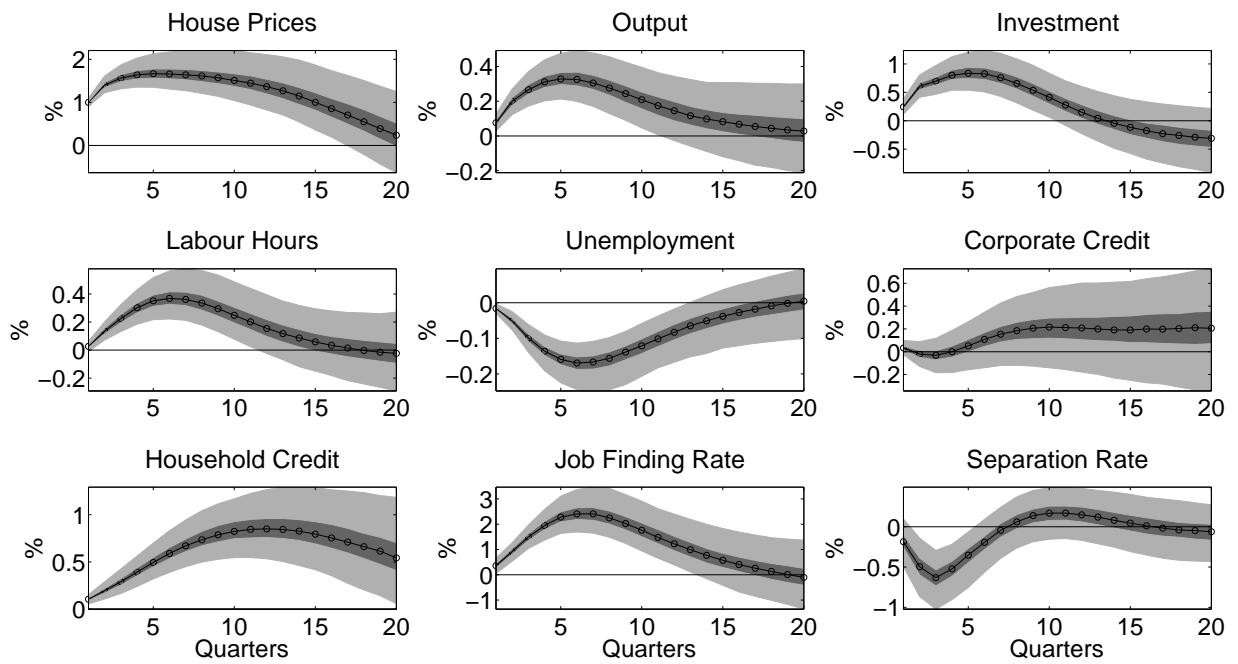

Note: The identification is with Choleski ordering. The sample period is 1977Q3 - 2010Q4. Each plot shows the pointwise median, 32nd-68th and 5th-95th percentiles from the posterior. Data source: Liu, Wang, and

Zha (2013) and separation and job finding rates are from Barnichon and Nekarda (2012).

job finding rates (after about six quarters). This suggests that separation rates may play an important role in the short-term propagation of housing shocks into US labour markets, whereas job finding rates are responsible for the longrun persistence of the effects. One implication is that the model of Liu, Miao, and Zha (2013) would likely generate a larger and more realistic multiplier if it accounted for endogenous job separation.

An additional difference between the US and the UK is related to the impact on credit markets: while housing shocks seem to have a larger impact on corporate credit than on household credit in the UK, the opposite is true in the US: the BVAR(2) model suggests that the peak impact on household debt is much larger than that on corporate debt, based on the median estimates. These results are in line with the recent work of Mian and Sufi (2011, 2014b,a) emphasising the role of the collateral channel on the household sector. Additional hypotheses that future research could test are whether (i) the relatively muted response of US corporate credit implies that the aggregate corporate collateral channel is weaker in the US than in the UK, and (ii) this may partly explain why the conditional volatility of US job separation rate is lower than in the UK. ${ }^{27}$

\footnotetext{
${ }^{27}$ In a related work, Sterk (2015) studies the conditional correlation between house prices, household credit and job finding rates in the US (which seems larger than that in the UK). He shows that house prices in the US affect real activity via the household collateral channel,
} 
Figure 11: Housing Shocks in the US and the UK
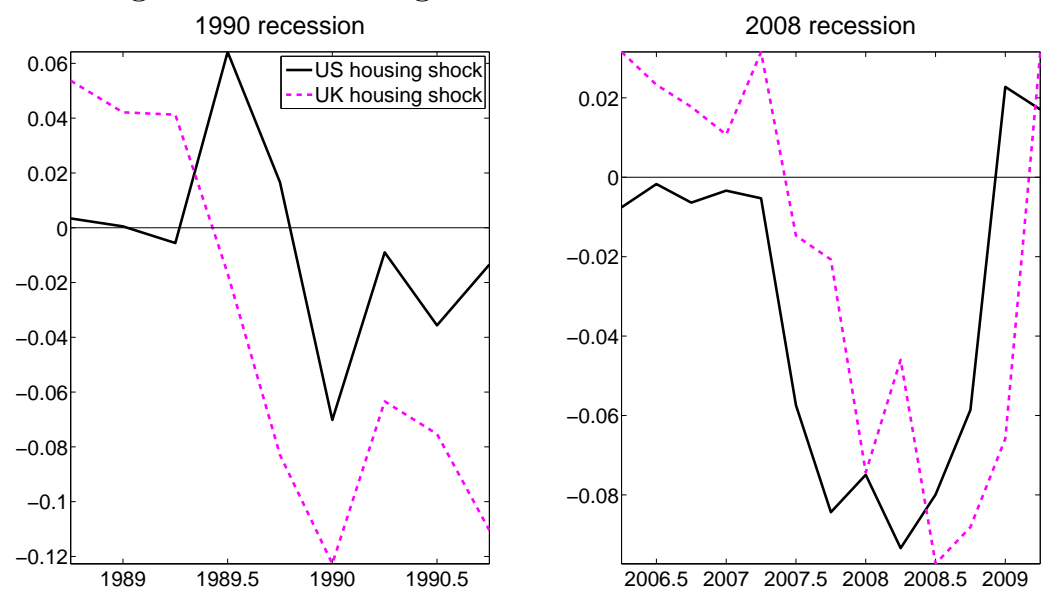

Note: The modes of the estimated parameters are used to calculate the Kalman-smoothed shock series in the DSGE model of Liu, Wang, and Zha (2013) (solid black line) and of the present paper (dashed magenta line).

Moreover, one of the notable features of the Great Recession was the synchronisation of the meltdown of financial markets and the correlation in output falls across countries. A popular narrative is that the crisis was triggered by the bursting of the housing bubble in the US subprime mortgage market, which subsequently spilled over to UK banks that had large exposures to foreign housing markets. To investigate this narrative further, the UK housing shock identified by the DSGE model is compared to that identified by Liu, Wang, and Zha (2013) recently. The correlation of the two shocks series is about $30 \%$ for the overlapping period (1985Q1-2010Q4).

The correlation does not seem to be high for the whole sample, however it is more pronounced during the two crisis periods studied above. Figure 11 shows that the large negative shocks to the UK housing market in 1989 and 2007 indeed coincided with large negative shocks to the US housing market, pointing to the possibly synchronised nature of housing shocks especially during downturns. Investigating further these international dimensions may be a fruitful avenue for future research.

because unemployed homeowners more often turn down job offers that would require them to move, in response to declines in their home equity levels. 


\section{Conclusion}

This paper presented evidence on the strong comovements between macroeconomic and labour market variables in the UK. The comovement between house prices and job separation rates is particularly striking and is not only a feature of the recent crisis, but characterises at least the last 30 years of UK business cycles. A DSGE model with credit constrained firms and search and matching frictions in labour markets was used to explain these empirical regularities. I find that shocks to house prices (that are unrelated to other structural disturbances in the economy such as technology shocks) explain about 10-20\% of output fluctuations and about $20-30 \%$ of fluctuations unemployment and job separation rates via the collateral channel over the forecast horizon.

Given the increased importance of labour market variables in the recent policy debate in the UK (particularly the choice of the unemployment rate as a key indicator in designing forward guidance) as well as the increased financial stability concerns regarding house price dynamics, it is vital to better understand the drivers of the striking comovement between house prices and labour markets. The present paper offered one possible narrative that can explain some fraction of this comovement. Future work should test alternative channels. This could include the extension of the present model by modelling the household sector in more detail with special regard to household debt dynamics and related demand channels.

\section{References}

Amaral, P. S., And M. Tasci (2014): "The Cyclical Behavior of Equilibrium Unemployment and Vacancies Across OECD Countries," Working Papers 1405, Koc University-TUSIAD Economic Research Forum.

Aoki, K., J. Proudman, and G. Vlieghe (2004): "House prices, consumption, and monetary policy: a financial accelerator approach," Journal of Financial Intermediation, 13(4), $414-435$.

Bahaj, S., A. Foulis, And G. Pinter (2015): "Collateral Channels," mimeo, Bank of England.

Banbura, M., D. Giannone, and L. Reichlin (2010): "Large Bayesian vector auto regressions," Journal of Applied Econometrics, 25(1), 71-92. 
Barnichon, R., And C. J. Nekarda (2012): "The Ins and Outs of Forecasting Unemployment: Using Labor Force Flows to Forecast the Labor Market," Brookings Papers on Economic Activity, 45(2), 83-131.

Bernanke, B. S., M. Gertler, and S. Gilchrist (1999): "The financial accelerator in a quantitative business cycle framework," in Handbook of Macroeconomics, ed. by J. B. Taylor, and M. Woodford, vol. 1, chap. 21, pp. 1341-1393. Elsevier.

Blanchard, O., and J. Gali (2010): "Labor Markets and Monetary Policy: A New Keynesian Model with Unemployment," American Economic Journal: Macroeconomics, 2(2), 1-30.

Buckle, M., And J. Thompson (1992): The UK Financial System: Theory and Practice. Manchester University Press.

Burgess, S., E. Fernandez-Corugedo, C. Groth, R. Harrison, F. Monti, K. Theodoridis, and M. WAldron (2013): "The Bank of England's forecasting platform: COMPASS, MAPS, EASE and the suite of models," Bank of England working papers 471, Bank of England.

Campbell, J. Y., and J. F. Cocco (2007): "How do house prices affect consumption? Evidence from micro data," Journal of Monetary Economics, 54(3), 591 621.

Chaney, T., D. Sraer, and D. Thesmar (2012): "The Collateral Channel: How Real Estate Shocks Affect Corporate Investment," American Economic Review, 102(6), 2381-2409.

Christiano, L. J., M. S. Eichenbaum, and M. Trabandt (2013): "Unemployment and Business Cycles," NBER Working Papers 19265, National Bureau of Economic Research, Inc.

Christiano, L. J., R. Motto, And M. Rostagno (2014): "Risk Shocks," American Economic Review, 104(1), 27-65.

Christiano, L. J., M. Trabandt, and K. Walentin (2011): "Introducing financial frictions and unemployment into a small open economy model," Journal of Economic Dynamics and Control, 35(12), 1999 - 2041.

Corradin, S., And A. Popov (2015): "House Prices, Home Equity Borrowing, and Entrepreneurship," Review of Financial Studies, Forthcoming. 
Diamond, P. A., And A. SAhin (2015): "Shifts in the Beveridge curve," Research in Economics, 69(1), 18-25.

Faccini, R., S. Millard, And F. Zanetti (2013): "Wage Rigidities in an Estimated Dynamic, Stochastic, General Equilibrium Model of the UK Labour Market," Manchester School, 81, 66-99.

Fujita, S., And G. Ramey (2009): "The Cyclicality of Separation and Job Finding Rates," International Economic Review, 50(2), 415-430.

HALL, R. E. (2005): "Employment Efficiency and Sticky Wages: Evidence from Flows in the Labor Market," The Review of Economics and Statistics, 87(3), 397-407.

HALL, S. (2001): "Financial accelerator effects in UK business cycles," Bank of England working papers 150, Bank of England.

Hilber, C. A. L., And W. Vermeulen (2015): "The Impact of Supply Constraints on House Prices in England," Economic Journal, Forthcoming.

Hobijn, B., And A. SAhin (2009): "Job-finding and separation rates in the OECD," Economics Letters, 104(3), 107 - 111.

(2013): "Beveridge Curve Shifts across Countries since the Great Recession," IMF Economic Review, 61(4), 566-600.

IACOViello, M., AND S. Neri (2010): "Housing Market Spillovers: Evidence from an Estimated DSGE Model," American Economic Journal: Macroeconomics, 2(2), $125-64$

IskREV, N. (2010): "Local identification in DSGE models," Journal of Monetary Economics, 57(2), 189-202.

Jermann, U., AND V. QuAdrini (2012): "Macroeconomic Effects of Financial Shocks," American Economic Review, 102(1), 238-71.

Kamber, G., And S. Millard (2012): "Using Estimated Models to Assess Nominal and Real Rigidities in the United Kingdom," International Journal of Central Banking, 8(4), 97-119.

Kiyotaki, N., And J. Moore (1997): "Credit Cycles," Journal of Political Economy, 105(2), 211-48. 
Krause, M. U., And T. A. Lubik (2007): "The (ir)relevance of real wage rigidity in the New Keynesian model with search frictions," Journal of Monetary Economics, $54(3), 706-727$.

Liu, Z., AND S. Leduc (2013): "Uncertainty Shocks Are Aggregate Demand Shocks," Discussion paper.

Liu, Z., J. Miao, And T. Zha (2013): "Land Prices and Unemployment," NBER Working Papers 19382, National Bureau of Economic Research, Inc.

LiU, Z., P. Wang, and T. Zha (2013): "Land-Price Dynamics and Macroeconomic Fluctuations," Econometrica, 81(3), 1147-1184.

Mian, A., And A. Sufi (2011): "House Prices, Home Equity-Based Borrowing, and the US Household Leverage Crisis," American Economic Review, 101(5), 2132-56.

(2014a): House of Debt. The University of Chicago Press.

(2014b): "What Explains the 20072009 Drop in Employment?," Econometrica, 82(6), 2197-2223.

Monacelli, T., V. Quadrini, and A. Trigari (2011): "Financial Markets and Unemployment," NBER Working Papers 17389, National Bureau of Economic Research, Inc.

Mortensen, D. T., And C. A. Pissarides (1994): "Job Creation and Job Destruction in the Theory of Unemployment," Review of Economic Studies, 61(3), 397-415.

Mumtaz, H., And F. Zanetti (2015): "The Effect of Labor and Financial Frictions on Aggregate Fluctuations," Macroeconomic Dynamics, forthcoming.

PDR (2014): "Property Data Report," Discussion paper, British Property Federation.

Petrongolo, B., And C. A. Pissarides (2001): "Looking into the Black Box: A Survey of the Matching Function," Journal of Economic Literature, 39(2), 390-431. (2008): "The Ins and Outs of European Unemployment," American Economic Review, 98(2), 256-62.

Petrosky-Nadeau, N. (2014): "Credit, Vacancies and Unemployment Fluctuations," Review of Economic Dynamics, 17(2), 191-205.

Pissarides, C. (2000): Equilibrium Unemployment Theory. The MIT Press, 2 edn. 
(2003): "Unemployment in Britain: a European success story," LSE Research Online Documents on Economics 2304, London School of Economics and Political Science, LSE Library.

Ramey, G., W. J. den HaAn, and J. Watson (2000): "Job Destruction and Propagation of Shocks," American Economic Review, 90(3), 482-498.

Ravn, M. O., And V. Sterk (2014): "Job Uncertainty and Deep Recessions," Discussion Papers 1501, Centre for Macroeconomics (CFM).

Schaffer, M. E. (2005): "XTIVREG2: Stata module to perform extended IV/2SLS, GMM and AC/HAC, LIML and k-class regression for panel data models," Statistical Software Components, Boston College Department of Economics.

Shimer, R. (2005): "The Cyclical Behavior of Equilibrium Unemployment and Vacancies," American Economic Review, 95(1), 25-49.

(2012): "Reassessing the Ins and Outs of Unemployment," Review of Economic Dynamics, 15(2), 127-148.

Smets, F., And R. Wouters (2007): "Shocks and Frictions in US Business Cycles: A Bayesian DSGE Approach," American Economic Review, 97(3), 586-606.

Smith, J. C. (2011): "The Ins and Outs of UK Unemployment," The Economic Journal, 121(552), 402-444.

Solon, G., R. Michaels, And M. W. L. Elsby (2009): "The Ins and Outs of Cyclical Unemployment," American Economic Journal: Macroeconomics, 1(1), 84110.

Sterk, V. (2015): "Home equity, mobility, and macroeconomic fluctuations," Journal of Monetary Economics, 74(0), 16 - 32 .

Trigari, A. (2009): "Equilibrium Unemployment, Job Flows, and Inflation Dynamics," Journal of Money, Credit and Banking, 41(1), 1-33.

Veracierto, M., J. Fisher, And M. Davis (2012): "The Role of Housing in Labor Reallocation," Discussion paper.

Walsh, C. E. (2005): "Labor Market Search, Sticky Prices, and Interest Rate Policies," Review of Economic Dynamics, 8(4), 829-849.

ZANETTi, F. (2011): "Labor market institutions and aggregate fluctuations in a search and matching model," European Economic Review, 55(5), 644-658. 


\section{Appendix For Online Publication}

\section{A Data Construction}

Baseline observables The baseline DSGE model is estimated on six UK aggregate time series: real house prices $\left(q_{l, t}^{\text {data }}\right)$, real per capita investment $\left(I_{t}^{\text {data }}\right)$, real per capita output $\left(Y_{t}^{\text {data }}\right)$, corporate debt $\left(B_{t}^{\text {data }}\right)$, unemployment rate $\left(U_{t}^{\text {data }}\right)$ and job separation rate $\left(\rho_{t}^{\text {data }}\right)$. The series are defined as follows:

$$
\begin{aligned}
q_{l, t}^{\text {data }} & =\frac{\text { Nationwide }}{c p i} \\
I_{t}^{\text {data }} & =\frac{\text { inv }}{\text { popindex }} \\
Y_{t}^{\text {data }} & =\frac{\text { output }}{\text { popindex }} \\
B_{t}^{\text {data }} & =\frac{\text { Bcorp } / \text { cpi }}{\text { popindex }} \\
U_{t}^{\text {data }} & =\text { Unemprate } \\
\rho_{t}^{\text {data }} & =\text { jspissarides }
\end{aligned}
$$

Nationwide: Seasonally adjusted house price index of all houses, derived from Nationwide lending data for properties at the post survey approval stage (source: http://www.nationwide.co.uk/about/house-price-index/headlines).

$c p i$ : Consumer price index - all item index. Quarterly averages of the monthly series are computed. Seasonal adjustment is done via the X12 method. (source: ONS; code: D7BT.Q).

popindex: The population index is based on the working age $(16+)$ population measure after normalising the 1985Q1 value to be 1. (source: LFS and ONS; code: MGSL.Q).

inv: Seasonally adjusted Total Gross Fixed Capital Formation at constant prices (source: ONS; code: NPQT.Q).

output: Seasonally adjusted Gross Domestic Product chained volume measures at constant prices (source: ONS; code: ABMI.Q).

Bcorp: Quarterly amounts outstanding of monetary financial institutions' (MFI) sterling net lending to private non-financial corporations (in sterling millions) seasonally adjusted. Lending is a sum of UK MFI loans plus UK MFI holdings of securities. Lending data are derived from the BE return submitted 
by monetary financial institutions (MFIs). The definition of loans includes overdrafts, loans, reverse repos and short term papers. The definition of holding of securities is the sum of quoted shares, unquoted shares, bonds and other debt securities, and other securities, which are issued by the private sector and held by MFIs for their own beneficial purposes. Securitisations and loan transfers within M4 lending, unless between MFIs (SPVs are not MFIs), reduce the stock of lending outstanding, and the monthly change in amount outstanding, the flow, by the amount of loans securitised. Private non-financial corporations (PNFCs) are companies that produce goods and/or provide non-financial services. They are mainly public limited companies, private companies and partnerships where these are distinct from their owners and not owned by government. (source: Bank of England Interactive Database, code: LPQBC57, further information: http://www.bankofengland.co.uk/statistics/Pages/iadb/notesiadb/m4_sectoral.aspx\#defs).

Unemprate: LFS unemployment rate in the working age $(16+)$ population (source: ONS; code: MGSX.Q).

jspissarides: quarterly job separation rates are constructed as described in Petrongolo and Pissarides (2008): during month $t$, the continuous-time transition rate from unemployment to employment is $f_{t}$ and that from employment to unemployment is $\rho_{t}$. The total unemployment outflow during $t$, denoted by $F_{t}$ is given by:

$$
F_{t}=\left[1-\exp \left(-f_{t}\right)\right] U_{t}+\int_{0}^{1}\left[1-\exp \left(-f_{t}(1-\tau)\right)\right] S_{t+\tau} d \tau
$$

where $\tau$ is the the time elapsed since the beginning of the current month, $U_{t}$ is unemployment at the start of the period and $S_{t+\tau}$ is the unemployment inflow at $t+\tau$. Assuming that the unemployment inflow is uniform during the month, equation A.1 approximates to:

$$
F_{t}=\left[1-\exp \left(-f_{t}\right)\right] U_{t}+\left(1-\frac{1-\exp \left(-f_{t}\right)}{f_{t}}\right) S_{t},
$$

where $S_{t}$ is the total inflow during the month. Equation A.2 is solved for $f_{t}$ using available data for $F_{t}, U_{t}$ and $S_{t}$. Similarly, the unemployment inflow rate $\rho_{t}$ is obtained from:

$$
S_{t}=\left[1-\exp \left(-\rho_{t}\right)\right] N_{t}+\left(1-\frac{1-\exp \left(-\rho_{t}\right)}{\rho_{t}}\right) F_{t}
$$


To get quarterly rates, I average over the monthly values.

Additional variables for the VAR estimation Bhh: Quarterly amounts outstanding of monetary financial institutions' sterling net lending to household sector (in sterling millions) seasonally adjusted. The household sector is the sum of unincorporated businesses, individuals and non-profit institutions serving households. (source: Bank of England Interactive Database, code: LPQBC44).

hours: LFS total actual weekly hours worked (source: ONS; code: YBUS.Q).

Consumption as an observable As a robustness check, the model is reestimated after replacing the investment series with consumption as an observable. The results are presented in section Subsection G.2 below. Consumption $C_{t}^{\text {data }}$ is constructed as follows:

$C_{t}^{\text {data }}=\frac{\text { consh }+ \text { consnpish }}{\text { popindex }}$ where

consh : Seasonally adjusted Household Final Consumption Expenditure at constant prices (source: ONS; code: ABJR.Q). The item covers traditional consumer spending on goods and services. However, national accounting concepts require the inclusion of income in kind, imputed rent for owner-occupied housing services and the consumption of own production. Note that the item does not include the purchase of dwellings or expenditure on valuables, which are part of capital formation, nor does it include any expenditure on goods or services for use in a business.

consnpish: Seasonally adjusted Final Consumption Expenditure of Non-profit Institutions Serving Households at constant prices (source: ONS; code: HAYO.Q). This sector includes mainly charities, trade unions, religious organisations, political parties and the majority of universities. 
Figure 12: House Prices, Corporate Credit and the Unemployment Rate in the Recent UK Recession

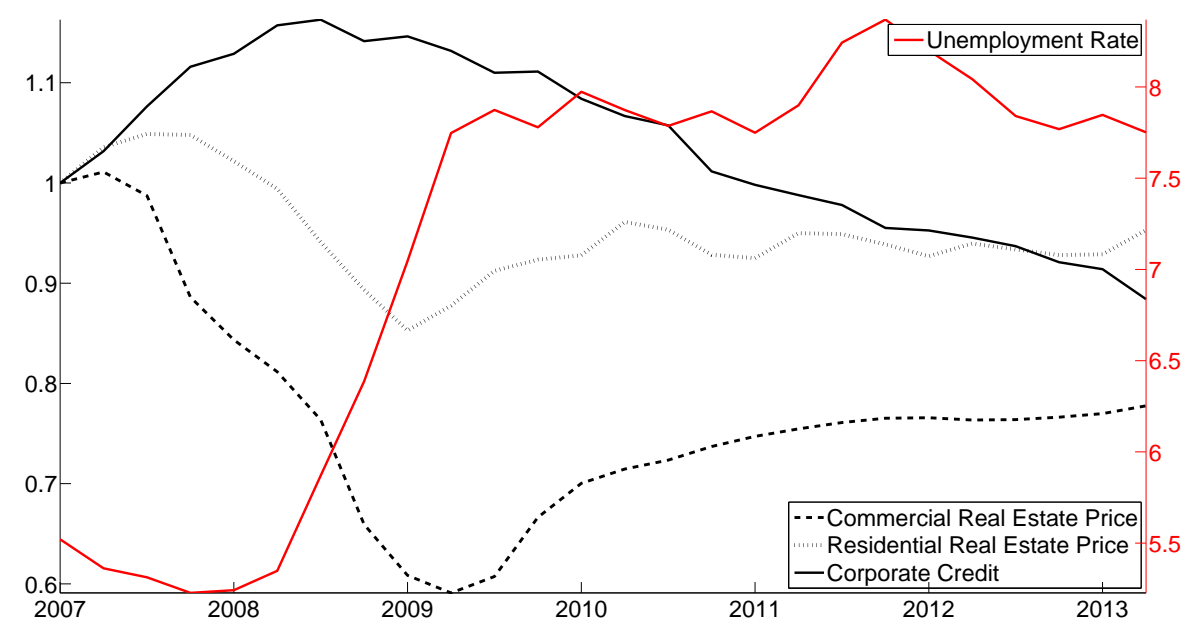

Note: The series for commercial and residential house prices and corporate credit are in nominal terms, normalised to take value one in 2007Q1 (left axis). The unemployment rate is in \% points (right axis).

\section{B Figures}

Figure 14: Level of UK House Prices and Unemployment

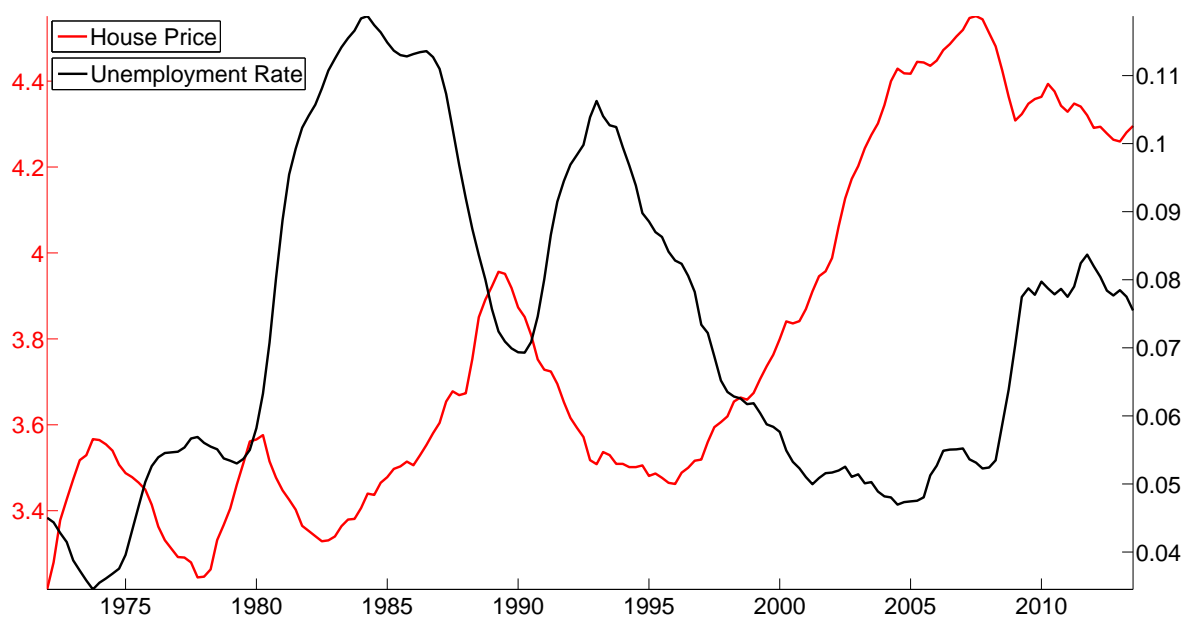

Note: House price data are from Nationwide and deflated by CPI; Unemployment data are from ONS. Real house prices are in logs. The data runs from 1971 to 2013. 
Figure 13: HP-filtered UK House Prices and Unemployment

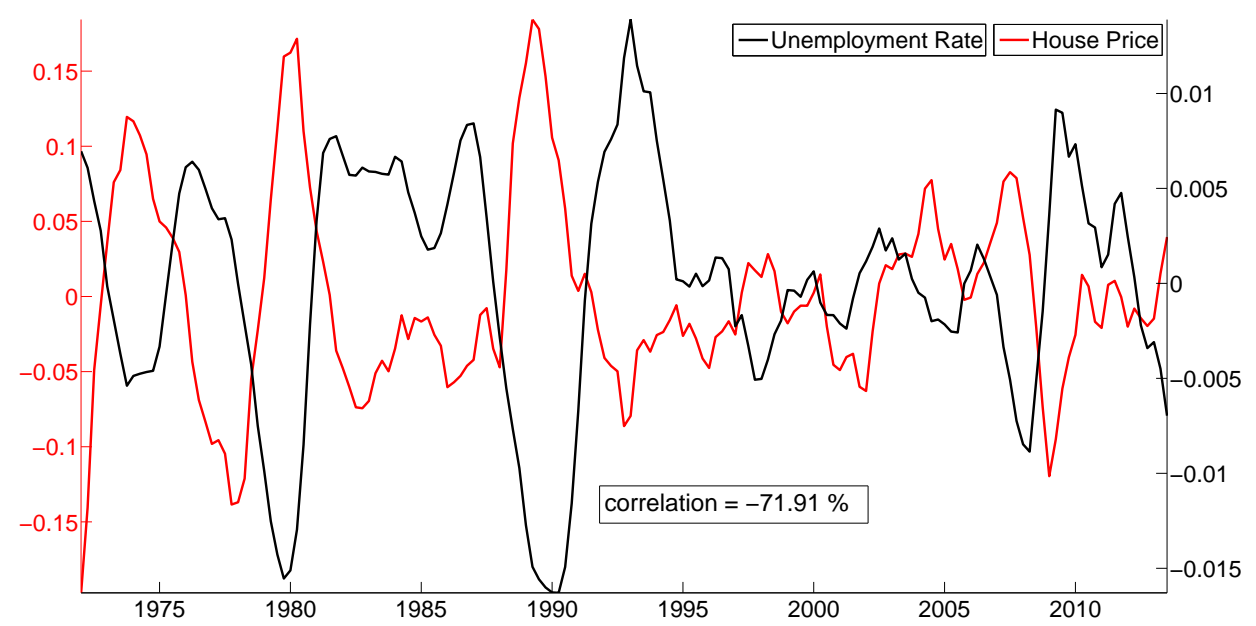

Note: House price data are from Nationwide and deflated by CPI; Unemployment data are from ONS. The data runs from 1972Q1 to 2013Q3. The logarithm of both series are HP-filtered with smoothing parameter,

$$
\lambda=1600 \text {. }
$$

Figure 16: HP-filtered UK House Prices and Job Finding Rates

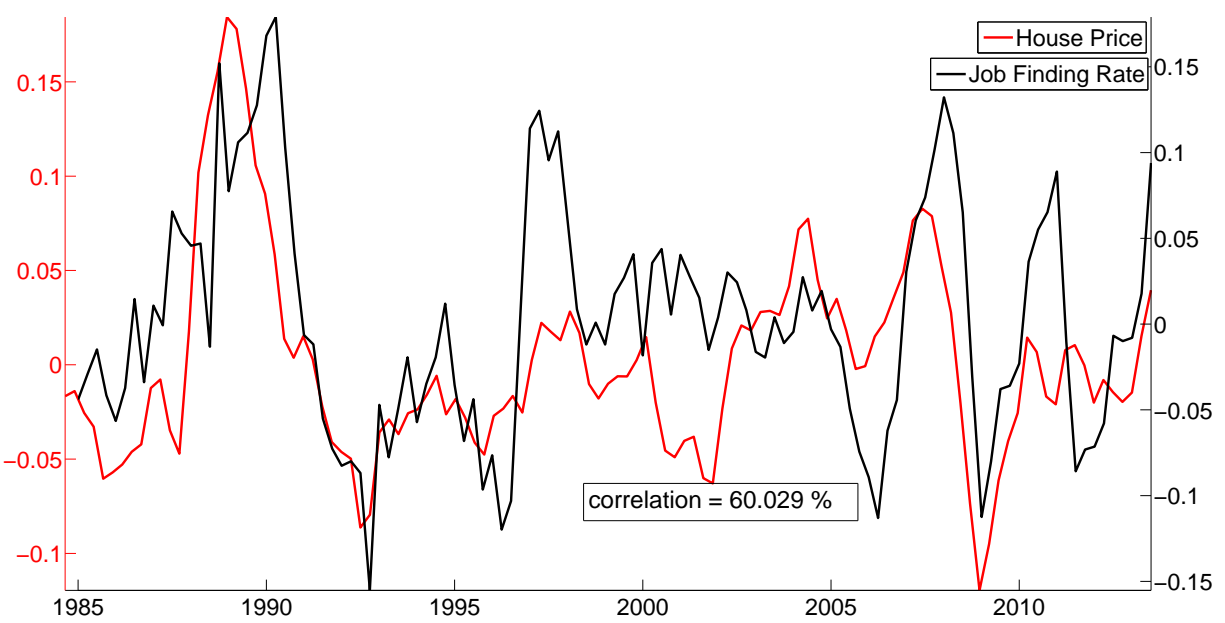

Note: House price data are from Nationwide; data on separation rates are from Petrongolo and Pissarides (2008). The updated data runs from 1985Q1 to 2013Q2. The logarithm of both series are HP-filtered with smoothing parameter, $\lambda=1600$. 
Figure 15: HP-filtered UK House Prices and the Vacancy-Unemployment Ratio

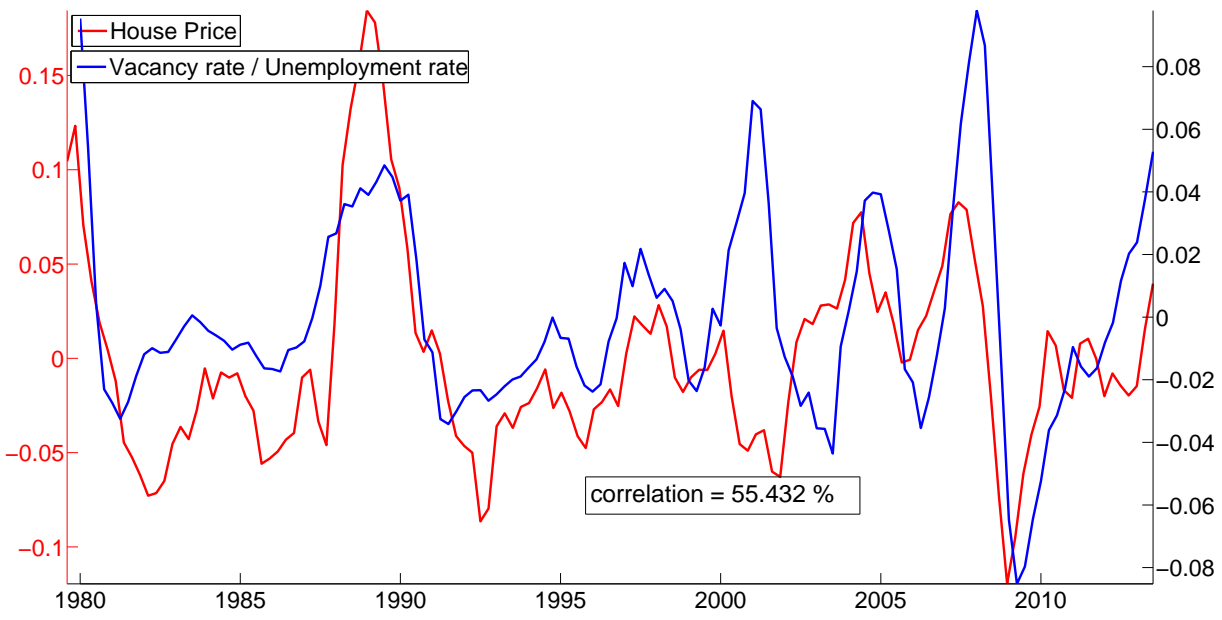

Note: House price data are from Nationwide; unemployment data are from ONS and vacancy rate is from the Bank of England. The data runs from 1980Q1 to 2013Q3. The logarithm of both series are HP-filtered with smoothing parameter, $\lambda=1600$.

Figure 17: UK Beveridge Curve

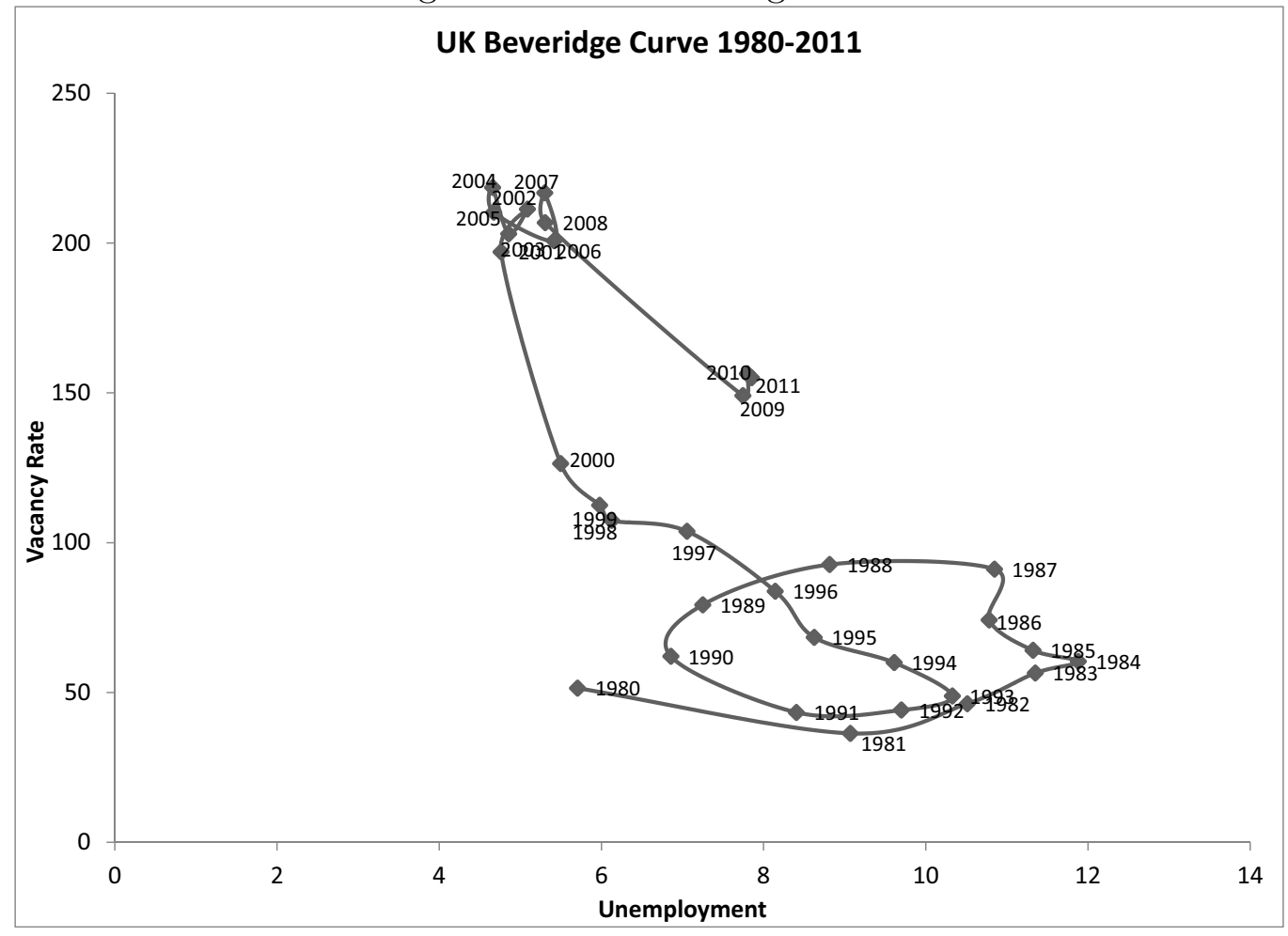

Source: Hobijn and Sahin (2013) 
Figure 18: Regional House Prices and Economic Activity
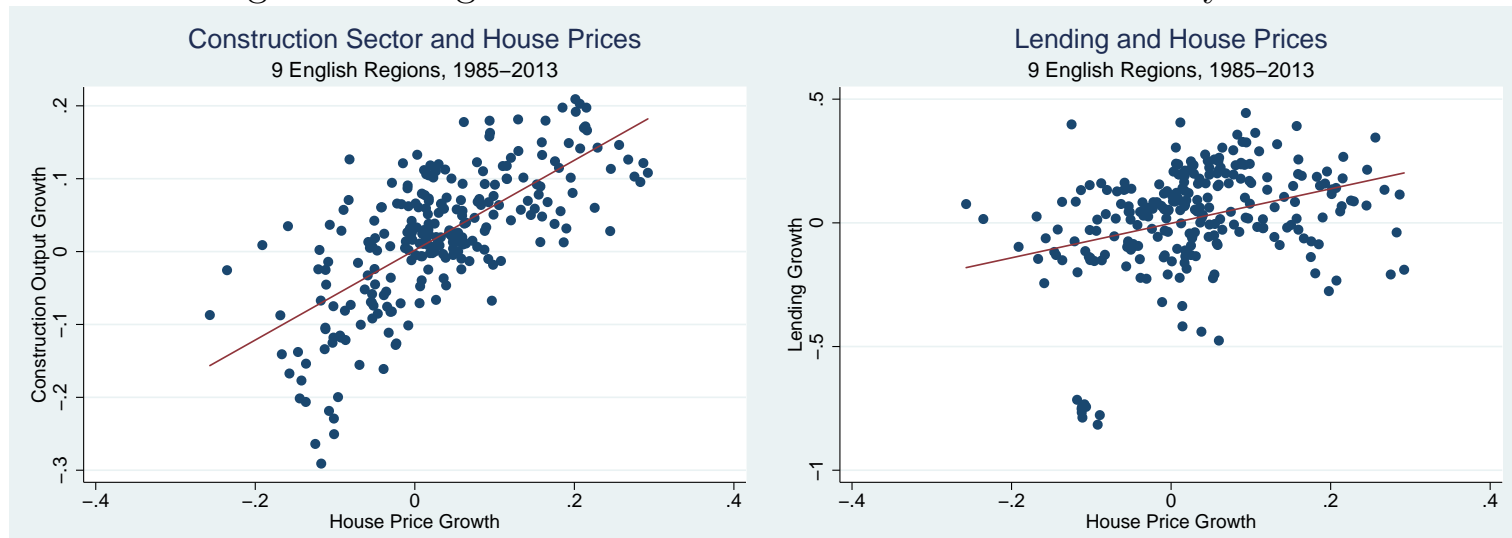

Firm Activity and House Prices 9 English Regions, 1985-2013
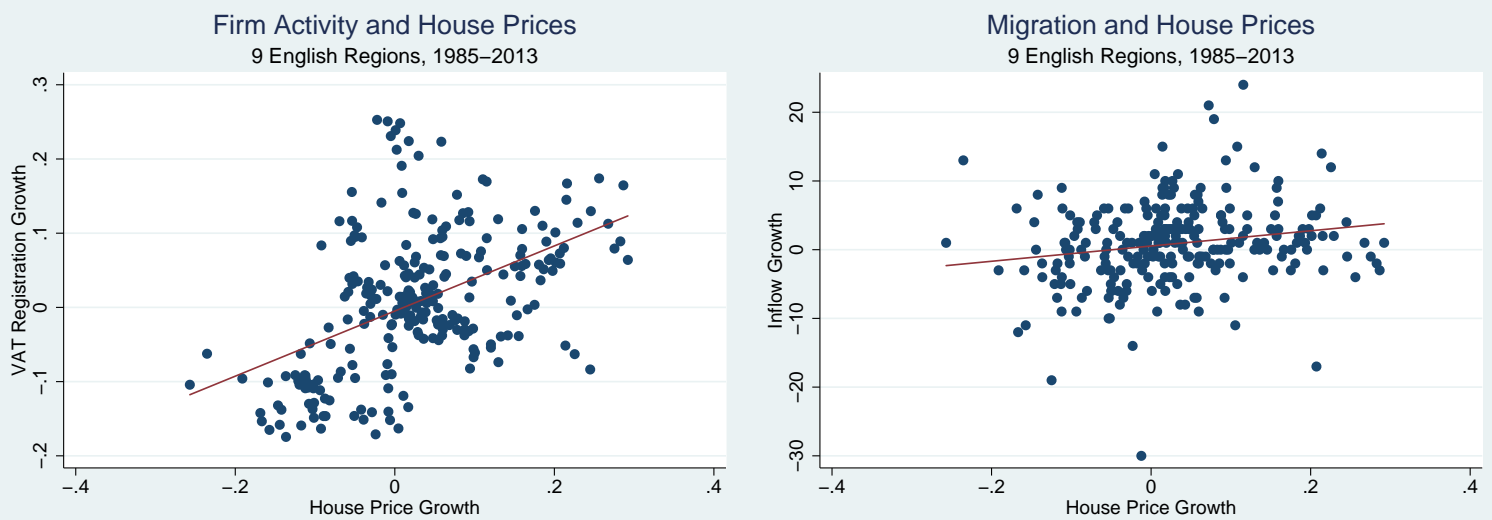

Investment and House Prices

Income and House Prices 9 English Regions, 2001-2012
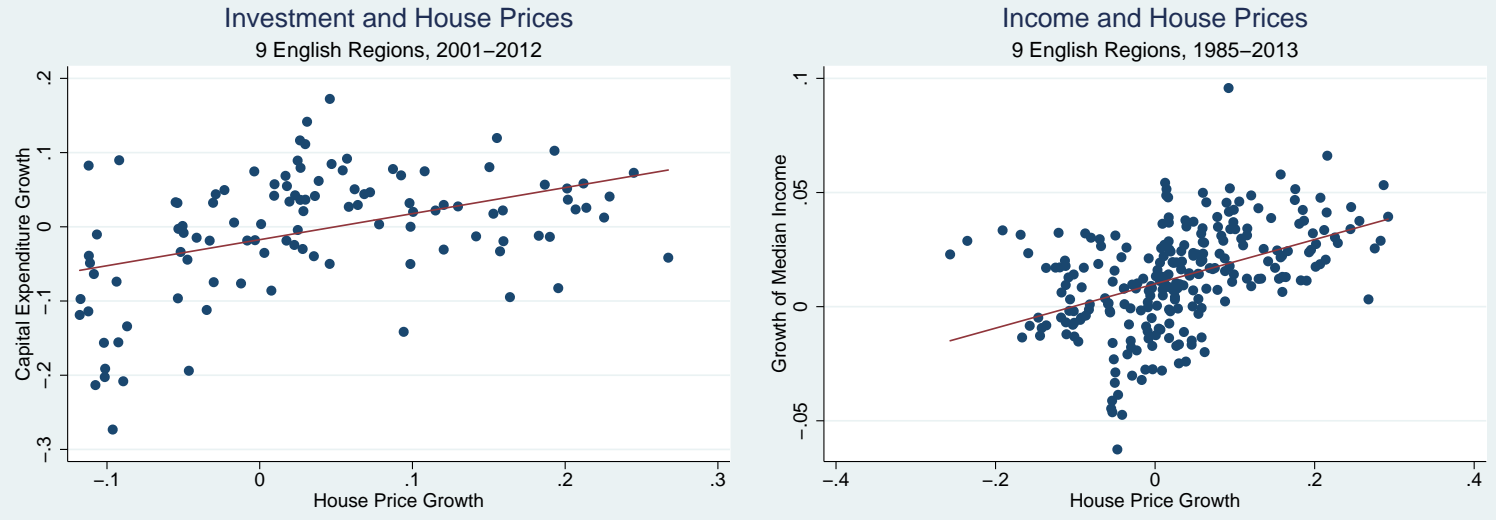

Note: Data on the value of construction output includes new housing and related work as well as all repair and maintenance (source: Construction Output survey, ONS). Lending is proxied by the value of new loans to home-owners for house purchase (source: Survey of Mortgage Lenders prior to 2005, and CML Regulated Mortgage Survey post 2005). Data on VAT-registrations are the benchmark indicators for the level of entrepreneurship (source: Department for Business, Enterprise and Regulatory Reform prior to 2007, and the Business Demography Survey for 2008-2013). Migration inflow is measured as international flows of migrants into the UK from EU and other countries (source: International Passenger Survey, ONS). Investment is proxied by fixed gross capital formation estimates of the ONS (source: 2014 Quarterly Survey of Capital Expenditure, ONS). Income is measured as the median gross wage of full-time male workers (source: Annual Survey of Hours and Earnings (1997-2011) and the New Earnings Survey (1985-1996)). All but VAT and migration data are deflated by CPI. 
Figure 19: Regional House Prices and Labour Markets
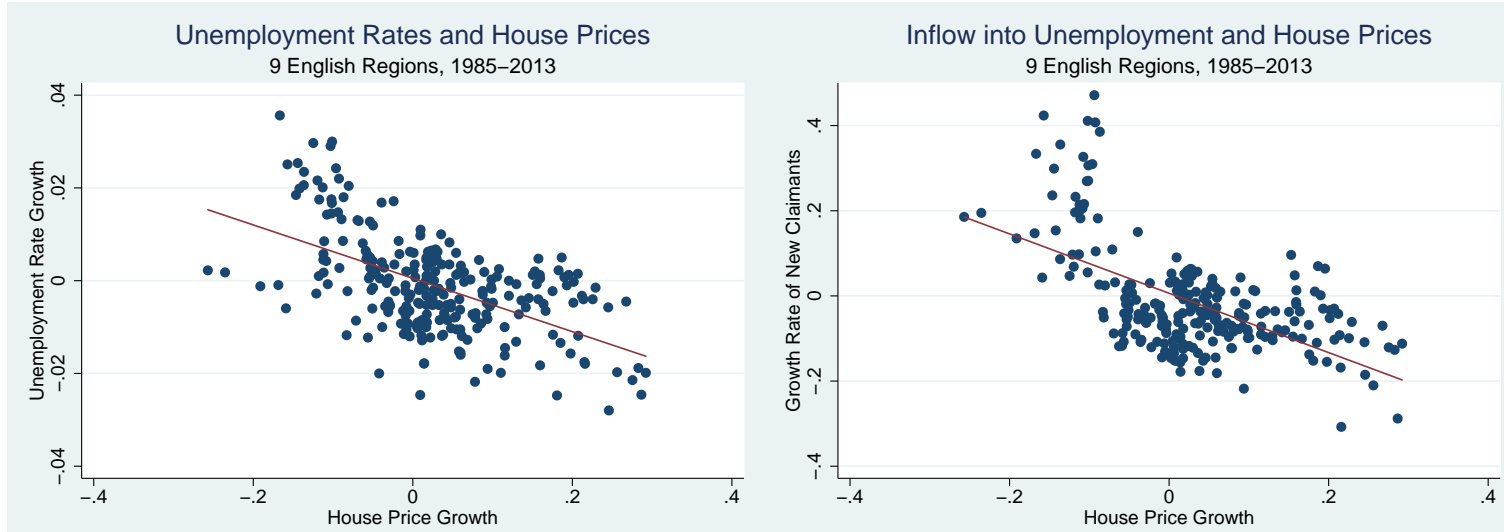

Job Finding and House Prices 9 English Regions, 1993-2013

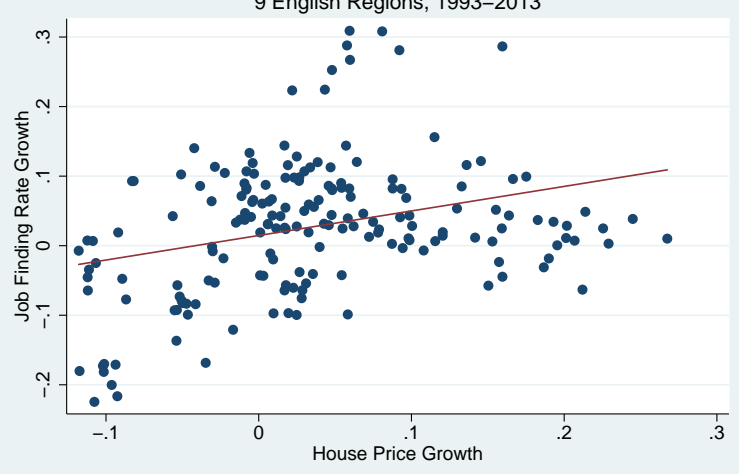

Job Separation and House Prices

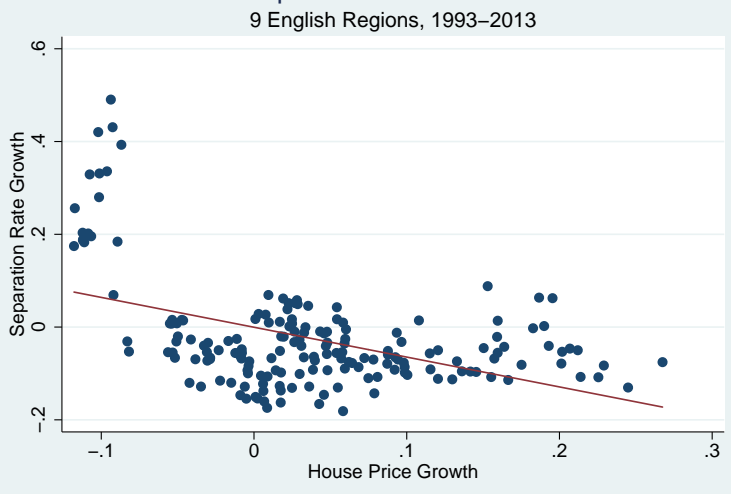

Note: Data on regional unemployment rates are calculated for people aged 16 and above (Source: Labour Force Survey for 1993-2013 and Regional Trends publications for 1985-1993, ONS). Inflow into unemployment is measured as the number of new claimants seeking Jobseeker's Allowance (source: claimant count, ONS). Job finding rates and job separation rates are calculated as in Petrongolo and Pissarides (2008) (source: Labour Force Survey and claimant count, ONS). 
Figure 20: Regional House Prices and Regulatory Housing Constraints

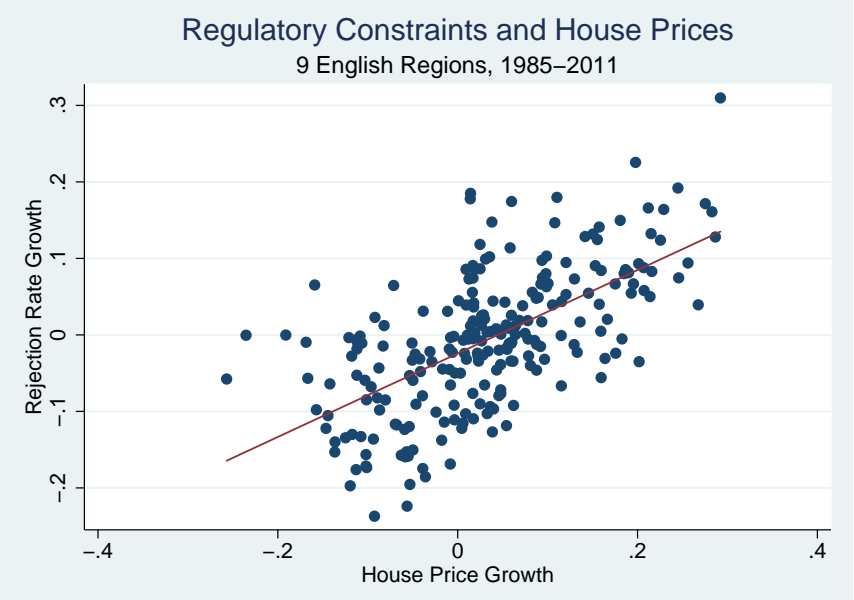

Note: Data on planning applications are from the Department for Communities and Local Government. The local authority level data are aggregated up to regional level.

\section{Results from a Regional Panel}

To provide further evidence, regional panel data are used to quantify the impact of house prices on labour markets. The panel covers the period 1985-2013 and uses annual data on the 9 English regions. ${ }^{28}$ Specifically, for region $i$, at time $t$ labour market variables are determined according to the following reduced-form regression:

$$
l_{i t}=\alpha_{i}+\mu_{t}+\beta \cdot \log \left(h p_{i t}\right)+\gamma \cdot \text { controls }_{i t}+\varepsilon_{i t},
$$

where $l=\{$ unemployment rate, log of separation rate, log of job finding rate $\}$ are the labour market variables, $\alpha_{i}$ is a time-invariant, region-specific fixed effect, $\delta_{t}$ is a time-variant fixed effect common across regions, thereby capturing macroeconomic fluctuations in house prices from which the microeconometric model aims to abstract. The control variables include earnings measured by the total weekly gross mean earnings for full-time male workers. Regional data on median gross wages of full-time male workers are obtained from the Annual Survey of Hours and Earnings (1997-2011) and the New Earnings Survey (19851996). Migration measured as the difference between the inflow and the outflow of migrants from the EU and other countries. ${ }^{29}$

Because of potential sources of endogeneity, I build on Mian and Sufi (2011),

\footnotetext{
${ }^{28}$ The regions are: North East, North West, Yorkshire and The Humber, East Midlands, West Midlands, East of England, London, South East, South West.

${ }^{29}$ Data on migration are from the International Passenger Survey (ONS).
} 
Chaney, Sraer, and Thesmar (2012) and Hilber and Vermeulen (2015) by instrumenting regional house prices by constraints on housing supply. I use measures of regional regulatory constraints, proxied by the rejection rate of planning applications for all developments. Data on planning application and decision statistics are available at the local planning authority (LPAs) level since 1979 from the Department for Communities and Local Government. At each quarter, LPAs are required to fill in two forms: The PS1 form provides high-level information about the number of planning and related applications on hand at the beginning of the quarter, received, withdrawn, called in or turned away during the quarter; the PS2 form provides more detailed information about the decisions made during the quarter, broken down by (i) development type; (ii) whether permission was granted or refused and (iii) the time elapsed from application to decision. As in Hilber and Vermeulen (2015), I use the PS2 form to measure the number of applications rejected relative to the number of received applications in a given year. I aggregate the LPA level data to get regional measures of rejection rates for the 9 English regions.

If housing supply is restricted by strict planning rules captured by higher rejection rates, then this will translate into higher prices rather than more real estate developments. If on the other hand regional planning authorities accept a higher fraction of planning applications, then this will translate into more construction and muted volatility in prices. In line with this reasoning, I estimate the following regression in the first-stage of the 2SLS procedure:

$$
\log \left(h p_{i t}\right)=a_{i}+b_{t}+\delta \cdot \log \left(\text { reject }_{i t}\right)+\psi \cdot \text { controls }_{i t}+u_{i t},
$$

where reject $_{i t}$ is the regional rejection rejection rate of planning permissions, $a_{i}$ is a regional-specific time-invariant fixed effect and $b_{t}$ denotes a time-variant fixed effects common to all regions. Figure 20 of this Appendix provides a pictorial illustration of the strength of the instrument, indicating the strong positive relationship between the annual growth rate of rejection rates of planning applications and the annual growth rate of house prices for the 9 English regions for the 1985-2011 period.

Table 4 reports estimates of various model specifications of equation C.1. Three estimators are considered: (i) the first-difference (FD) estimator that is consistent when the regional effects are fixed, (ii) the fixed effect estimator (FE) that is more efficient than the FD if the idiosyncratic error $u_{i t}$ is iid, and (iii) the 
Table 4: House Prices and Labour Markets

\begin{tabular}{|c|c|c|c|c|c|}
\hline & (1) & (2) & (3) & (4) & (5) \\
\hline & FD & $\mathrm{FE}$ & $\mathrm{FE}$ & $\mathrm{FE}$ & FE-IV \\
\hline \multicolumn{6}{|c|}{ Unemployment Rate } \\
\hline \multirow[t]{2}{*}{ House Prices } & $-0.018^{* * *}$ & $-0.041^{* * *}$ & $-0.056^{* * *}$ & $-0.056^{* * *}$ & $-0.075^{* * *}$ \\
\hline & $(0.003)$ & $(0.007)$ & $(0.009)$ & $(0.008)$ & $(0.027)$ \\
\hline \multirow[t]{2}{*}{ Earnings } & & & $0.212^{* * *}$ & $0.214^{* * *}$ & $0.242^{* * *}$ \\
\hline & & & $(0.062)$ & $(0.059)$ & $(0.039)$ \\
\hline \multirow[t]{2}{*}{ Migration } & & & & -0.015 & -0.044 \\
\hline & & & & $(0.078)$ & $(0.055)$ \\
\hline$N$ & 252 & 261 & 261 & 261 & 243 \\
\hline$R^{2}$ & 0.876 & 0.873 & 0.909 & 0.909 & 0.908 \\
\hline \multicolumn{6}{|c|}{ Separation Rate } \\
\hline \multirow[t]{2}{*}{ House Prices } & $-0.374^{* * *}$ & $-0.770^{* *}$ & $-0.897^{* * *}$ & $-0.902^{* * *}$ & $-0.996^{* * *}$ \\
\hline & $(0.096)$ & $(0.234)$ & $(0.196)$ & $(0.195)$ & $(0.332)$ \\
\hline \multirow[t]{2}{*}{ Earnings } & & & 0.979 & 0.941 & 1.148 \\
\hline & & & $(0.749)$ & $(0.661)$ & $(0.794)$ \\
\hline \multirow[t]{2}{*}{ Migration } & & & & 0.370 & 0.426 \\
\hline & & & & $(0.896)$ & $(0.592)$ \\
\hline$N$ & 162 & 171 & 171 & 171 & 171 \\
\hline$R^{2}$ & 0.887 & 0.939 & 0.941 & 0.941 & 0.941 \\
\hline \multicolumn{6}{|c|}{ Job Finding Rate } \\
\hline \multirow[t]{2}{*}{ House Prices } & -0.032 & $0.169^{* *}$ & $0.231^{* *}$ & $0.256^{* * *}$ & 0.161 \\
\hline & $(0.066)$ & $(0.052)$ & $(0.074)$ & $(0.067)$ & $(0.205)$ \\
\hline \multirow[t]{2}{*}{ Earnings } & & & -0.478 & -0.273 & -0.064 \\
\hline & & & $(0.446)$ & $(0.600)$ & $(0.466)$ \\
\hline \multirow[t]{2}{*}{ Migration } & & & & $-1.973^{*}$ & $-1.918^{* * *}$ \\
\hline & & & & $(0.915)$ & $(0.612)$ \\
\hline$N$ & 162 & 171 & 171 & 171 & 171 \\
\hline$R^{2}$ & 0.873 & 0.968 & 0.969 & 0.973 & 0.973 \\
\hline Year fixed eff. & Yes & Yes & Yes & Yes & Yes \\
\hline Regional fixed eff. & Yes & Yes & Yes & Yes & Yes \\
\hline
\end{tabular}

Notes: The dependent variables are the unemployment rate (upper panel), job separation rates (middle panel) and job finding rates (lower panel). All models control for time fixed and region fixed effects. Column 1 is the first-difference panel model. Columns 2, 3 and 4 are fixed effects panel models. Column 5 shows results from Panel-IV models where rejection rates of planning applications are used as instruments for house prices. Data on separation and job finding rates start in 1993, and data on rejection rates end in 2011. 
panel instrumental variable (FE-IV) estimator adapted to equations C.1-C.2 as implemented by Schaffer (2005).

As shown by Table 4 the effect of a $1 \%$ increase in real house prices on the unemployment rate is significantly negative in all model specifications. This effect is estimated to be the smallest by the FD model $(-0.02 \%)$ and largest by FE-IV $(-0.075 \%)$ models. The effect on separation rates is significantly positive in all model speficifications. The estimated impact of a $1 \%$ increase in house prices ranges between $-0.4 \%$ and $-1 \%$ across the five models. The impact on job finding rates is substantially smaller and less statistically significant with the estimates ranging between zero and $0.3 \%$. Overall, the results are consistent with the strong unconditional comovements between house prices and unemployment and job separation rates, shown by Figures 13-1.

The collateral channel that will take center stage in the theoretical model developed in Section 3 could provide a possible explanation for the estimation results. Higher house prices increase collateral values fueling more borrowing in both the household and corporate sectors, leading to increased economic activity. To provide further illustrative evidence on this channel, I modify the regression model C.1 to estimate the impact of house prices on (i) bank lending and (ii) on firm creation.

Given that data on lending to corporates are not readily available at regional level, I proxy bank lending by the total value of new mortgage lending for house purchases. Firm creation is proxied by the total number of VAT registration in a given region for all industries. Data on the total value of mortgage loans (loans to home-owners for house purchase) is from the Survey of Mortgage Lenders (prior to 2005) and from the CML Regulated Mortgage Survey (after 2005). Data on regional VAT-registrations are from the ONS and the Business Demography Survey. Table 5 presents the estimation results, suggesting that house prices have a statistically and economically significant effect on new firm creation and bank lending. 
Table 5: House Prices, Lending and Firm Creation

\begin{tabular}{|c|c|c|c|c|c|}
\hline & (1) & $(2)$ & (3) & (4) & $(5)$ \\
\hline & FD & $\mathrm{FE}$ & $\mathrm{FE}$ & $\mathrm{FE}$ & FE-IV \\
\hline \multicolumn{6}{|c|}{ VAT Registrations (Firm Birth) } \\
\hline \multirow[t]{2}{*}{ House Prices } & $0.153^{* *}$ & $0.240^{*}$ & $0.163^{*}$ & $0.163^{*}$ & $0.598^{* *}$ \\
\hline & $(0.049)$ & $(0.126)$ & (0.078) & $(0.079)$ & $(0.244)$ \\
\hline \multirow[t]{2}{*}{ Earnings } & & & $1.122^{* *}$ & $1.127^{* *}$ & $0.552^{*}$ \\
\hline & & & $(0.375)$ & $(0.480)$ & $(0.310)$ \\
\hline \multirow[t]{2}{*}{ Migration } & & & & -0.049 & 0.131 \\
\hline & & & & (1.130) & $(0.578)$ \\
\hline$R^{2}$ & 0.907 & 0.852 & 0.875 & 0.875 & 0.820 \\
\hline \multicolumn{6}{|c|}{ Mortgage Lending } \\
\hline \multirow[t]{2}{*}{ House Prices } & $0.337^{*}$ & $0.452^{*}$ & $0.289^{* *}$ & $0.289^{* *}$ & $0.714^{* *}$ \\
\hline & $(0.172)$ & $(0.200)$ & $(0.106)$ & $(0.104)$ & $(0.326)$ \\
\hline \multirow[t]{2}{*}{ Earnings } & & & $2.385^{* *}$ & $2.278^{* *}$ & $1.783^{* * *}$ \\
\hline & & & $(0.957)$ & $(0.958)$ & $(0.474)$ \\
\hline \multirow[t]{2}{*}{ Migration } & & & & 1.112 & 1.076 \\
\hline & & & & $(0.639)$ & $(0.791)$ \\
\hline$R^{2}$ & 0.851 & 0.944 & 0.957 & 0.958 & 0.955 \\
\hline Year fixed eff. & Yes & Yes & Yes & Yes & Yes \\
\hline Regional fixed eff. & Yes & Yes & Yes & Yes & Yes \\
\hline$N$ & 252 & 261 & 261 & 261 & 243 \\
\hline
\end{tabular}

Notes: The table reports the empirical link between house prices and labour market variables. The dependent variables are the number of VAT registrations (upper panel) and total value of mortgage lending (lower panel). All models control for time-variant fixed effects and region-specific time-invariant fixed effects. Column 1 is the first-difference panel model. Columns 2, 3 and 4 are fixed effects panel models. Column 5 shows results from Panel-IV models where rejection rates of planning applications are used as instruments for house prices. 


\section{Stationary Equilibrium}

I follow Liu, Wang, and Zha (2013) in transforming the trending variables into their stationary counterparts:

$$
\begin{aligned}
& \tilde{Y}_{t} \equiv \frac{Y_{t}}{\Gamma_{t}}, \quad \tilde{C}_{h, t} \equiv \frac{C_{h, t}}{\Gamma_{t}}, \quad \tilde{C}_{e, t} \equiv \frac{C_{e, t}}{\Gamma_{t}}, \quad \tilde{I}_{t} \equiv \frac{I_{t}}{Q_{t} \Gamma_{t}}, \quad \tilde{K}_{t} \equiv \frac{K_{t}}{\lambda_{t} \Gamma_{t}}, \quad \tilde{B}_{t} \equiv \frac{B_{t}}{\Gamma_{t}}, \\
& \tilde{W}_{t} \equiv \frac{W_{t}}{\Gamma_{t}}, \quad \tilde{\lambda}_{h, t} \equiv \frac{\lambda_{h, t}}{\Gamma_{t}}, \quad \tilde{\lambda}_{e, t} \equiv \frac{\lambda_{e, t}}{\Gamma_{t}}, \quad \tilde{\mu}_{e, t} \equiv \frac{\mu_{e, t}}{\Gamma_{t}}, \quad \tilde{q}_{l, t} \equiv \frac{q_{l, t}}{\Gamma_{t}}, \quad \tilde{q}_{k, t} \equiv q_{k, t} Q_{t},
\end{aligned}
$$

where the trending factor is defined as:

$$
\Gamma_{t} \equiv\left[Z_{t} Q_{t}^{(1-\phi) \alpha}\right]^{\frac{1}{1-(1-\phi) \alpha}}
$$

The stationary equilibrium is characterised by the following system:

\section{D.1 Household}

$$
\begin{aligned}
\tilde{\lambda}_{h, t} & =\frac{1}{\tilde{C}_{h, t}-h_{h} \tilde{C}_{h, t-1} \Gamma_{t-1} / \Gamma_{t}}-\mathbb{E}_{t} \frac{\beta_{h} h_{h}}{\tilde{C}_{h, t+1} \Gamma_{t+1} / \Gamma_{t}-h_{h} \tilde{C}_{h, t}} \\
\frac{1}{R_{t}} & =\beta_{h} \mathbb{E}_{t} \frac{\tilde{\lambda}_{h, t+1}}{\tilde{\lambda}_{h, t}} \frac{\Gamma_{t}}{\Gamma_{t+1}} \\
\tilde{q}_{l, t} & =\beta_{h} \mathbb{E}_{t} \frac{\tilde{\lambda}_{h, t+1}}{\tilde{\lambda}_{h, t}} \tilde{q}_{l, t+1}+\frac{\varphi_{t}}{\tilde{\lambda}_{h, t} L_{h, t}} .
\end{aligned}
$$

\section{D.2 Entrepreneur}

$$
\begin{aligned}
& \tilde{\lambda}_{e, t}=\frac{1}{\tilde{C}_{e, t}-\frac{h_{e} \tilde{C}_{e, t-1}}{g_{t}}}-\mathbb{E}_{t} \frac{\beta h_{e}}{\tilde{C}_{e, t+1} g_{t+1}-h_{e} \tilde{C}_{e, t}} \\
& \frac{1}{R_{t}}=\beta \mathbb{E}_{t} \tilde{\Lambda}_{t, t+1}^{e} \frac{\Gamma_{t}}{\Gamma_{t+1}}+\frac{\tilde{\mu}_{e, t}}{\tilde{\lambda}_{e, t}} \\
& 1=\tilde{q}_{k, t}\left[1-\frac{\Omega}{2}\left(\frac{\tilde{I}_{t}}{\tilde{I}_{t-1}} \frac{Q_{t} \Gamma_{t}}{Q_{t-1} \Gamma_{t-1}}-\bar{\lambda}_{I}\right)^{2}-\Omega\left(\frac{\tilde{I}_{t}}{\tilde{I}_{t-1}} \frac{Q_{t} \Gamma_{t}}{Q_{t-1} \Gamma_{t-1}}-\bar{\lambda}_{I}\right) \frac{\tilde{I}_{t}}{\tilde{I}_{t-1}} \frac{Q_{t} \Gamma_{t}}{Q_{t-1} \Gamma_{t-1}}\right] \\
& +\mathbb{E}_{t} \tilde{\Lambda}_{t, t+1}^{e} \frac{Q_{t} \Gamma_{t}}{Q_{t+1} \Gamma_{t+1}} \tilde{q}_{k, t+1}\left(\frac{\tilde{I}_{t+1}}{\tilde{I}_{t}} \frac{Q_{t+1} \Gamma_{t+1}}{Q_{t} \Gamma_{t}}-\bar{\lambda}_{I}\right)\left(\frac{\tilde{I}_{t+1}}{\tilde{I}_{t}} \frac{Q_{t+1} \Gamma_{t+1}}{Q_{t} \Gamma_{t}}\right)^{2} \\
& \tilde{q}_{k, t}=\mathbb{E}_{t} \tilde{\Lambda}_{t, t+1}^{e}\left[\alpha(1-\phi) \frac{\tilde{Y}_{t}}{\tilde{K}_{t}}+\tilde{q}_{k, t} \frac{Q_{t} \Gamma_{t}}{Q_{t+1} \Gamma_{t+1}}(1-\delta)\right]+\frac{\tilde{\mu}_{e, t}}{\tilde{\lambda}_{e, t}} \mathbb{E}_{t} \theta_{e, t} \tilde{q}_{k, t+1} \frac{Q_{t}}{Q_{t+1}} \\
& \tilde{q}_{l, t}=\mathbb{E}_{t} \tilde{\Lambda}_{t, t+1}^{e}\left[\alpha \phi \frac{\tilde{Y}_{t}}{L_{e, t}}+\tilde{q}_{l, t+1}\right]+\frac{\tilde{\mu}_{e, t}}{\tilde{\lambda}_{e, t}} \mathbb{E}_{t} \theta_{t} \tilde{q}_{l, t+1} \frac{\Gamma_{t+1}}{\Gamma_{t}} .
\end{aligned}
$$




\section{D.3 Labour Markets}

$$
\begin{aligned}
m_{t} & =\psi_{t} u_{t}^{\omega} v_{t}^{1-\omega} \\
q_{t}^{u} & =\frac{m_{t}}{u_{t}} \\
q_{t}^{v} & =\frac{m_{t}}{v_{t}} \\
\Theta_{t} & =\frac{q_{t}^{u}}{q_{t}^{v}}=\frac{v_{t}}{u_{t}} \\
N_{t} & =\left(1-\rho_{t}\right) N_{t-1}+m_{t} \\
u_{t} & =1-\left(1-\rho_{t}\right) N_{t-1} \\
\frac{\kappa}{q_{t}^{v}} & =\mathbb{E}_{t} \tilde{\Lambda}_{t, t+1}^{e}\left(1-\rho_{t+1}\right)\left[(1-\alpha) \frac{\tilde{Y}_{t+1}}{N_{t+1}}-\tilde{W}_{t+1} h_{t+1}+\frac{\kappa}{q_{t+1}^{v}}\right] \\
\tilde{W}_{t} h_{t} & =\xi_{t}\left(\tilde{\pi}_{t}+\kappa \Theta_{t}\right)+\left(1-\xi_{t}\right)\left(\frac{\chi \frac{h_{t}^{1+\nu}}{1+\nu}+\int_{0}^{\bar{a}_{t}} a_{t} \frac{d F\left(a_{t+1}\right)}{F\left(\bar{a}_{t+1}\right)}}{\tilde{\lambda}_{h, t}}+b\right) \\
\tilde{\pi}_{t} & =\frac{g\left(h_{t}, \bar{a}_{t}\right)}{\tilde{\lambda}_{h, t}}+b-\frac{1-\xi_{t+1} q_{t}^{u}}{1-\xi_{t+1}} \frac{\kappa}{q_{t}^{v}} \\
\rho_{t} & =1-F\left(\bar{a}_{t}\right) \\
U_{t} & =1-N_{t} \\
\chi \frac{h_{t}^{\nu}}{\tilde{\lambda}_{h, t}} & =(1-\alpha) \frac{\tilde{Y}_{t}}{N_{t} h_{t}} .
\end{aligned}
$$

\section{D.4 The Rest of the Model}

$$
\begin{aligned}
\tilde{Y}_{t} & =\left(\frac{Z_{t} Q_{t}}{Z_{t-1} Q_{t-1}}\right)^{-\frac{(1-\phi) \alpha}{1-(1-\phi) \alpha}}\left[\tilde{K}_{t-1}^{1-\phi} L_{e, t-1}^{\phi}\right]^{\alpha}\left(h_{t} N_{t}\right)^{1-\alpha} \\
\tilde{Y}_{t} & =\tilde{C}_{h, t}+\tilde{C}_{e, t}+\tilde{I}_{t}+\kappa v_{t} \\
\bar{L} & =L_{h, t}+L_{e, t} \\
\tilde{B}_{t} & =\theta_{t} \mathbb{E}_{t}\left[\tilde{q}_{l, t+1} L_{e, t} \frac{\Gamma_{t+1}}{\Gamma_{t}}+\tilde{q}_{k, t+1} K_{t} \frac{Q_{t}}{Q_{t+1}}\right] .
\end{aligned}
$$

\section{E Steady-state}

\section{E.1 Consumers}

The steady-state interest rate and shadow prices are: 


$$
\begin{aligned}
\frac{1}{R} & =\frac{\beta_{h}}{g_{\gamma}} \\
\frac{\tilde{\mu}_{e}}{\tilde{\lambda}_{e}} & =\frac{\beta_{h}-\beta}{g_{\gamma}} .
\end{aligned}
$$

The marginal utility of consumption of the two agents:

$$
\begin{aligned}
& \tilde{\lambda}_{h}=\frac{1}{\tilde{C}_{h}}\left[\frac{g_{\gamma}-\beta_{h} h_{h}}{g_{\gamma}-h_{h}}\right] \\
& \tilde{\lambda}_{e}=\frac{1}{\tilde{C}_{e}}\left[\frac{g_{\gamma}-\beta h_{e}}{g_{\gamma}-h_{e}}\right] .
\end{aligned}
$$

To get the ratio of commercial land to output, use the entrepreneurial land Euler-equation and the definition E.1:

$$
\frac{\tilde{q}_{l} L_{e}}{\tilde{Y}}=\frac{\alpha \phi \beta}{1-\beta-\left(\beta_{h}-\beta\right) \theta} .
$$

So the parameter $\phi$ is given by:

$$
\phi=\frac{\frac{\tilde{q}_{l} L_{e}}{\tilde{Y}}\left[1-\beta-\left(\beta_{h}-\beta\right) \theta\right]}{\alpha \beta},
$$

whereas the scale parameter $\alpha$ is given by capital demand:

$$
\alpha=\frac{\frac{1-\frac{\tilde{\mu}_{e}}{\tilde{\lambda}_{e}} \theta}{\beta / g_{\gamma}}-(1-\delta)}{g_{\gamma}(1-\phi)} \frac{\tilde{K}}{\tilde{Y}} .
$$

Given the target values for the steady-state $\frac{\tilde{K}}{\tilde{Y}}$ and $\frac{\tilde{q}_{l} L_{e}}{\tilde{Y}}$, equations E.4-E.5 pin down $\phi$ and $\alpha$. The steady-state investment-output ratio can be matched by choosing the appropriate value for $\delta$ :

$$
\frac{\tilde{I}}{\tilde{K}}=1-\frac{1-\delta}{\lambda_{k}} .
$$

Using the definition of the return on capital, the steady-state capital-output ratio is:

$$
\frac{\tilde{K}}{\tilde{Y}}=\frac{g_{\gamma} \alpha(1-\phi)}{R_{k} e} .
$$

The investment-output ratio is: 


$$
\frac{\tilde{I}}{\tilde{Y}}=\frac{\tilde{I}}{\tilde{K}} \frac{\tilde{K}}{\tilde{Y}}=\left[1-\frac{1}{\lambda_{k}}\left(\left(\beta_{h}-\beta\right) \theta+\beta(1-\delta)\right)\right]^{-1} \beta \alpha(1-\phi)
$$

The binding entrepreneurial credit-constraint implies:

$$
\frac{\tilde{B}}{\tilde{Y}}=\theta\left[g \frac{\tilde{q}_{l} L_{e}}{\tilde{Y}}+\frac{\tilde{K}}{\bar{\lambda}_{q} \tilde{Y}}\right] .
$$

Using the definition of the return on entrepreneurial land $\left(R_{l}=\alpha \phi Y / L_{c}\right)$, the entrepreneurial flow-of-funds constraint implies:

$$
\frac{\tilde{C}_{e}}{\tilde{Y}}=R_{k} \frac{\tilde{K}}{\tilde{Y}}+\alpha \phi-\frac{\tilde{I}}{\tilde{Y}}-\left[\frac{1}{g}-\frac{1}{R}\right] \frac{\tilde{B}}{\tilde{Y}} .
$$

The aggregate resource constraint implies:

$$
\frac{\tilde{C}_{h}}{\tilde{Y}}=1-\frac{\tilde{C}_{e}}{\tilde{Y}}-\frac{\tilde{I}}{\tilde{Y}}-\frac{\kappa v}{\tilde{Y}}
$$

To solve for $\frac{L_{h}}{L_{e}}$, use the steady-state land demand ratios E.3:

$$
\frac{L_{h}}{L_{e}}=\frac{\varphi_{L}\left(g_{\gamma}-h_{h}\right)\left(1-\beta-\left(\beta_{h}-\beta\right) \theta\right)}{\alpha \phi \beta \theta\left(1-g_{\gamma} / R\right)\left(1-h_{h} / R\right)} \frac{\tilde{C}_{h}}{\tilde{Y}} .
$$

Given the steady-state of the average unemployment rate $U$, employment is:

$$
N=1-U .
$$

The matching function:

$$
m=\rho N .
$$

Endogenous separation rate:

$$
\rho^{n}=\frac{\rho-\rho^{x}}{1-\rho^{x}} .
$$

The threshold value of the idiosyncratic preference shock:

$$
\bar{a}=F^{-1}\left(1-\rho^{n}\right) .
$$

The number of searching workers:

$$
u=1-(1-\rho) N .
$$


The job finding rate is:

$$
q^{u}=\frac{m}{u}
$$

Using the matching function, the number of vacancies:

$$
v=\left(\frac{m}{\psi u^{\omega}}\right)^{\frac{1}{1-\omega}} .
$$

The vacancy filling rate:

$$
q^{v}=\frac{m}{v}
$$

To derive steady-states levels, use the condition for labour hours:

$$
\frac{\chi h^{\nu}}{\tilde{\lambda}_{h}}=(1-\alpha) \frac{\tilde{Y}}{N h}
$$

Using the definition of the shadow price, $\frac{1}{\tilde{\lambda}_{h}}=\tilde{Y}\left[\frac{\tilde{C}_{h}}{\tilde{Y}}\right]\left(\frac{g_{\gamma}-h_{h}}{g_{\gamma}-\beta h_{h}\left(1+\lambda_{a}\right)}\right)$, and setting labour hours $h=1 / 4$ in steady state, the labour scale parameter is given:

$$
\chi=\frac{(1-\alpha) \frac{1}{N}}{h^{1+\nu}\left[\frac{\tilde{C}_{h}}{\tilde{Y}}\right]\left(\frac{g-h_{h}}{g-\beta h_{h}\left(1+\lambda_{a}\right)}\right)} .
$$

Using the production function:

$$
\tilde{Y}^{1-(1-\phi) \alpha}=(h N)^{1-\alpha}\left[\left(\tilde{K} /\left(\tilde{Y} g_{\gamma}\right)\right)^{1-\phi}\left(L_{e}\right)^{\phi}\right]^{\alpha} .
$$

Given the level of output E.19, investment, capital and consumption are determined by the ratios derived above. To obtain a solution for wages, operate on the following labour market conditions:

$$
\begin{gathered}
\frac{\kappa}{q^{v}}=\frac{\beta(1-\rho)\left[(1-\alpha) \frac{\tilde{Y}}{N}-\tilde{W} h\right]}{1-\beta(1-\rho)} \\
\frac{\bar{a}}{\tilde{\lambda}_{h}}=\frac{\nu}{1+\nu}(1-\alpha) \frac{\tilde{Y}}{N}-b+\frac{1-\bar{\xi} q^{u}}{1-\bar{\xi}} \frac{\kappa}{q^{v}} \\
\tilde{W} h=\bar{\xi}\left((1-\alpha) \frac{\tilde{Y}}{N}+\kappa \Theta\right)+(1-\bar{\xi})\left(\left(\frac{1-\alpha}{1+\nu}\right) \frac{\tilde{Y}}{N}+\frac{H(\bar{a})}{\tilde{\lambda}_{h}}+b\right),
\end{gathered}
$$


where E.20 is vacancy posting equation, E.21 determines the threshold $\bar{a}$, and E.22 is the steady-state wage equation. Some useful derivatives for the distribution of the idiosyncratic preference shock are as follows. The steady-state of the conditional expectation of $a$ given $\bar{a}$ can be written using the formula for the partial expectation of the log-normal distribution:

$$
H(\bar{a}) \equiv \int_{0}^{\bar{a}} a \frac{d F(a)}{F(\bar{a})}=\frac{1}{F(\bar{a})} \exp \left(\mu_{a}+\frac{1}{2} \sigma_{a}^{2}\right) \Phi\left(\frac{\ln (\bar{a})-\mu_{a}-\sigma_{a}^{2}}{\sigma_{a}}\right)
$$

where $\Phi$ is the CDF of the standard normal distribution. The semi-elasticity of the conditional expectation with respect to $\bar{a}$ is given by the Leibniz rule:

$$
\begin{aligned}
\frac{\partial H(\bar{a})}{\partial \bar{a}} \bar{a} & =\left[\int_{0}^{\bar{a}} \frac{\partial\left(a \frac{d F(a)}{F(\bar{a})}\right)}{\partial \bar{a}}+\bar{a} \frac{f(\bar{a})}{F(\bar{a})}\right] \bar{a}=\left[\int_{0}^{\bar{a}}-a d F(a) F(\bar{a})^{-2} f(\bar{a})+\bar{a} \frac{f(\bar{a})}{F(\bar{a})}\right] \bar{a} \\
& =\left[-\frac{f(\bar{a})}{F(\bar{a})} H(\bar{a})+\bar{a} \frac{f(\bar{a})}{F(\bar{a})}\right] \bar{a}=\frac{\bar{a} f(\bar{a})}{F(\bar{a})}[\bar{a}-H(\bar{a})]
\end{aligned}
$$

Substituting E.20 and E.21 into E.22 and simplifying yields:

$$
\tilde{W} h=(1-\alpha) \frac{\tilde{Y}}{N}-(1-\beta(1-\rho))(1-\bar{\xi})\left(\frac{\bar{a}-H(\bar{a})}{\tilde{\lambda}_{h}}\right)
$$

Further complication is that the real wage $\tilde{W}$ in E.25 depends on the shadow price $\tilde{\lambda}_{h}$ which needs to be expressed. To do so, I use E.2 together with the steady-state of the household's budget constraint 3.4 to write:

$$
\frac{1}{\tilde{\lambda}_{h}}=\left[\tilde{W} h N+\left(1-\frac{1}{R}\right) \tilde{B}\right] \frac{g_{\gamma}-h_{h}}{g_{\gamma}-\beta_{h} h_{h}}
$$

which is substituted into E.25 to yield (after some rearranging) the steady-state solution for the real wage:

$$
\tilde{W} h=\frac{\frac{(1-\alpha)}{1-\beta(1-\rho)} \frac{\tilde{Y}}{N}-(1-\bar{\xi})\left([\bar{a}-H(\bar{a})]\left(1-\frac{1}{R}\right) \tilde{B} \varsigma\right)}{\frac{1}{1-\beta(1-\rho)}+(1-\bar{\xi})[\bar{a}-H(\bar{a})] N \varsigma} .
$$

where $\varsigma \equiv\left(g_{\gamma}-h_{h}\right) /\left(g_{\gamma}-\beta_{h} h_{h}\right)$. Given the level of wages E.27, the vacancy posting condition E.20 is used to pin down the cost parameter $\kappa$. Substituting into E.21 pins down the unemployment benefit parameter $b$. 


\section{F The Log-linearised System}

Given the steady-states and the defined constants $\Omega_{h} \equiv\left(g_{\gamma}-\beta_{h} h_{h}\right)\left(g_{\gamma}-h_{h}\right)$ and $\Omega_{e} \equiv\left(g_{\gamma}-\beta h_{e}\right)\left(g_{\gamma}-h_{e}\right)$, the log-linearised first-order conditions are:

$$
\begin{aligned}
& \hat{\Omega}_{h} \hat{\lambda}_{h}=-\left[g_{\gamma}^{2}+h_{h} \beta_{h}\right] \hat{C}_{h, t}+g_{\gamma} h_{h}\left(\hat{C}_{h, t-1}-\hat{g}_{\gamma, t}\right)+\beta_{h} g_{\gamma} h_{h} \mathbb{E}_{t}\left(\hat{C}_{h, t+1}+\hat{g}_{\gamma, t+1}\right) \\
& \hat{\Omega}_{e} \hat{\lambda}_{e}=-\left[g_{\gamma}^{2}+h_{e} \beta\right] \hat{C}_{e, t}+g_{\gamma} h_{e}\left(\hat{C}_{e, t-1}-\hat{g}_{\gamma, t}\right)+\beta g_{\gamma} h_{e} \mathbb{E}_{t}\left(\hat{C}_{e, t+1}+\hat{g}_{\gamma, t+1}\right) \\
& \hat{\lambda}_{h, t}-\hat{R}_{t}=\beta_{h} \mathbb{E}_{t}\left[\hat{\lambda}_{h, t+1}+\hat{q}_{l, t+1}\right]+\left[1-\beta_{h}\right]\left(\hat{\varphi}_{t}-\hat{L}_{i, t}\right) \\
& \hat{\lambda}_{e, t}-\hat{R}_{t}=\frac{\beta}{\beta_{h}}\left[\mathbb{E}_{t}\left(\hat{\lambda}_{e, t+1}-\hat{g}_{\gamma, t+1}\right)+\frac{\beta_{h}-\beta}{\beta} \hat{\mu}_{e, t}\right] \\
& \hat{q}_{l, t}+\hat{\lambda}_{e, t}=\frac{\tilde{\mu}_{e}}{\tilde{\lambda}_{e}} g_{\gamma} \theta\left(\hat{\mu}_{e, t}+\hat{\theta}_{t}\right)+\left(1-\frac{\tilde{\mu}_{e}}{\tilde{\lambda}_{e}} g_{\gamma} \theta\right) \mathbb{E}_{t} \hat{\lambda}_{e, t+1}+\frac{\tilde{\mu}_{e}}{\tilde{\lambda}_{e}} g_{\gamma} \theta \mathbb{E}_{t}\left(\hat{q}_{l, t+1}+\hat{g}_{\gamma, t+1}\right) \\
& +\beta \mathbb{E}_{t} \hat{q}_{l, t+1}+\left(1-\beta-\left(\beta_{h}-\beta\right) \theta\right) \mathbb{E}_{t}\left[\hat{Y}_{t+1}-\hat{L}_{e, t}\right] \\
& \hat{q}_{k, t}+\hat{\lambda}_{e, t}=\frac{\tilde{\mu}_{e}}{\tilde{\lambda}_{e}} \frac{\theta}{\bar{\lambda}_{q}}\left(\hat{\mu}_{e, t}+\hat{\theta}_{t}\right)+\frac{\beta(1-\delta)}{\lambda_{k}} \mathbb{E}_{t}\left(\hat{q}_{k, t+1}-\hat{g}_{q, t+1}-\hat{g}_{\gamma, t+1}\right)+\left(1-\frac{\tilde{\mu}_{e}}{\tilde{\lambda}_{e}} \frac{\theta}{\bar{\lambda}_{q}}\right) \mathbb{E}_{t} \hat{\lambda}_{e, t+1} \\
& +\frac{\tilde{\mu}_{e}}{\tilde{\lambda}_{e}} \frac{\theta}{\bar{\lambda}_{q}} \mathbb{E}_{t}\left(\hat{q}_{k, t+1}-\hat{g}_{\gamma, t+1}\right)+\beta \alpha(1-\kappa) \frac{\tilde{Y}}{\tilde{K}} \mathbb{E}_{t}\left(\hat{Y}_{t+1}-\hat{K}_{t}\right) \\
& \hat{q}_{k, t}=\Omega \lambda_{k}^{2}\left[(1+\beta) \hat{I}_{t}-\hat{I}_{t-1}\right]+\Omega \lambda_{k}^{2}\left(\hat{q}_{q, t}+\hat{g}_{\gamma, t}\right)-\beta \Omega \lambda_{k}^{2} \mathbb{E}_{t}\left[\hat{I}_{t+1}+\hat{q}_{q, t+1}+\hat{g}_{\gamma, t+1}\right] \\
& \hat{m}_{t}=\hat{\psi}_{t}+\omega \hat{u}_{t}+(1-\omega) \hat{v}_{t} \\
& \hat{q}_{t}^{u}=\hat{m}_{t}-\hat{u}_{t} \\
& \hat{q}_{t}^{v}=\hat{m}_{t}-\hat{v}_{t} \\
& \hat{\Theta}_{t}=\hat{v}_{t}-\hat{u}_{t} \\
& \hat{N}_{t}=(1-\rho) \hat{N}_{t-1}-\rho \hat{\rho}_{t}+\rho \hat{m}_{t} \\
& \hat{u}_{t}=\frac{-(1-\rho) N \hat{N}_{t-1}+\rho N \hat{\rho}_{t}}{1-(1-\rho) N} \\
& \hat{\rho}_{t}=\frac{\left(1-\rho^{x}\right) \rho^{n} \hat{\rho}_{t}^{n}}{\rho} \\
& \hat{\rho}_{t}^{n}=\frac{-f(\bar{a}) \bar{a}}{1-F(\bar{a})} \hat{\bar{a}}_{t}
\end{aligned}
$$




$$
\begin{aligned}
-\frac{\kappa}{q^{v}} \hat{q}_{t}^{v}= & \beta(1-\rho)\left[(1-\alpha) \frac{\tilde{Y}}{N}\left(\hat{Y}_{t+1}-\hat{N}_{t+1}\right)-\tilde{W} h\left(\hat{W}_{t+1}+\hat{h}_{t+1}\right)-\frac{\kappa}{q^{v}}\left(\hat{q}_{t+1}^{v}\right)\right] \\
& +\beta\left((1-\alpha) \frac{\tilde{Y}}{N}-\tilde{W} h+\frac{\kappa}{q^{v}}\right)\left[(1-\rho)\left(\hat{\lambda}_{e, t+1}-\hat{\lambda}_{e, t}\right)-\rho \hat{\rho}_{t+1}\right] \\
\nu \hat{h}_{t}= & \hat{\lambda}_{h, t}+\hat{Y}_{t}-\hat{N}_{t}-\hat{h}_{t} \\
\hat{U}_{t}= & -\frac{N}{1-N} \hat{N}_{t}
\end{aligned}
$$

The log-linearised zero surplus condition:

$$
\begin{aligned}
\frac{\bar{a}}{\tilde{\lambda}_{h}}\left(\hat{\bar{a}}_{t}-\hat{\lambda}_{h, t}\right)= & \frac{\nu}{1+\nu}(1-\alpha) \frac{\tilde{Y}}{N}\left(\hat{Y}_{t}-\hat{N}_{t}\right) \\
& +\frac{1-\xi q^{u}}{1-\xi} \frac{\kappa}{q^{v}}\left(\frac{\xi}{1-\xi} \hat{\xi}_{t+1}-\left(\frac{\xi q^{u}}{1-\xi q^{u}}\right)\left(\hat{\xi}_{t+1}+\hat{q}_{t}^{u}\right)-\hat{q}_{t}^{v}\right)
\end{aligned}
$$

where I used the fact $g\left(h_{t}, \bar{a}_{t}\right)=\chi \frac{h_{t}^{1+\nu}}{1+\nu}+\bar{a}_{t}=\frac{1-\alpha}{1+\nu} \frac{\tilde{Y}_{t}}{N_{t}} \tilde{\lambda}_{h, t}+\bar{a}_{t}$. The log-linearised wage equation:

$$
\begin{aligned}
\tilde{W} h\left(\hat{W}_{t}+\hat{h}_{t}\right)=\xi( & -\alpha) \frac{\tilde{Y}}{N}\left(\hat{\xi}_{t}+\hat{Y}_{t}-\hat{N}_{t}\right)+\xi \kappa \Theta\left(\hat{\xi}_{t}+\hat{q}_{t}^{u}-\hat{q}_{t}^{v}\right) \\
& +(1-\xi) \chi \frac{h^{1+\nu}}{\lambda_{h}(1+\nu)}\left((1+\nu) \hat{h}_{t}-\hat{\lambda}_{h, t}\right)+\frac{1-\xi}{\tilde{\lambda}_{h}}\left(\frac{\partial H(\bar{a})}{\partial \bar{a}} \overline{\hat{a}_{t}}-\hat{\lambda}_{h, t}\right) \\
& -\xi\left(\frac{\chi \frac{h^{1+\nu}}{(1+\nu)}+H(\bar{a})}{\tilde{\lambda}_{h}}+b\right) \hat{\xi}_{t}
\end{aligned}
$$

The log-linearised equations for the rest of the model: 


$$
\begin{aligned}
\hat{Y}_{t}= & \alpha \phi \hat{L}_{e, t-1}+\alpha(1-\phi) \hat{K}_{t-1}+(1-\alpha)\left(\hat{N}_{t}+\hat{h}_{t}\right)-\frac{(1-\phi) \alpha}{1-(1-\phi) \alpha}\left[\hat{g}_{z, t}+\hat{g}_{q, t}\right] \\
\hat{K}_{t}= & \frac{1-\delta}{\lambda_{k}}\left[\hat{K}_{t-1}-\hat{g}_{\gamma, t}-\hat{g}_{q, t}\right]+\left(1-\frac{1-\delta}{\lambda_{k}}\right) \hat{I}_{t} \\
\hat{Y}_{t}= & \frac{\tilde{C}_{h}}{\tilde{Y}} \hat{C}_{h, t}+\frac{\tilde{C}_{e}}{\tilde{Y}} \hat{C}_{e, t}+\frac{\tilde{I}}{\tilde{Y}} \hat{I}_{t}+\frac{\kappa v}{\tilde{Y}} \hat{v}_{t} \\
0= & \frac{L_{h}}{\bar{L}} \hat{L}_{h, t}+\frac{L_{e}}{\bar{L}} \hat{L}_{e, t} \\
\alpha \hat{Y}_{t}= & \frac{\tilde{C}_{e}}{\tilde{Y}} \hat{C}_{e, t}+\frac{\tilde{I}}{\tilde{Y}} \hat{I}_{t}+\frac{\tilde{q}_{l} L_{e}}{\tilde{Y}}\left(\hat{L}_{e, t}-\tilde{L}_{e, t-1}\right) \\
& +\frac{1}{g_{\gamma}} \frac{\tilde{B}}{\tilde{Y}}\left(\hat{B}_{t-1}-\hat{g}_{\gamma, t}\right)-\frac{1}{R} \frac{\tilde{B}}{\tilde{Y}}\left(\hat{B}_{t}-\hat{R}_{t}\right) \\
\hat{B}_{t}= & \hat{\theta}_{t}+g_{\gamma} \theta \frac{\tilde{q}_{l} L_{e}}{\tilde{B}} \mathbb{E}_{t}\left(\hat{q}_{l, t+1}+\hat{L}_{e, t}+\hat{g}_{\gamma, t+1}\right) \\
& +\left(1-g_{\gamma} \theta \frac{\tilde{q}_{l} L_{e}}{\tilde{B}}\right) \mathbb{E}_{t}\left(\hat{q}_{k, t+1}+\hat{K}_{t}-\hat{g}_{q, t+1}\right)
\end{aligned}
$$

The terms $\hat{g}_{z, t}, \hat{g}_{q, t}$ and $\hat{g}_{\gamma, t}$ are given by:

$$
\begin{aligned}
& \hat{g}_{z, t}=\hat{\lambda}_{z, t}+\hat{\nu}_{z, t}-\hat{\nu}_{z, t-1} \\
& \hat{g}_{q, t}=\hat{\lambda}_{q, t}+\hat{\nu}_{q, t}-\hat{\nu}_{q, t-1} \\
& \hat{g}_{\gamma, t}=\frac{1}{1-(1-\phi) \alpha} \hat{g}_{z, t}+\frac{(1-\phi) \alpha}{1-(1-\phi) \alpha} \hat{g}_{q, t}
\end{aligned}
$$

The technology shocks follow the processes:

$$
\begin{aligned}
& \hat{\lambda}_{z, t}=\rho_{z} \hat{\lambda}_{z, t-1}+\hat{\varepsilon}_{z, t} \\
& \hat{\lambda}_{q, t}=\rho_{q} \hat{\lambda}_{q, t-1}+\hat{\varepsilon}_{q, t} \\
& \hat{\nu}_{z, t}=\rho_{\nu_{z}} \hat{\nu}_{z, t-1}+\hat{\varepsilon}_{\nu_{z}, t} \\
& \hat{\nu}_{q, t}=\rho_{\nu_{q}} \hat{\nu}_{q, t-1}+\hat{\varepsilon}_{\nu_{q}, t}
\end{aligned}
$$

The other shocks follow the processes:

$$
\begin{aligned}
& \hat{\varphi}_{t}=\rho_{\varphi} \hat{\varphi}_{t-1}+\hat{\varepsilon}_{\varphi, t} \\
& \hat{\psi}_{t}=\rho_{\psi} \hat{\psi}_{t-1}+\hat{\varepsilon}_{\psi, t} \\
& \hat{\theta}_{t}=\rho_{\theta} \hat{\theta}_{t-1}+\hat{\varepsilon}_{\theta, t} \\
& \hat{\xi}_{t}=\rho_{\xi} \hat{\xi}_{t-1}+\hat{\varepsilon}_{\xi, t}
\end{aligned}
$$




\section{G Additional Tables and Figures}

\section{G.1 Baseline Estimation}

Figure 21: Comparing the Housing Shock to the Investment Specific Shock in the DSGE model
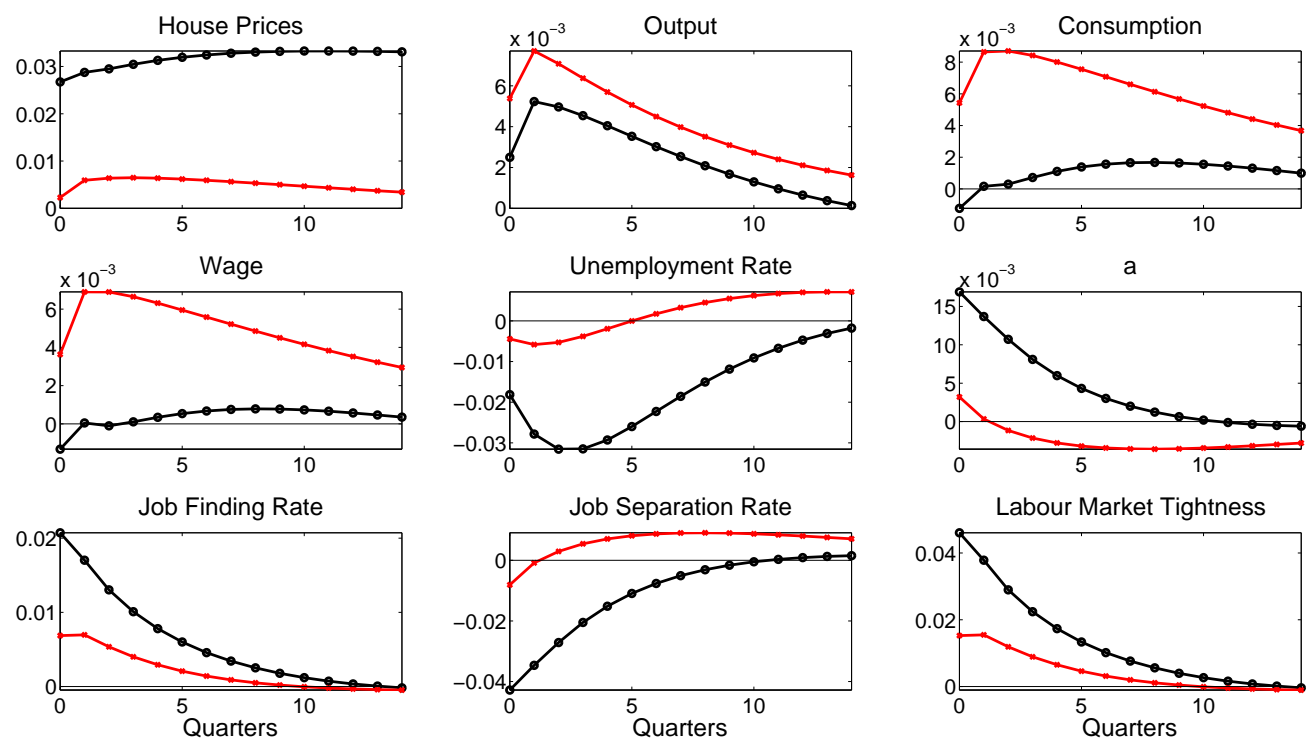

Note: The black circled (red crossed) lines represent the IRFs to a one standard deviation housing shock (permanent investment specific shock) in the DSGE model using the estimated posterior modes of the parameters.

Figure 22: FEVD: The Importance of Housing Shocks in the DSGE and BVAR models
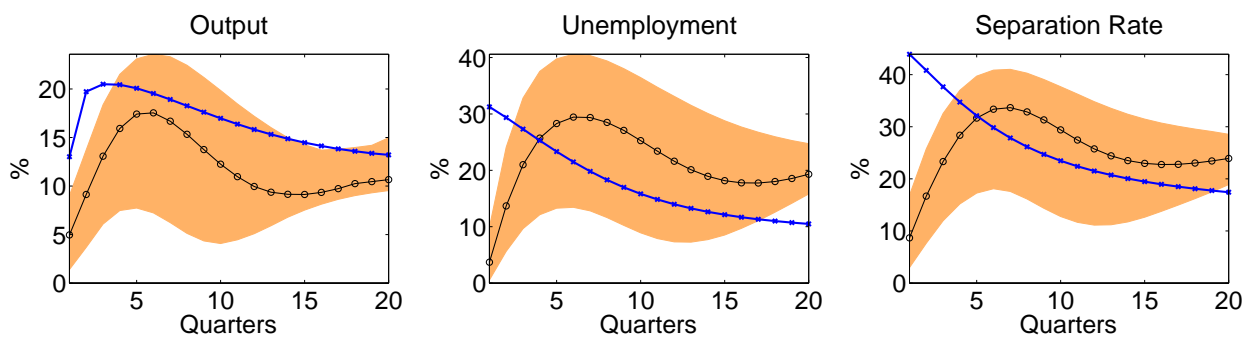

Note: The figure shows the FEVD results for the housing shock up to a 20-quarter horizon. The blue lines are from the DSGE model using the estimated modes. The black lines and shaded areas (10th-90th percentiles) are the results from the $\operatorname{BVAR}(2)$, which is estimated in the levels of the six observables used in the DSGE model. The identification of the housing shock in the BVAR model is based on Choleski orthogonalisation with real house price ordered as the first variable. The priors in the BVAR are set following Banbura, Giannone, and Reichlin (2010), using relatively loose priors, captured by the hyper parameter $\lambda=1$. 
Figure 23: Vacancy-Unemployment Ratio: the Lack of Explanatory Power of Technology Shocks

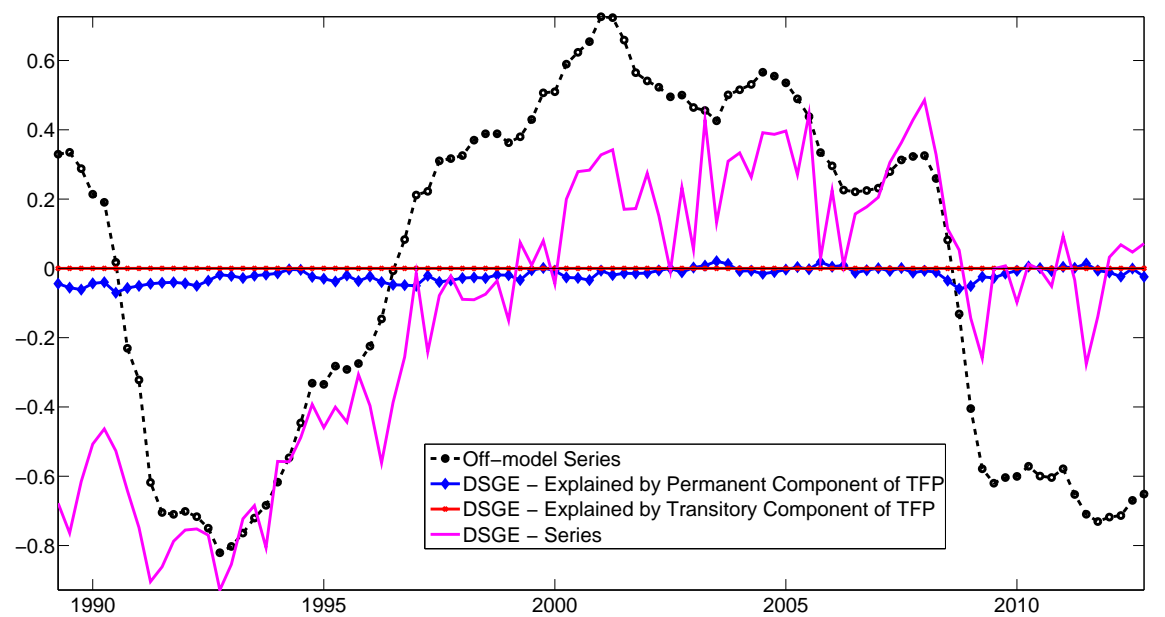

Note: The modes of the estimated parameters are used to compute the $\%$ deviation of the ratio of the vacancy rate and the unemployment rate (magenta solid line) and the contribution of the permanent and transitory components of the TFP shock to this series (blue diamond and red circles lines) in the DSGE model. The off-model estimate (black dashed line) is constructed by demeaning and linearly detrending the logarithm of the ratio of the vacancy rate and the unemployment rate, where vacancy data are from the ONS's Vacancy Survey and Job Centres records. 


\section{G.2 Using Consumption as Observable}

This subsection presents additional robustness check on the estimation results. Per capita investment is replaced with per capital consumption as the sixth observable in the Bayesian estimation of the DSGE model.

Figure 24: The Impact of Housing Shocks in the DSGE model
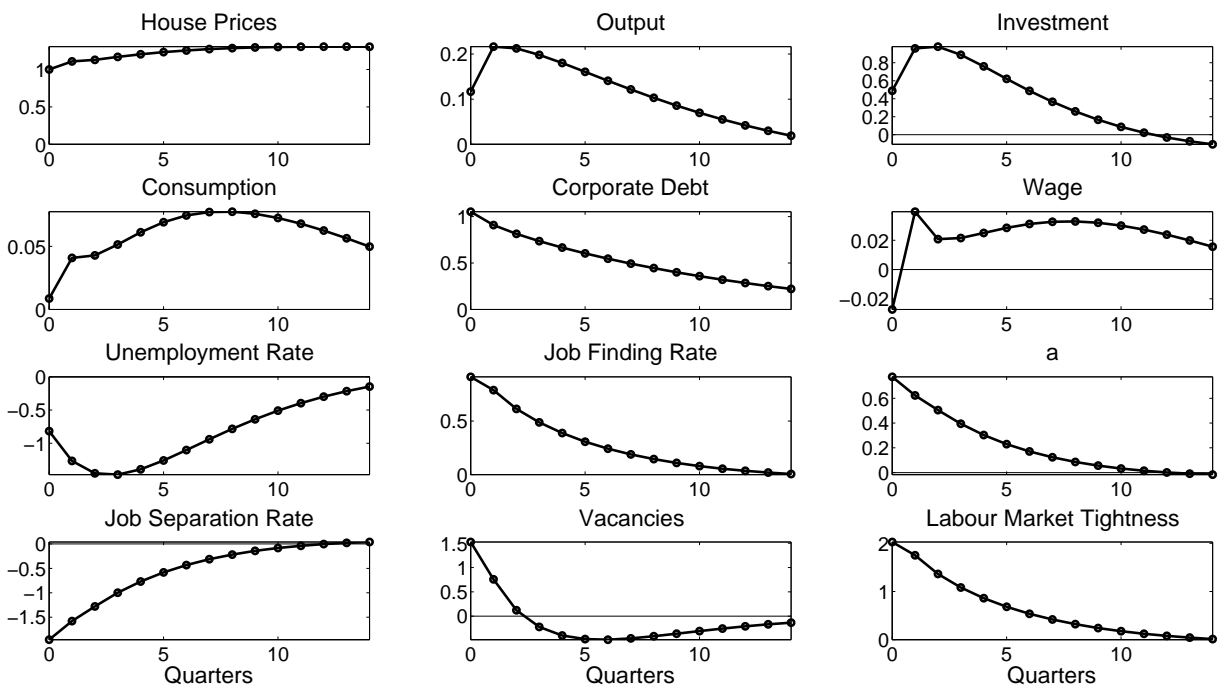

Note: The black lines represent the IRFs to a housing shock in the DSGE model using the estimated posterior modes of the parameters. The IRFs are normalised to give a $1 \%$ increase in house prices.

Figure 25: FEVD: The Importance of Housing Shocks in the DSGE and BVAR models
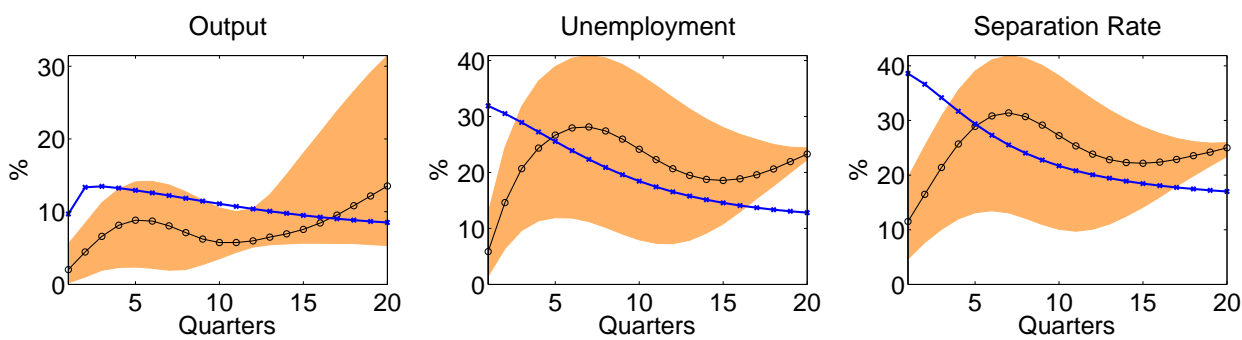

Note: The figure shows the FEVD results for the housing shock up to a 20-quarter horizon. The blue lines are from the DSGE model using the estimated modes. The black lines and shaded areas (10th-90th percentiles) are the results from the $\operatorname{BVAR}(2)$, which is estimated in the levels of the six observables used in the DSGE model. The identification of the housing shock in the BVAR model is based on Choleski orthogonalisation with real house price ordered as the first variable. The priors in the BVAR are set following Banbura, Giannone, and Reichlin (2010), using relatively loose priors, captured by the hyper parameter $\lambda=1$. 